\title{
Improving the school food environment for the prevention of childhood obesity: What works and what doesn't
}

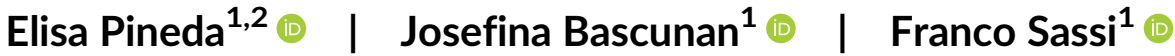

${ }^{1}$ Centre for Health Economics \& Policy Innovation (CHEPI), Imperial College Business School, London, UK

${ }^{2}$ School of Public Health, Imperial College London, London, UK

\section{Correspondence}

Elisa Pineda, Centre for Health Economics \& Policy Innovation (CHEPI), Imperial College Business School, London SW7 2AZ, UK, and School of Public Health, Imperial College London, London W6 8RP, UK.

Email: e.pineda@imperial.ac.uk

Funding information

European Commission, Grant/Award Number: $\mathrm{H} 2020$ SC2

\begin{abstract}
Summary
The food environment has a significant influence on dietary choices, and interventions designed to modify the food environment could contribute to the prevention of childhood obesity. Many interventions have been implemented at the school level, but effectiveness in addressing childhood obesity remains unclear.

We undertook a systematic review, a meta-analysis, and meta-regression analyses to assess the effectiveness of interventions on the food environment within and around schools to improve dietary intake and prevent childhood obesity. Estimates were pooled in a random-effects meta-analysis with stratification by anthropometric or dietary intake outcome. Risk of bias was formally assessed. One hundred papers were included. Interventions had a significant and meaningful effect on adiposity (body mass index $[\mathrm{BMI}] \mathrm{z}$ score, standard mean difference: $-0.12,95 \%$ confidence interval: $0.15,0.10$ ) and fruit consumption (portions per day, standard mean difference: +0.19 , $95 \%$ confidence interval: $0.16,0.22)$ but not on vegetable intake. Risk of bias assessment indicated that $n=43(81 \%)$ of non-randomized controlled studies presented a high risk of bias in the study design by not accounting for a control. Attrition bias $(n=34,79 \%)$ and low protection of potential contamination $(n=41,95 \%)$ presented the highest risk of bias for randomized controlled trials.

Changes in the school food environment could improve children's dietary behavior and BMI, but policy actions are needed to improve surrounding school food environments to sustain healthy dietary intake and BMI.
\end{abstract}

\section{KEYWORDS}

dietary intake, interventions, obesity, policies, school food environment

\section{1 | INTRODUCTION}

Obesity is a complex public health issue that requires large-scale and population-based solutions. ${ }^{1-3}$ Schools are the places where children spend most of their time and have access to a significant part of the food they eat; therefore, they are key settings for the prevention of obesity. ${ }^{4}$ The food environment exerts important influences on dietary intake and the prevention of childhood obesity. 5,6 The food environment is defined as a combination of physical, economic, political, and sociocultural surroundings as well as opportunities and conditions that influence food choice. ${ }^{7}$ It encompasses geographic access, food availability, food affordability, and food quality. ${ }^{7}$

The food environment within schools includes canteens, kiosks, and vending machines, ${ }^{8}$ whereas the food environment around or 
outside schools includes the location and concentration of food retailers such as convenience stores, take-aways, and fast-food outlets. ${ }^{9}$ Vending machines within schools and fast-food outlets around schools have been associated with low dietary quality and higher body mass index (BMI) among children. ${ }^{10,11}$ Other reviews ${ }^{12-15}$ have focused on policies that target the provision of food or physical activity programs. A previous review of the effectiveness of school food environment policies ${ }^{16}$ included a meta-analysis of studies published up to 2014 for a range of food and nutrient intakes but did not detect significant effects on total calorie intake.

Several studies published in the past seven years have identified effects of school food environment policies on children's BMI, providing an opportunity to capture a broader range of effects of such policies. Therefore, we have designed a new systematic review, metaanalysis, and meta-regression aimed at assessing the effectiveness of school food environment interventions in the prevention of childhood obesity, with a focus on adiposity and dietary intake outcomes, based on studies published up to 2020. In this review, we define school food environment interventions as programs, strategies, guidelines, policies, or laws that modify food choice architecture, built environment, or a physical aspect of the food environment, within or around schools, aimed to prevent childhood obesity. Food choice architecture and physical aspects of the food environment refer to all related aspects of how food choice is framed and how it influences food selection, including school ambience modifications, placement, presentation, availability, and accessibility of food within or around schools. ${ }^{17}$

\section{2 | METHODS}

\section{1 | Search strategy}

We systematically reviewed the effects of school food environment interventions aimed at improving children's obesity-related outcomes and identified features of interventions of the food environment within and around schools that enable or impede their implementation or effectiveness. The search strategy was based on the population, intervention, comparison, and outcome (PICO) framework shown in Table 1. We included school food environment interventions that aimed to prevent obesity and improve food choice selection (e.g., increased consumption of fruit and vegetables) through modifications of the school's built or physical food environment, food choice architecture, modification and implementation of guidelines, or direct food provision (Table 1). The search strategy was designed in consultation with a specialist subject (health) librarian from Imperial College London. CINAHL, Embase, Global Health, MEDLINE, SciELO, and Cochrane databases were searched for relevant articles published in scholarly journals until January 2020 through keyword searches (Table S1). Additional articles were added using a snowballing approach. The search strategy was refined by conducting a sensitivity analysis in Embase with a test set of 10 key papers selected from existing systematic reviews. The protocol was registered with Prospective Register of Systematic Reviews (PROSPERO, CRD42019125039). A second reviewer conducted a reliability check on $10 \%$ of publications.
TABLE 1 Description of the PICO framework implemented for the assessment of effective school food environment interventions for the prevention of childhood obesity

\begin{tabular}{|l}
\hline PICO \\
feature \\
Population \\
Inclusion: School aged children, $\leq 19$ years of age, as \\
defined by the World Health Organization. ${ }^{18}$ \\
Exclusion: Children with a critical illness or severe \\
comorbidities (e.g., diabetes) or special populations \\
(e.g., blind or physically disabled). \\
Interventions that focus on the school food \\
environment and that aim to shape accessibility, \\
affordability, desirability, and convenience of food \\
acquirement and consumption to prevent obesity/ \\
improve dietary intake. \\
The school food environment incorporates all the \\
spaces, infrastructure and conditions inside and \\
around the school premises where food is available, \\
obtained, purchased, and/or consumed (e.g., tuck \\
shops, kiosks, canteens, food vendors, and vending \\
machines), also taking into account the provision \\
and nutritional content of food in school grounds. \\
The environment also includes all of the \\
information available, promotion (marketing, \\
advertisements, branding, food labels, packages, \\
promotions, etc.), and the pricing of foods and food \\
products. \\
Comparators may include no intervention, or a \\
comparison of the same group before the \\
implementation of the intervention. \\
Primary outcomes: Weight and height, fat mass \\
percent, BMI, ponderal index, skin-fold thickness, \\
waist circumference, waist-hip ratio, prevalence of \\
overweight and obesity, BMl z score, dietary intake, \\
and food purchasing. \\
Excluded outcomes: Changes in awareness, \\
knowledge, opinions, or beliefs. \\
outcomes. Cost to participants (\$ or time), \\
related outcomes, health inequity.
\end{tabular}

Abbreviations: BMI, body mass index; PICO, population, intervention, comparison, and outcomes.

This step was carried out during the title and abstract revision of papers for their inclusion or exclusion in the review. The reference managing software Rayyan was used to carry out this process. Intercoder reliability for the $10 \%$ of manuscripts with reliability checks was assessed using Cohen's kappa ( $\kappa$ ). The $10 \%$ reliability check led to 16 conflicts, all resolved after discussion, and the relevant papers were subsequently included for full-text review. The intercoder reliability for the $10 \%$ of manuscripts for this review indicated a reliability of $85 \%(\kappa=0.85)$.

\subsection{Data extraction}

After study selection, the following information was extracted from each retrieved article: type of document, school setting, country, 
number of intervention components, type and elements of intervention, analytical sample size, age groups, ethnicity and socioeconomic position (SEP) of population, baseline and follow-up outcome measures, obesity measure, inclusion of physical activity, statistical method of assessment, study design, intervention duration, effectiveness of intervention, sustainability of intervention, main findings, and study limitations. Reported outcomes were taken directly from published studies.

\section{3 | Statistical analyses}

We conducted random-effect meta-analyses to investigate the impact of interventions on BMI $z$ score (relative weight for child age) and fruit and vegetable intake. These three outcome measures are key in assessing changes in weight and dietary intake associated with obesity ${ }^{19}$; additionally, these outcomes facilitate translation into policies and actions. These outcomes are also the most often reported measures of the impacts of school food environment interventions, which allows wider comparisons between studies and interventions. The numbers of studies using different outcome measures were too small to undertake meta-regressions on those outcomes with reliable estimation of the effects of moderators. ${ }^{20}$

We reported the mean difference (MD) between the intervention group and the control group of BMI $z$ score and fruit and vegetable intake outcomes when values were available (preferentially); alternatively, baseline and follow-up time points were considered for each outcome (Figures 2-4).

Equivalent estimates were combined, and a pooled estimate and confidence interval $(\mathrm{Cl})$ for the treatment effect was extracted or calculated when possible. Meta-analyses were carried out to assess the effect of school food environment interventions on children's BMI $z$ score and dietary intake. Effect sizes were calculated when data were missing. Results are presented by study design. All statistical analyses were conducted in Stata 16.0 (College Station, TX: StataCorp LP).

\subsection{Meta-regression analyses}

To assess heterogeneity, meta-regression analyses were carried out in studies that assessed intervention and control differences or baseline and follow-up differences for BMI $z$ score, fruit intake, and vegetable intake. Pilot studies, non-peer-reviewed studies, and studies that did not clearly state differences between intervention and control groups, or baseline and follow-up measures, were excluded from the metaanalyses. Meta-regression analyses tested the association of study design (quasi-experimental design [QED] or randomized controlled trial $[R C T]$ ), type of study (scientific article, pilot study, policy, or program), school setting (internal, external, or both), country (United States, China, Latin American countries, European countries, Middle Eastern countries, United Kingdom, and others), components (single

FIGURE 1 Preferred Reporting Items for Systematic Reviews and MetaAnalyses (PRISMA) flow chart of study selection process
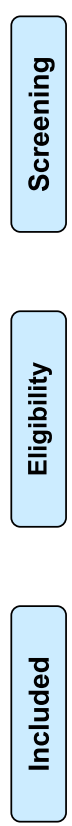

Records identified through database searching $(n=4,307)$
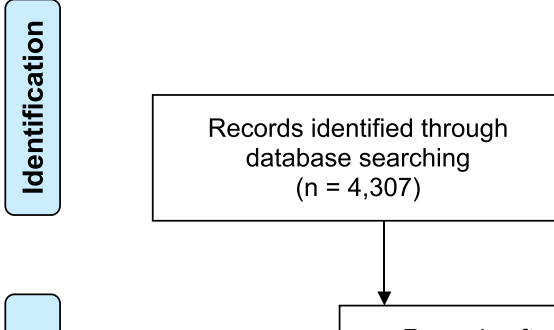

Records after duplicates removed $(n=814)$

Additional records identified through other sources $(n=63)$

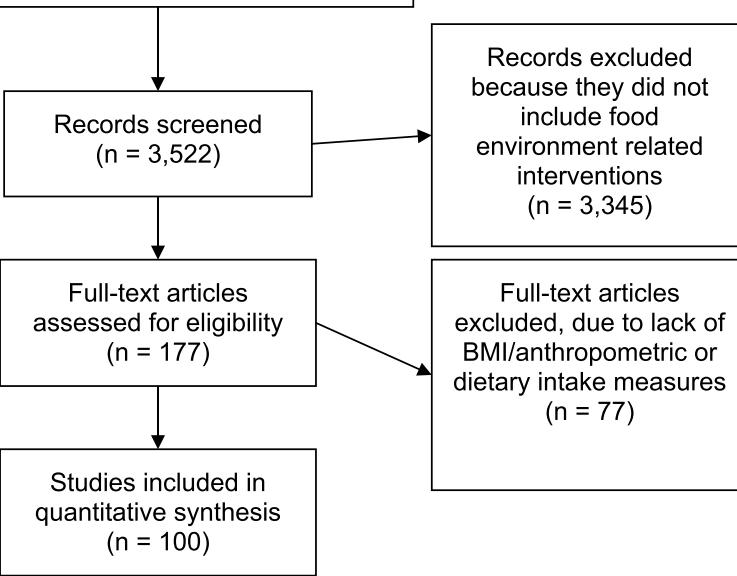




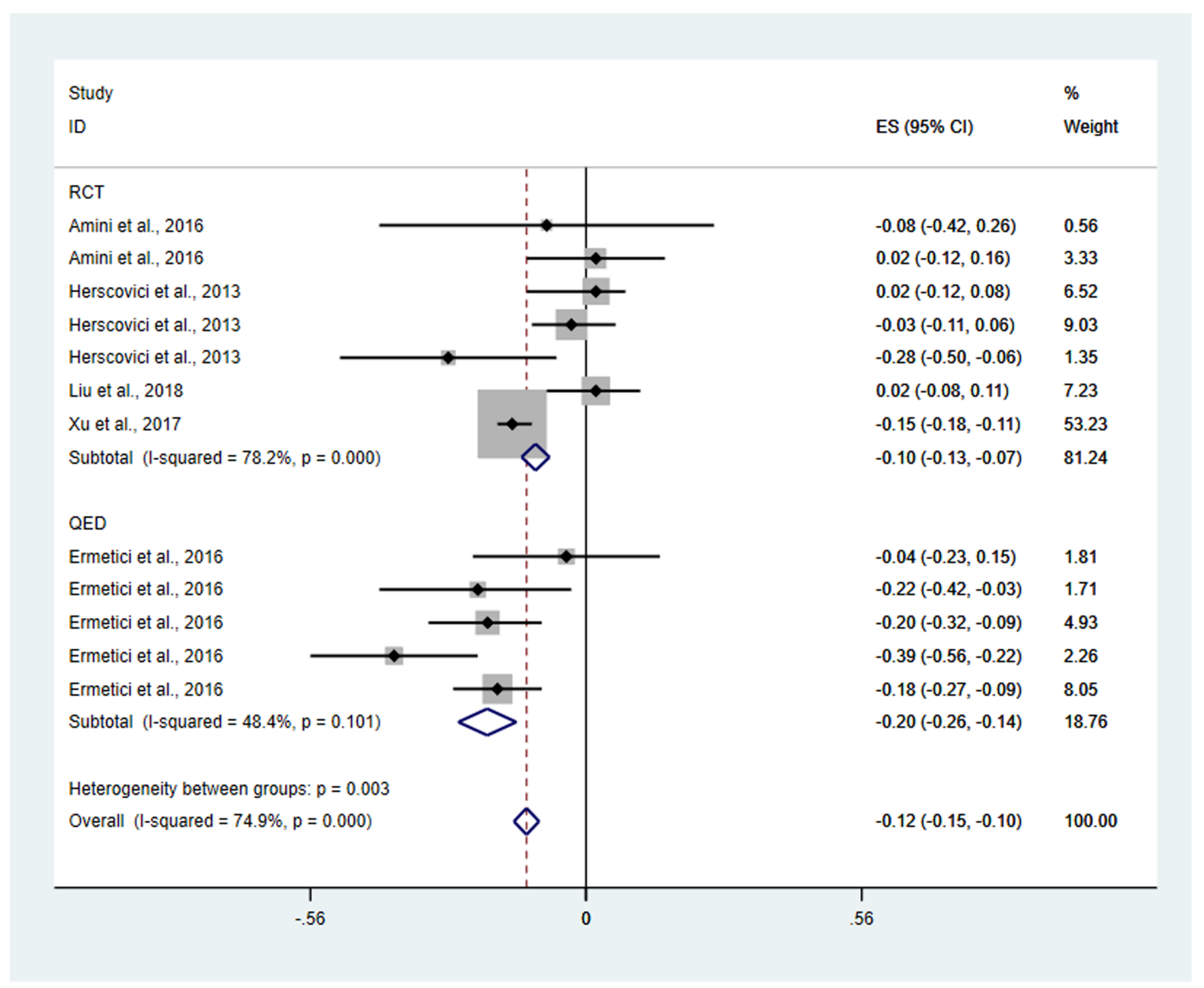

FIGURE 2 School food environment interventions and their effect on BMI z score. Study ID: Author, year, intervention period, sample size (N); I/C: Intervention versus control; F/B, Follow-up versus baseline. Solid squares represent study specific continuous changes in reported intakes and lines 95\% confidence intervals (Cls). The vertical line represents pooled effect size (ES) and open diamond the corresponding $95 \%$ $\mathrm{Cl}$. Multicomponent strategies were included only if the food environment policy was a major component. QED, quasi-experimental design; RCT, randomized controlled trial

component and multicomponent), type of intervention (vending machines, fruit and vegetable provision, breakfast provision, food placement, food modification, fruit provision, and guidelines), duration of the intervention in years (continuous variable), sex (boys, girls, or both), SEP (considered or not considered in intervention), and physical activity (considered or not considered in intervention). Mean effect sizes and $95 \% \mathrm{Cl}$ were calculated for intervention and control differences from baseline to follow-up for BMI $z$ score, fruit intake, and vegetable intake. Analyses were carried out in Stata 16.0 (College Station, TX: StataCorp LP).

\subsection{Quality and risk of bias assessment}

A risk of bias assessment was carried out using the version 2 of the Cochrane risk of bias tool for randomized trials (RoB 2) for RCTs and the Risk of Bias in Non-Randomized Studies of Interventions (ROBINS-I) for non-randomized studies to determine the grading quality, certainty of evidence, and strength of recommendations.

For RCTs, eight components were evaluated: randomization, allocation concealment, baseline outcome measurements, baseline characteristics, attribution bias, allocation knowledge, contamination protection, and selective reporting. An intervention was considered to have an overall high risk of bias if $\geq 4$ bias components were high risk, medium risk if 3 components where high risk, and low risk of bias if $<3$ bias components were high risk.

For non-RCTs, recorded as QED studies, risk of bias assessment was summarized into (1) selection bias (representation of exposed, baseline characteristics and baseline outcome). One point was given if the study sample was representative of the population, participants had a healthy weight with normal variations by sociodemographic characteristics, if baseline characteristics were not statistically significant or differences were controlled for in analyses, and if there was evidence that the outcome of interest was controlled for at baseline. Next is (2) comparability (adjusted confounders and extra confounders). One point was given if the study controlled for main confounders associated with childhood obesity and respective outcomes (e.g., SEP) and if the paper included covariates that could mediate or moderate the relationship of interest (in addition to including basic covariates such as age, gender, and SEP). Risk of bias assessment was also summarized into (3) study design. One point was given if controls were implemented and if control groups were in the same population. (4) Last 


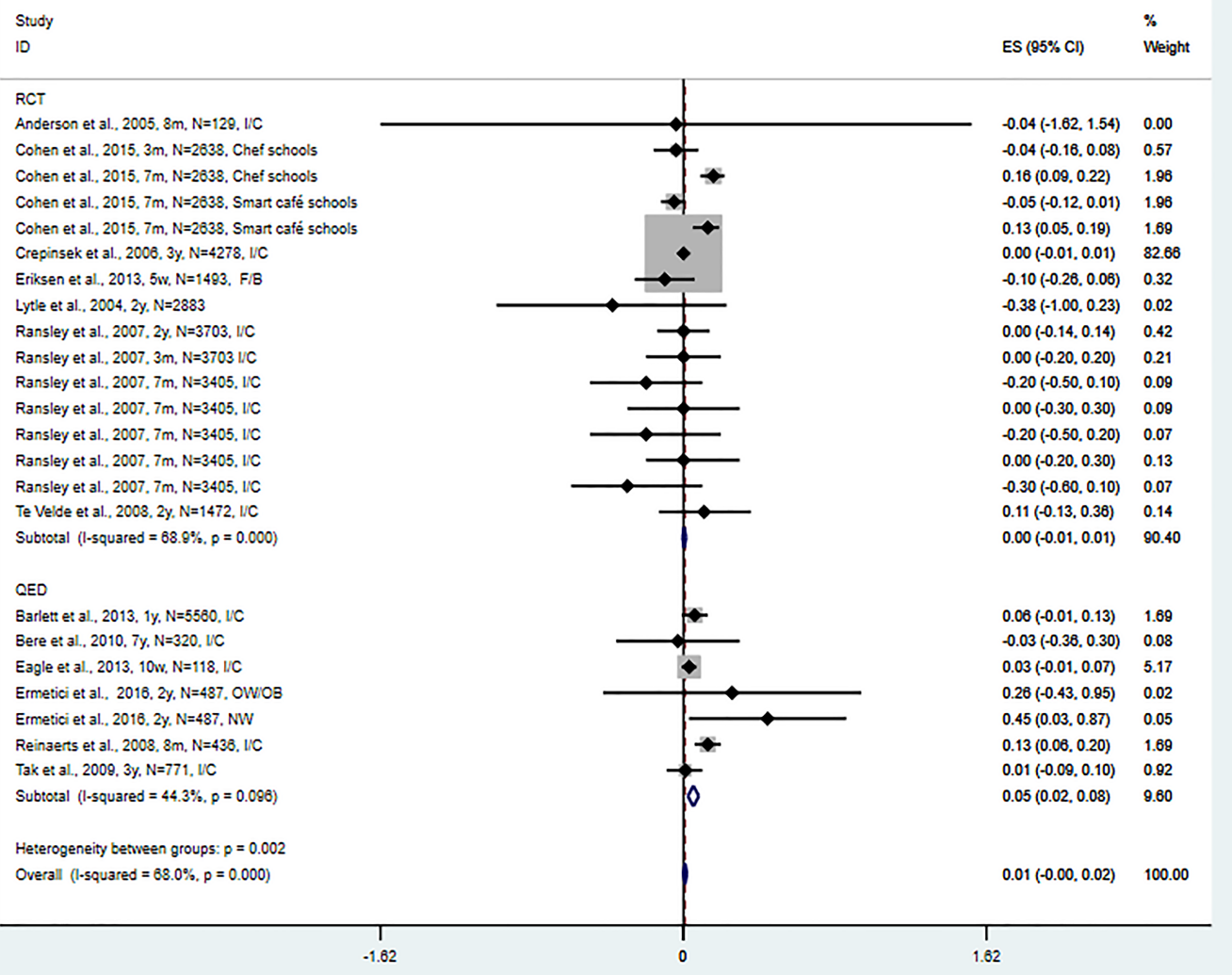

FIGURE 3 School food environment interventions and their effect on vegetable intake meta-analysis plot. Study ID: Author, year, intervention period, sample size (N); I/C: Intervention versus control; F/B: Follow-up versus baseline. Intakes represent habitual (not just inschool) consumption. Solid squares represent study-specific continuous changes in reported intakes and lines $95 \%$ confidence intervals (Cls). The vertical line represents pooled effect size (ES) and open diamond the corresponding $95 \% \mathrm{Cl}$. Multicomponent strategies were included only if the food environment policy was a major component. QED, quasi-experimental design; RCT, randomized controlled trial

is outcome (outcome ascertain and follow-up). One point was given if the outcome of interest was obtained objectively and if the paper reported the sample attrition rates and/or discussed the implications of follow-up rates. An overall score was generated for each intervention study, which represented the sum of obtained points in relation to selection bias, comparability, study design, and outcome measure.

\section{3 | RESULTS}

The search strategy retrieved 4,307 studies, and searches in the gray literature and reference lists of included studies led to 63 additional papers (Figure 1). The full text of 177 papers was checked against eligibility criteria, and 100 peer-reviewed papers were selected.

The revised literature consisted of $76 \%$ interventions, $14 \%$ policies, $3 \%$ government programs, $6 \%$ pilot studies related to food environment interventions and obesity, and $1 \%$ other related literature. In terms of setting, $92 \%$ of studies focused on the food environment within schools or food choice architecture interventions (e.g., the relative availability and presentation of different foods), whereas $4 \%$ focused on the food environment around schools. Most interventions were carried out in the United States (53\%), 10\% in the United Kingdom, $6 \%$ in Norway, and $6 \%$ in Latin America. In terms of the interventions, $63 \%$ involved a single component, such as food provision, whereas $37 \%$ encompassed multiple components. For single-component interventions, $n=31$ (49\% out of the $n=63$ single-component interventions) were effective in the reduction of $\mathrm{BMI}$ or in the increase of fruits and/or vegetables, whereas for multicomponent interventions, $n=21$ (57\% out of 37 multicomponent interventions) were effective in health outcome improvements. No statistically significant association was found between the number of components and intervention effectiveness when looking at all anthropometrical and dietary outcomes together (Pearson chi-squared $=1.22, p=0.270$ ). Most of the interventions (60\%) involved the direct provision of food (e.g., breakfast, lunch, snacks, or fruit and vegetables), $5 \%$ introduced or modified dietary guidelines in schools, and 9\% modified existing school meals. Thirty-one percent of the interventions addressed aspects of the school food environment other than meals, such as the regulation of vending machines and kiosks or food stores, introduction of cafes, snack bars, or fruit and vegetable buffets. Thirty-seven percent of the studies tested interventions addressing both diet and physical 


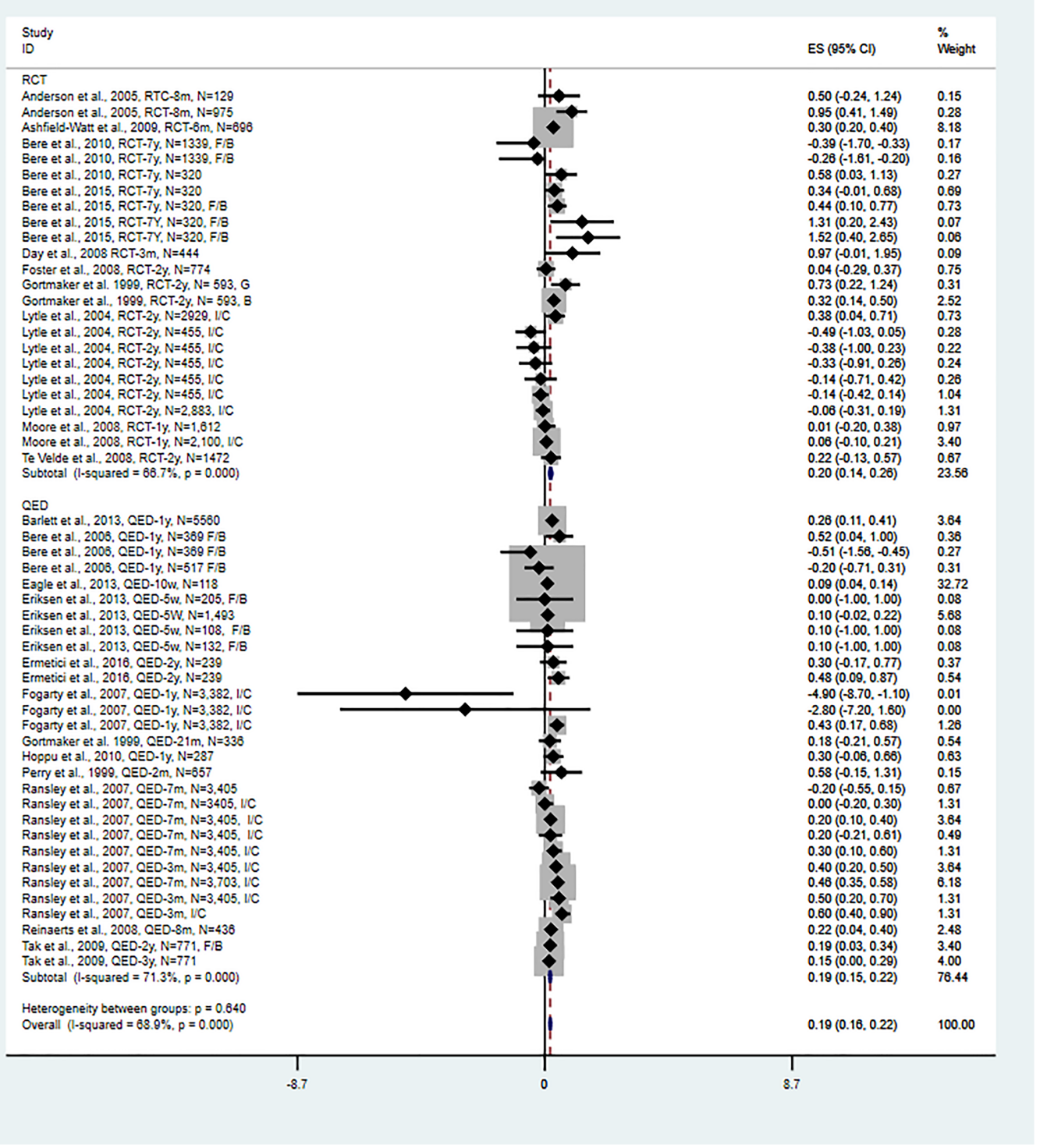

FIGURE 4 School food environment interventions and their effect on fruit intake. Study ID: Author, year, intervention period, sample size ( $N$ ); I/C: Intervention versus control; F/B, Follow-up versus baseline. Intakes represent habitual (not just in-school) consumption. Solid squares represent study specific continuous changes in reported intakes and lines $95 \%$ confidence intervals (Cls). The vertical line represents pooled effect size (ES) and open diamond the corresponding $95 \% \mathrm{Cl}$. Multicomponent strategies were included only if the food environment policy was a major component. QED, quasi-experimental design; RCT, randomized controlled trial

activity. Values do not add to $100 \%$ as multicomponent interventions used multiple approaches.

Regarding effectivity, $51 \%$ of interventions reduced $\mathrm{BMI}$ or improved dietary intake; however, only $24 \%$ of the effective interventions (51\%) showed a sustained improvement regarding fruit and vegetable intake or the reduction of BMI/BMI $z$ score after conclusion of the intervention (e.g., food provision). From food provision type interventions $(n=60), 32 \%$ were effective in the increase of healthy food consumption. For internal school food environment interventions ( $n=25), 12 \%$ were effective and $3 \%$ had a partial effect in the reduction of BMI. A summary of the reviewed school food environment intervention characteristics may be found in Table 2 .

\section{1 | Meta-analysis results}

Three meta-analyses were carried out. The first focused on BMI $z$ score and included $n=5$ studies, which provided 12 measured observations. The second focused on fruit intake and included 22 studies, which provided 53 observations. The third focused on vegetable intake and included $n=13$ studies, with a total of 23 observations. The characteristics of the studies included in meta-analyses are shown in Table 3. Figures 2-4 present forest plots of meta-analyses regarding policy interventions on school food environments aimed at decreasing $\mathrm{BMI} z$ score and increasing fruit and vegetable intake in children. Forest plots have been stratified by study design to explore 


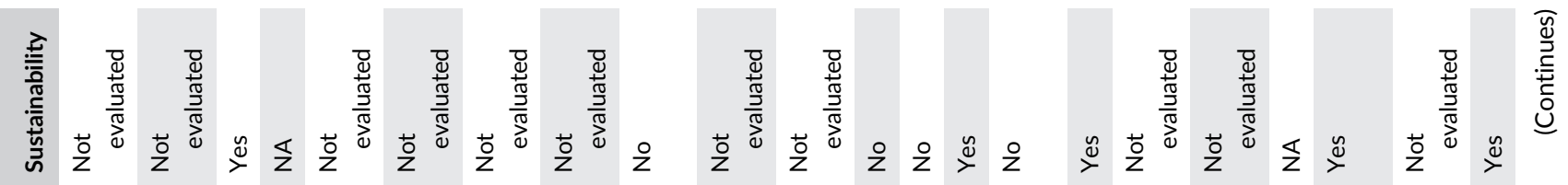

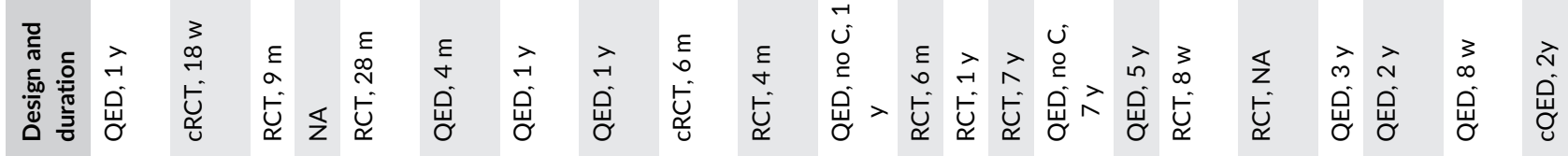
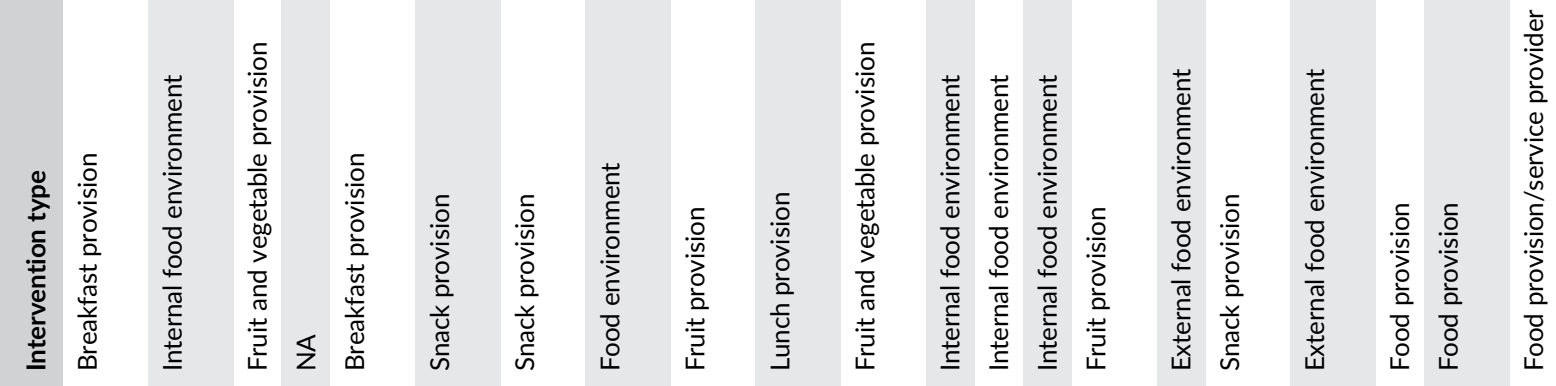

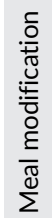

岕

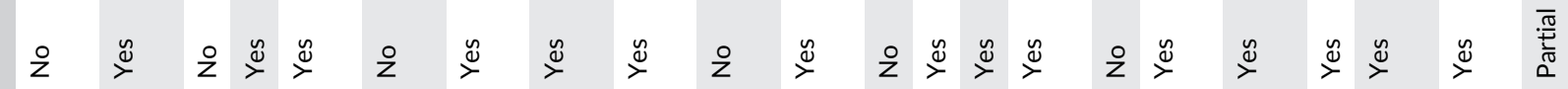

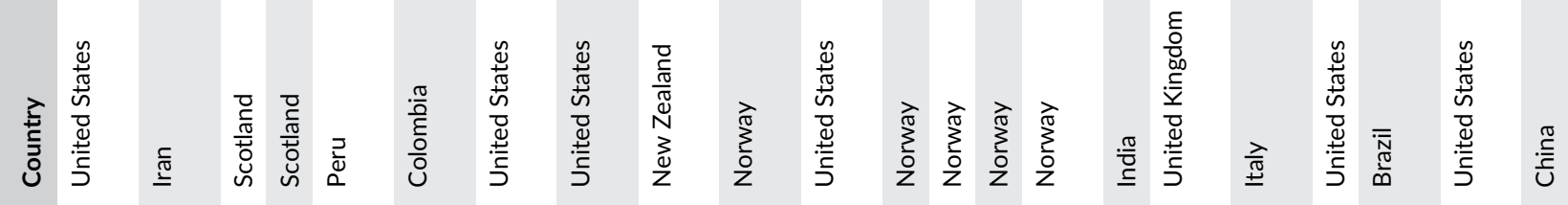

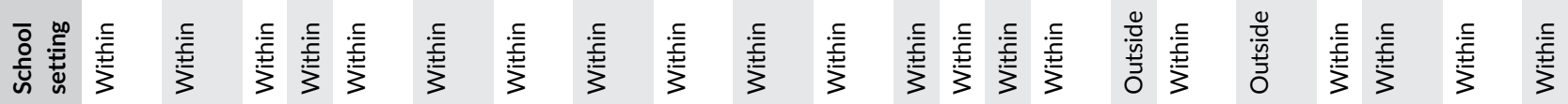

के 


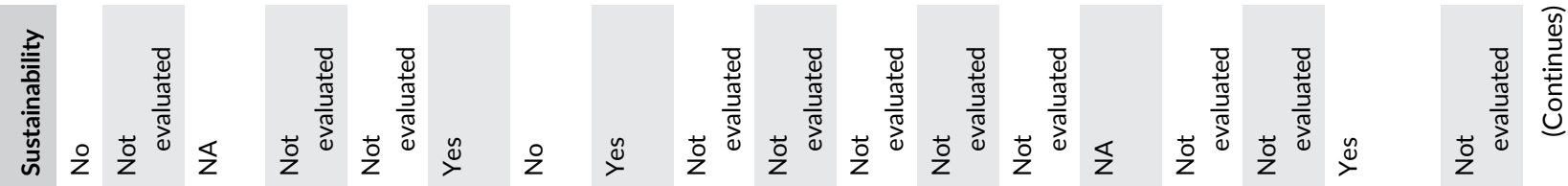

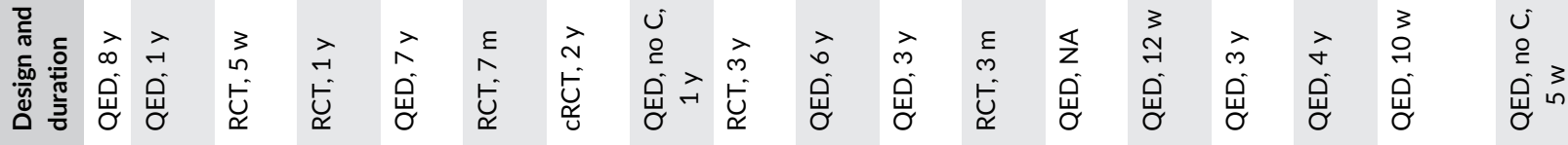

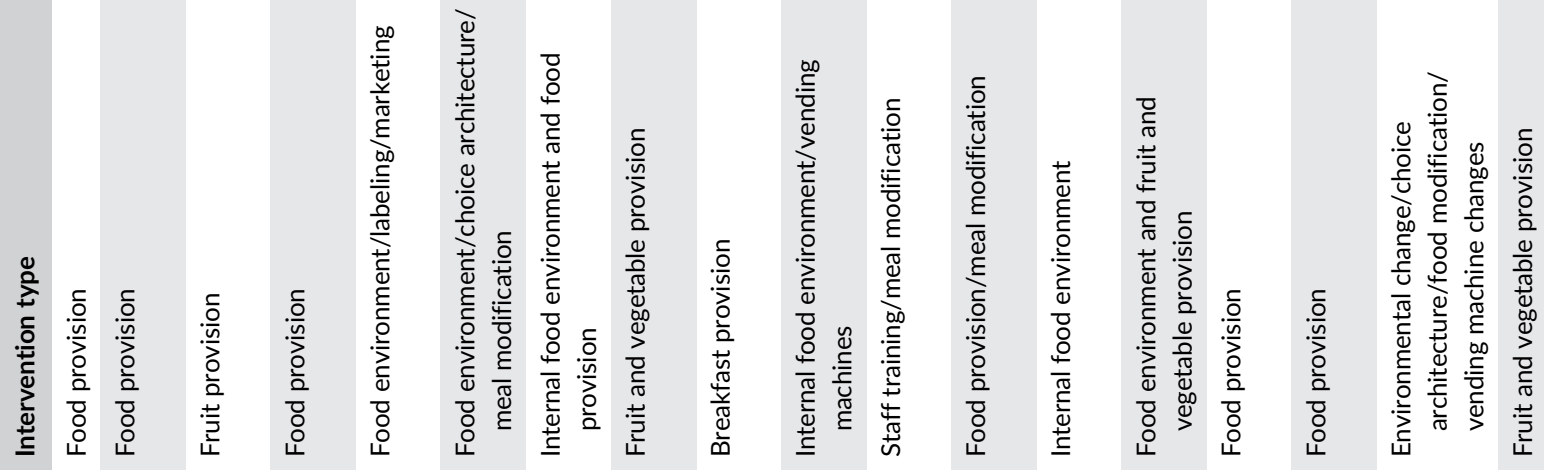

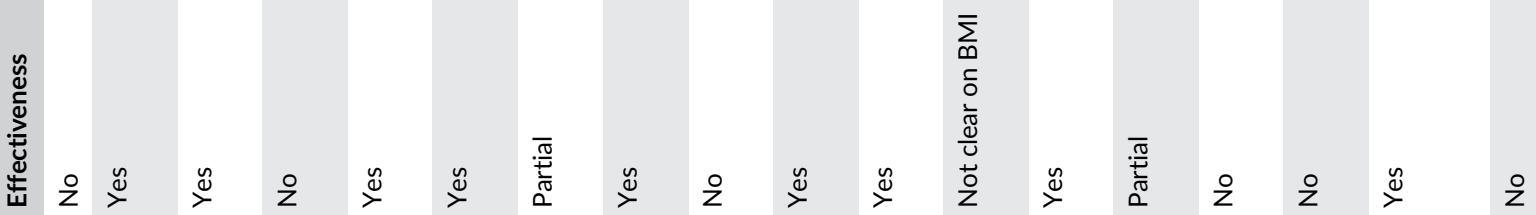

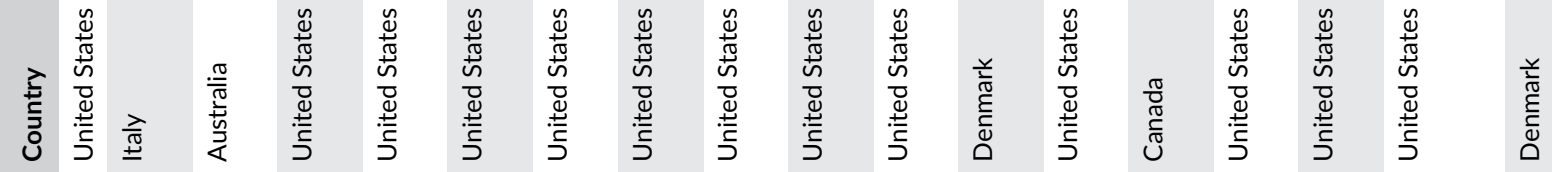

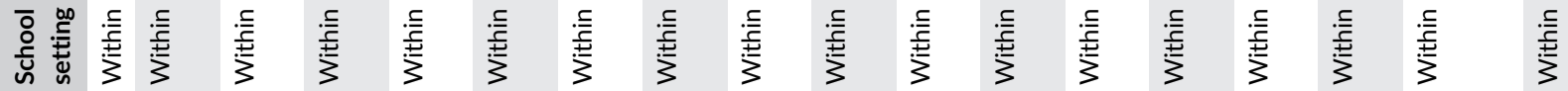

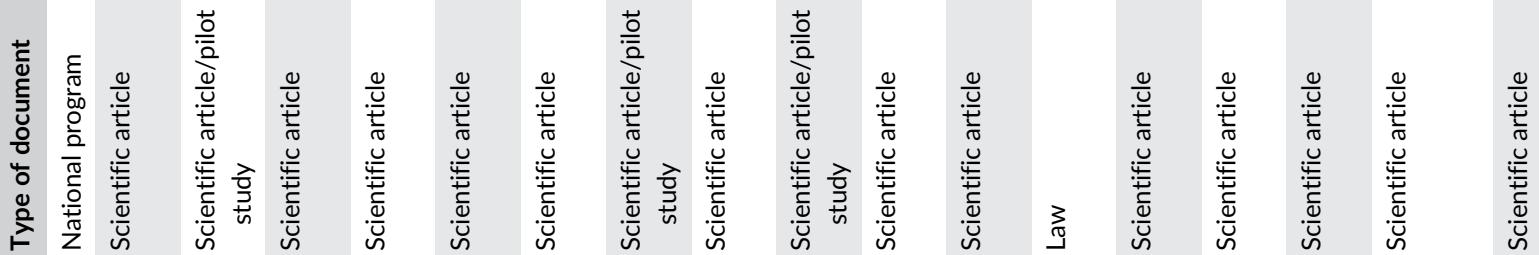

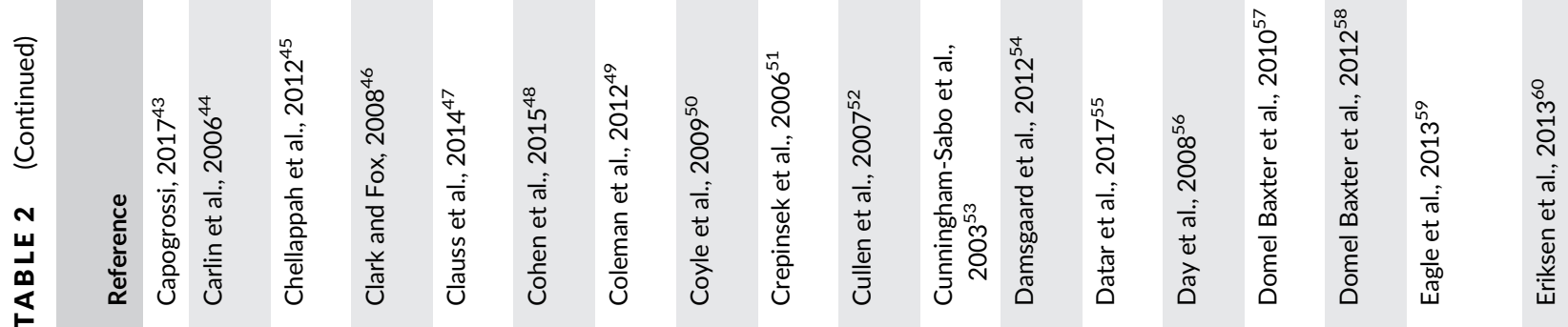




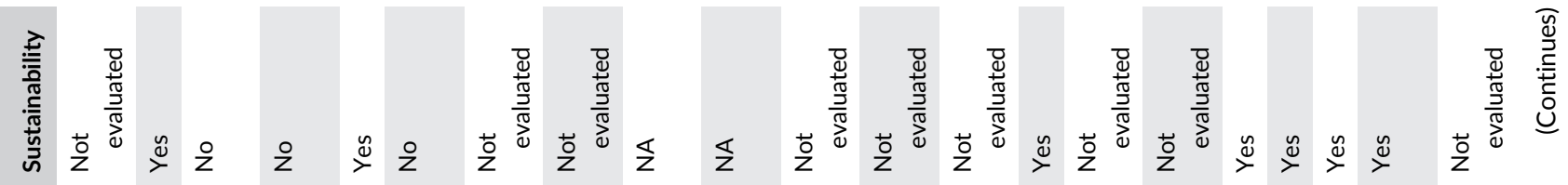

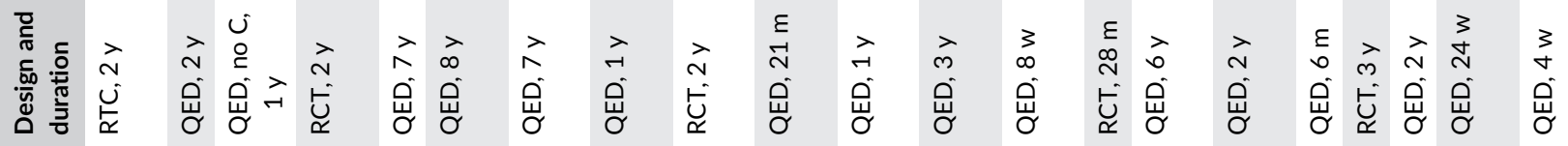
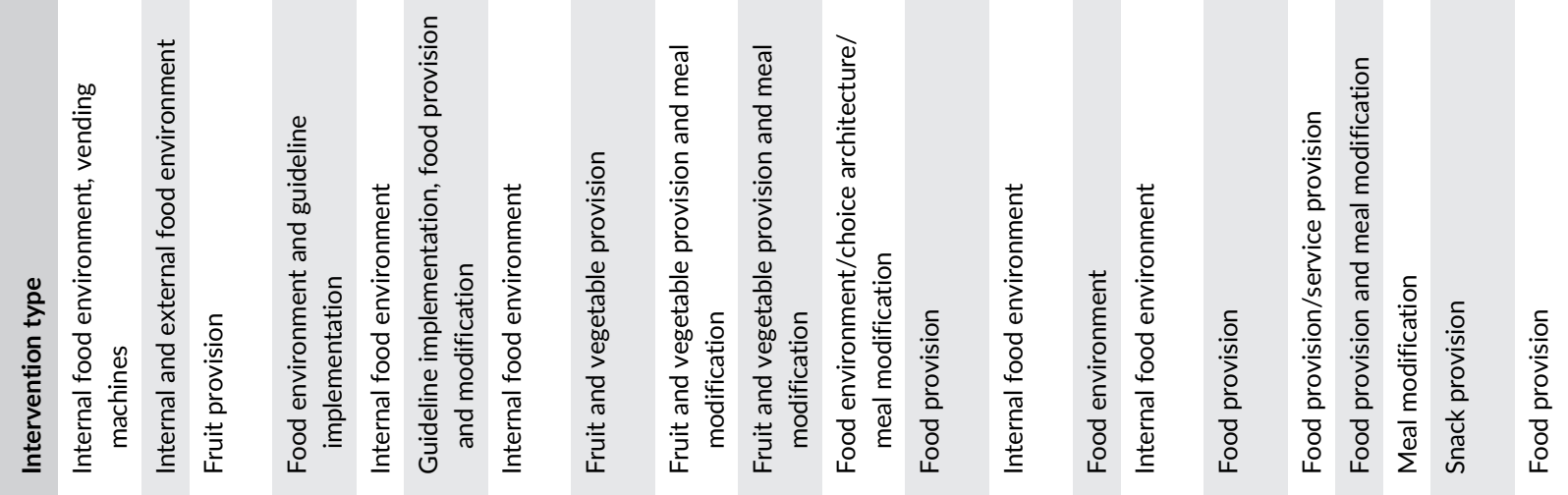

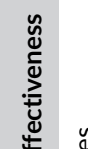

总 娄

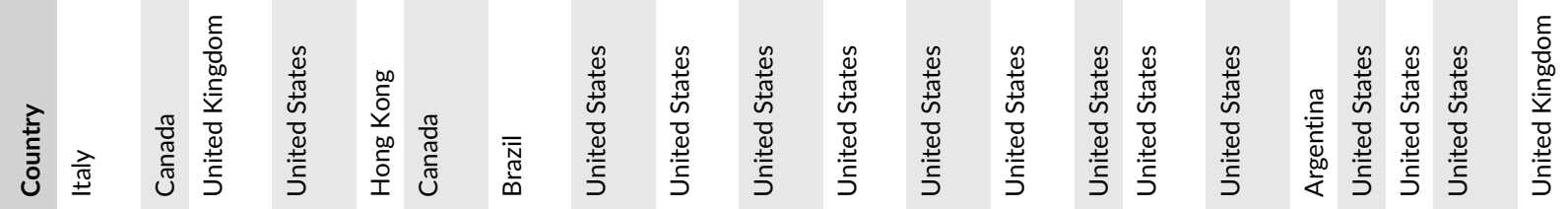

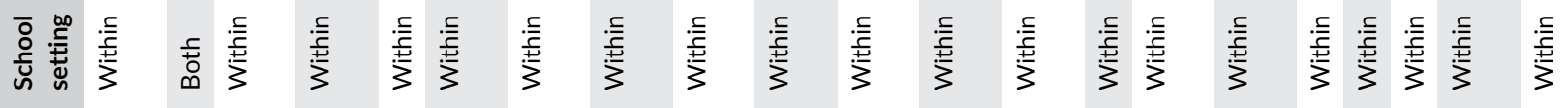

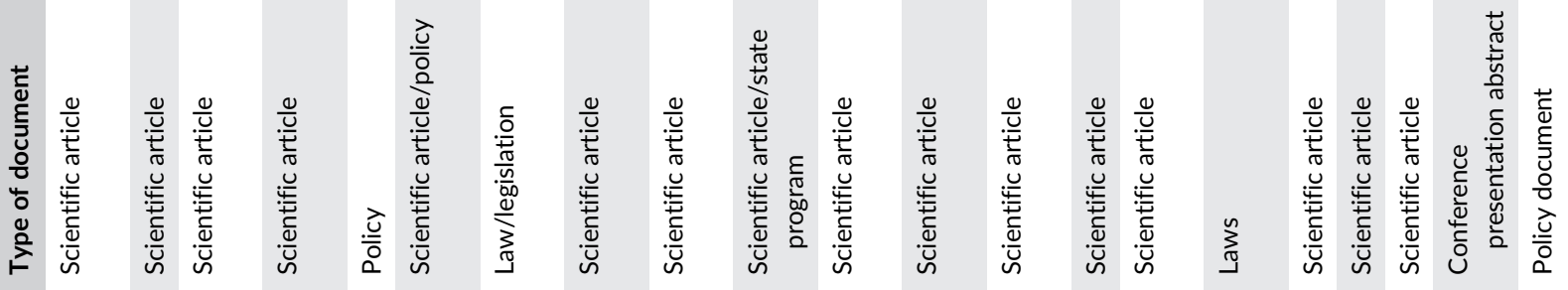

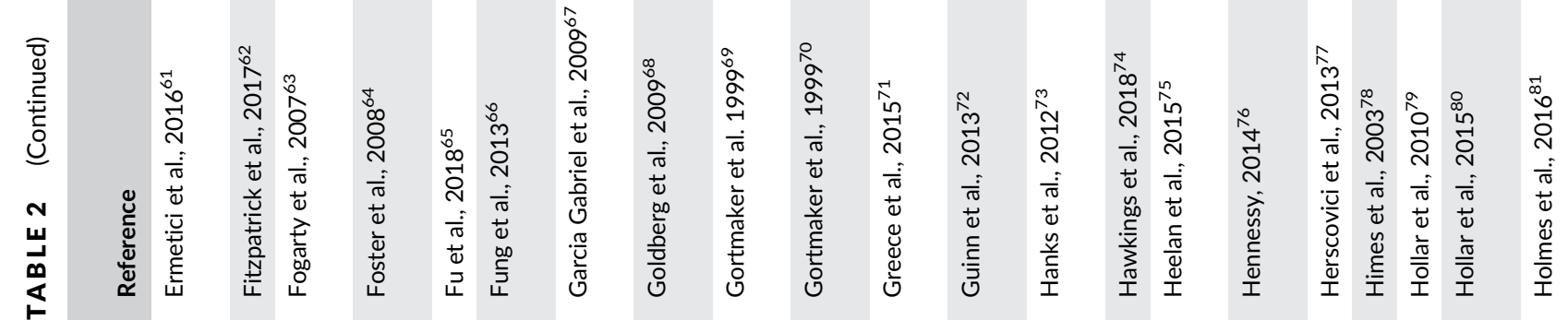




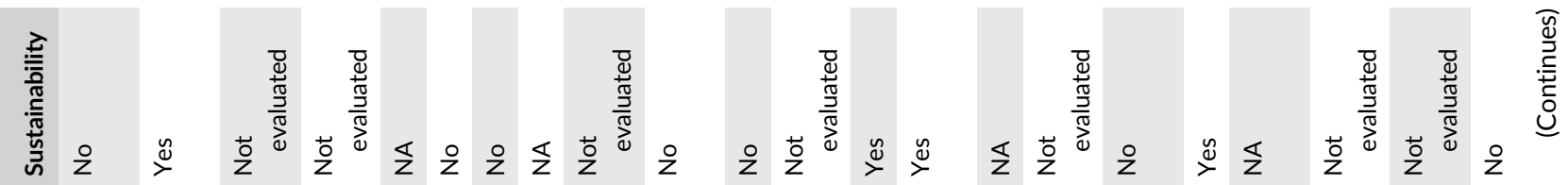

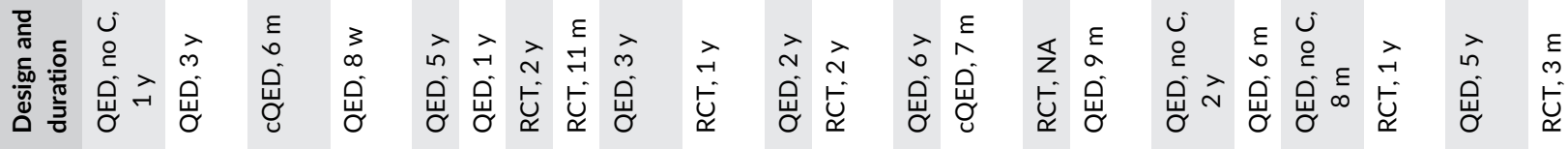
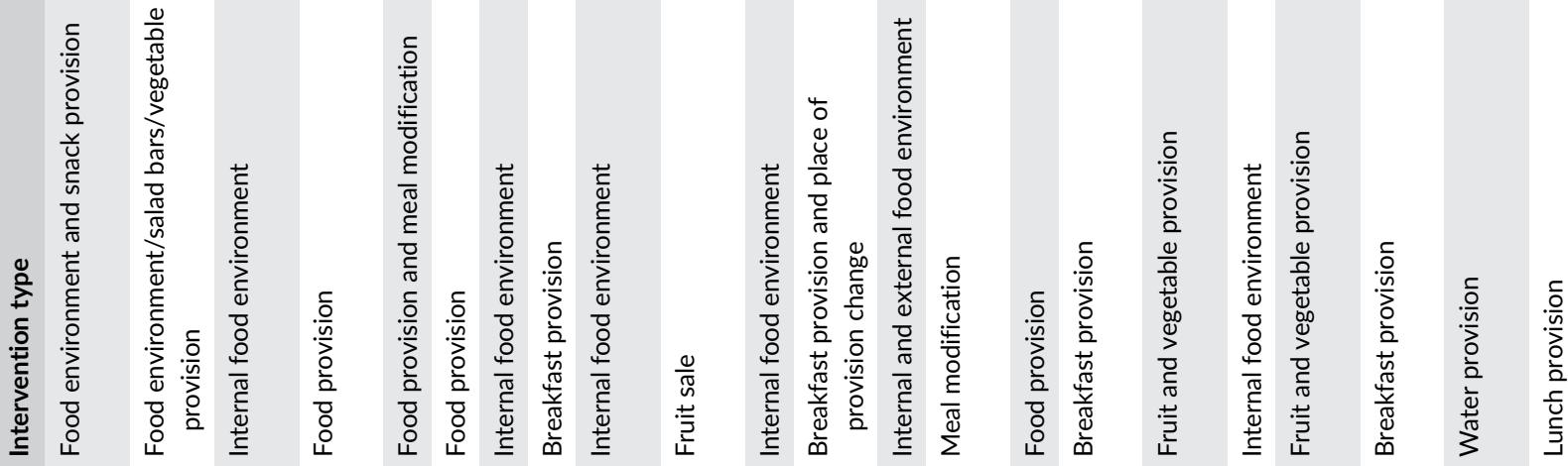

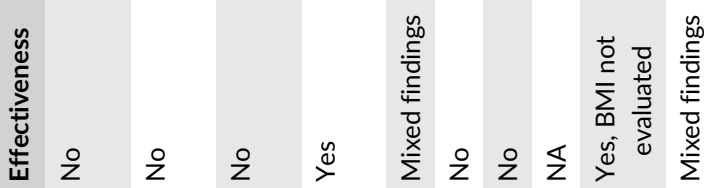

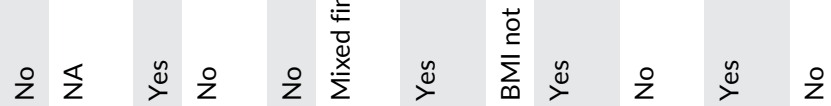

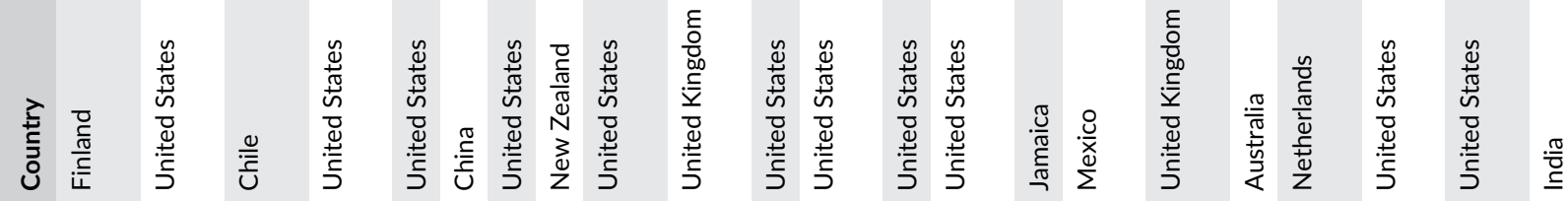

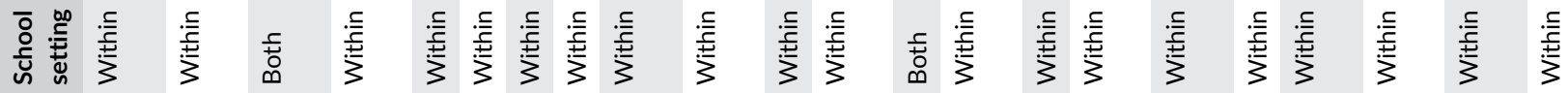

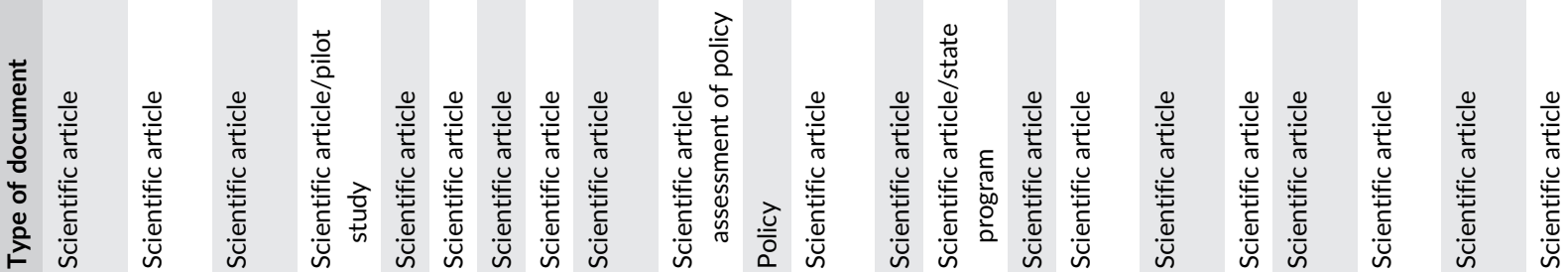

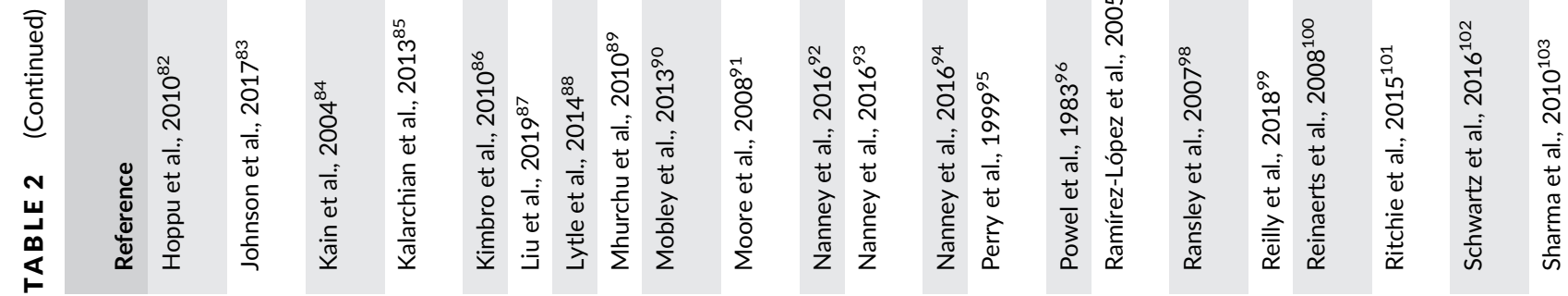

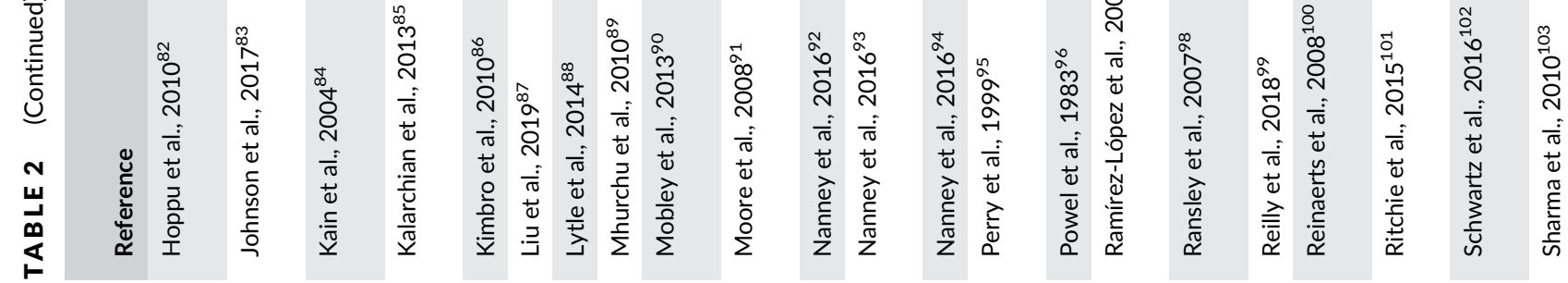

$\stackrel{0}{\infty}$

突 


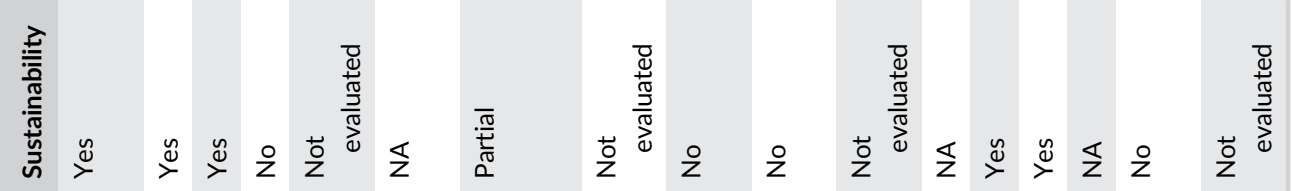

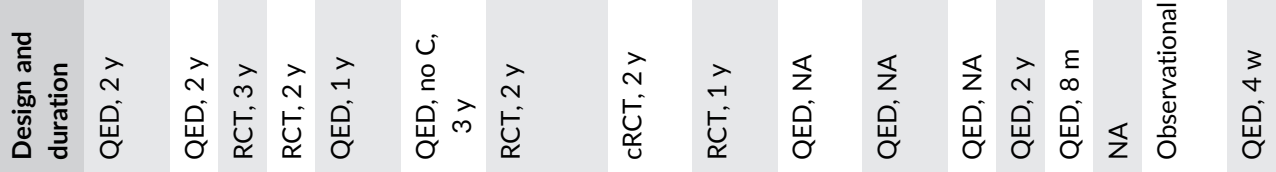

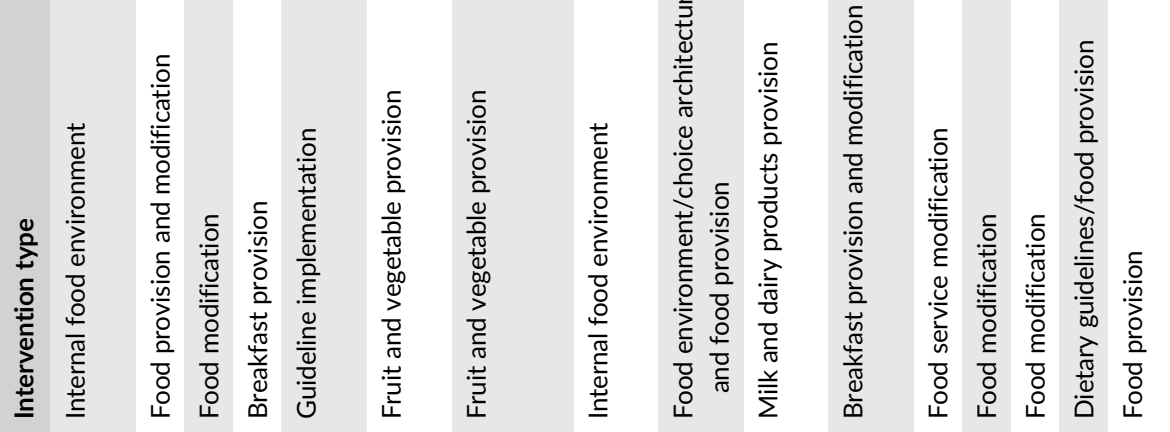

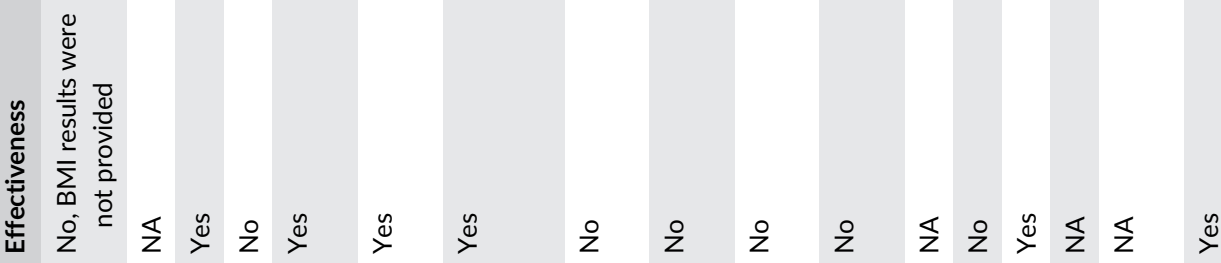

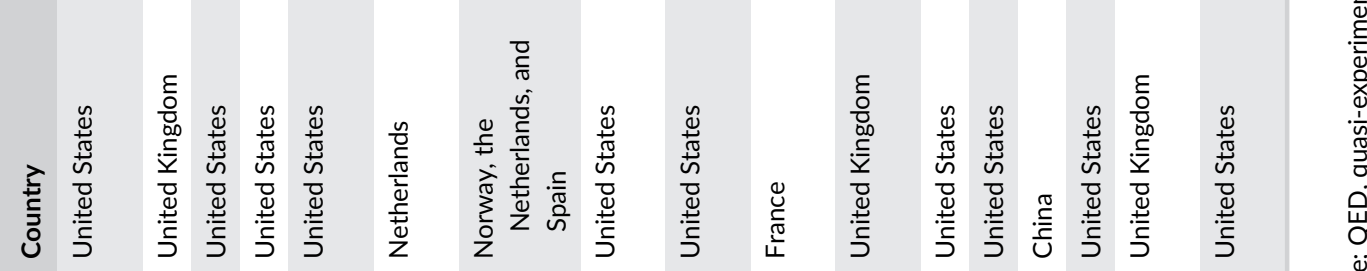

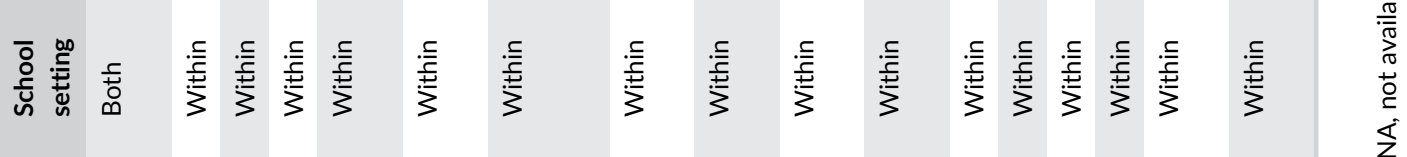

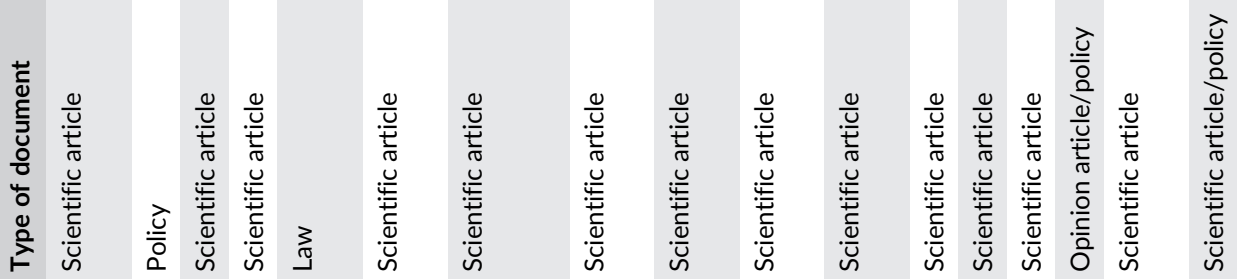

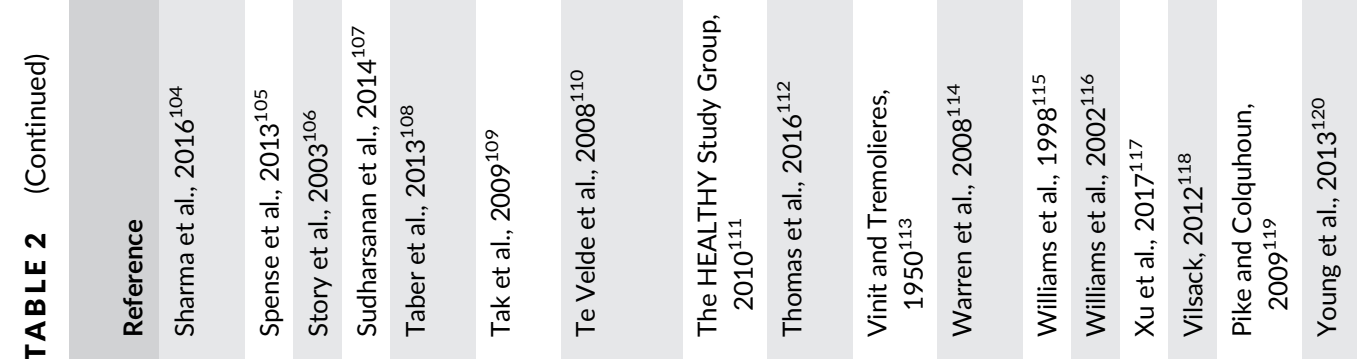
3

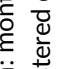
$\ddot{\varepsilon} \frac{\mathrm{n}}{\mathrm{v}}$

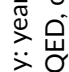

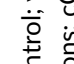




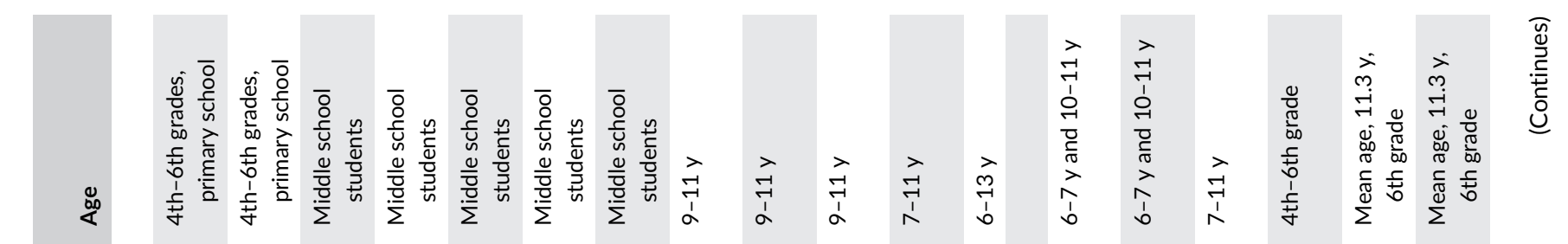

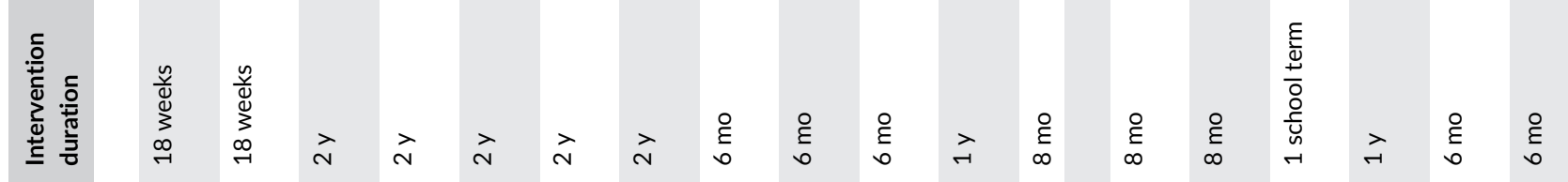

旁哭

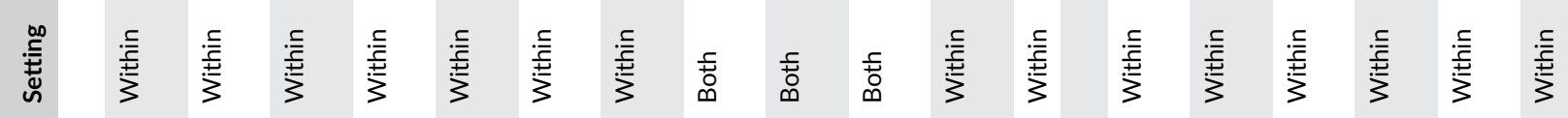
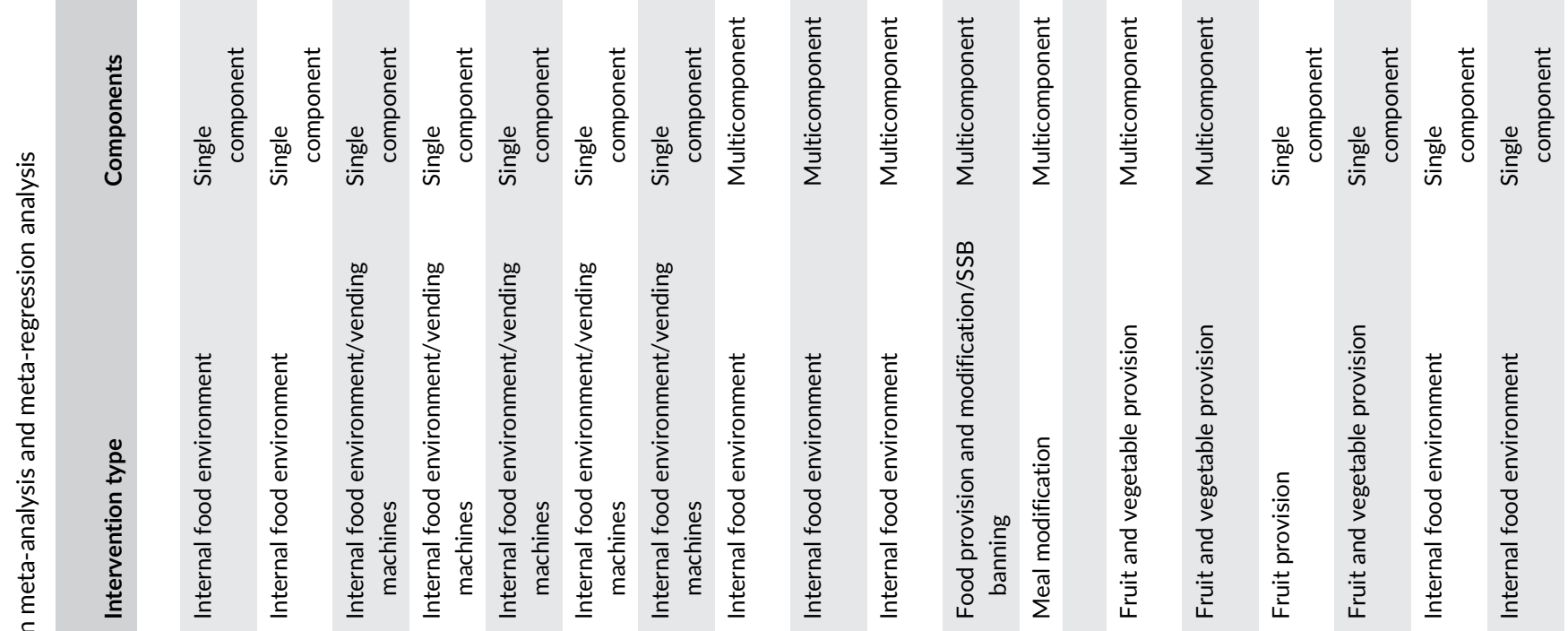

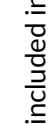

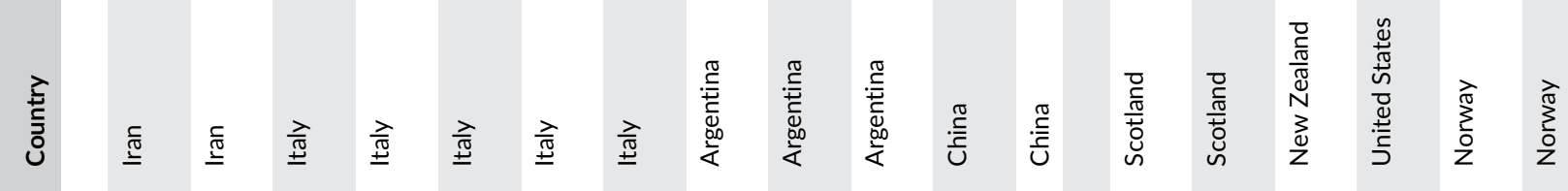

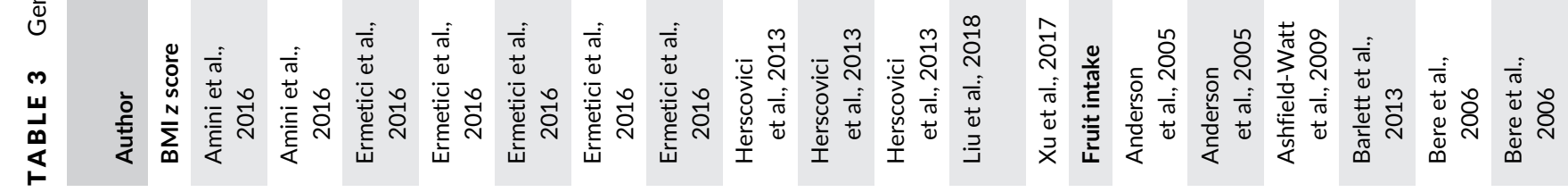




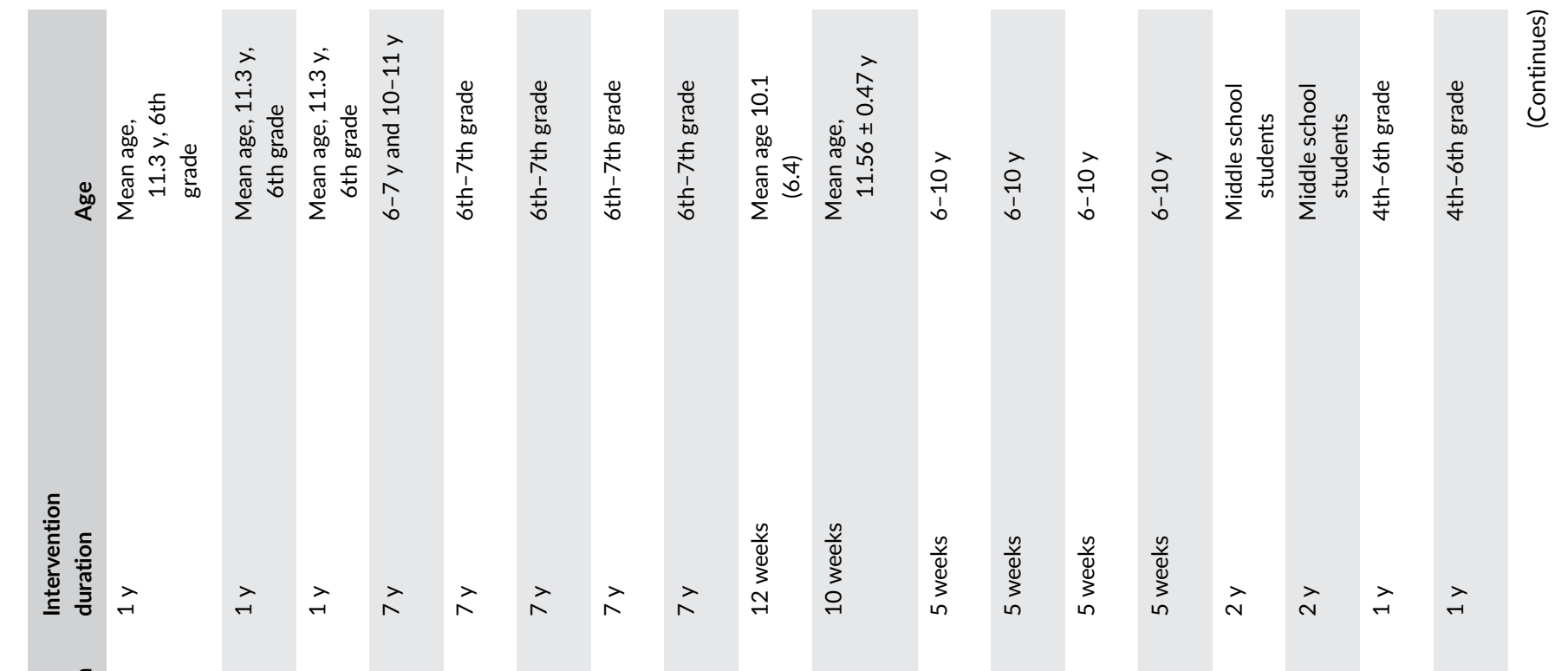

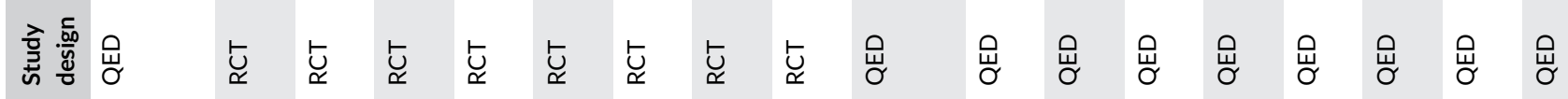

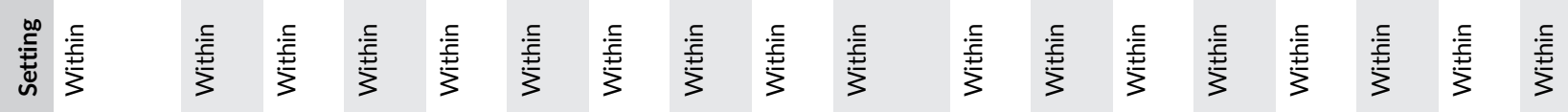

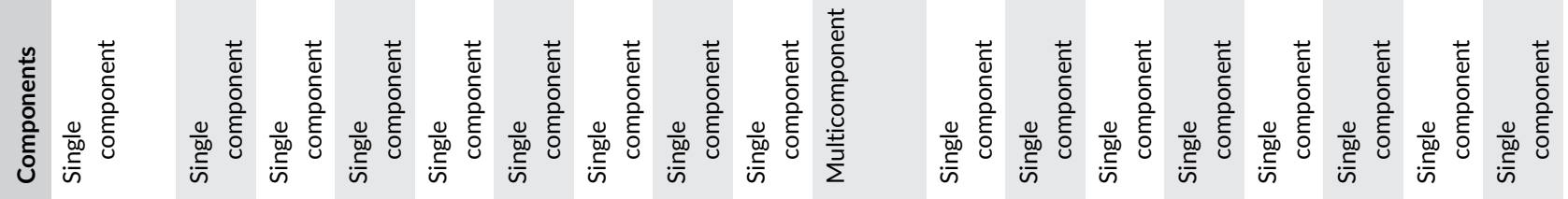

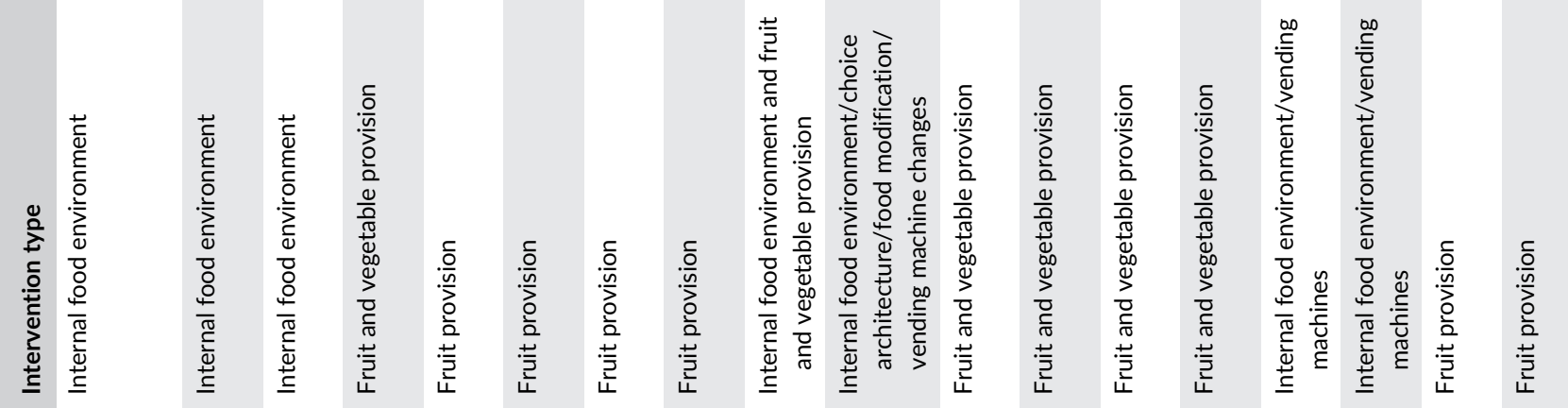

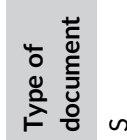

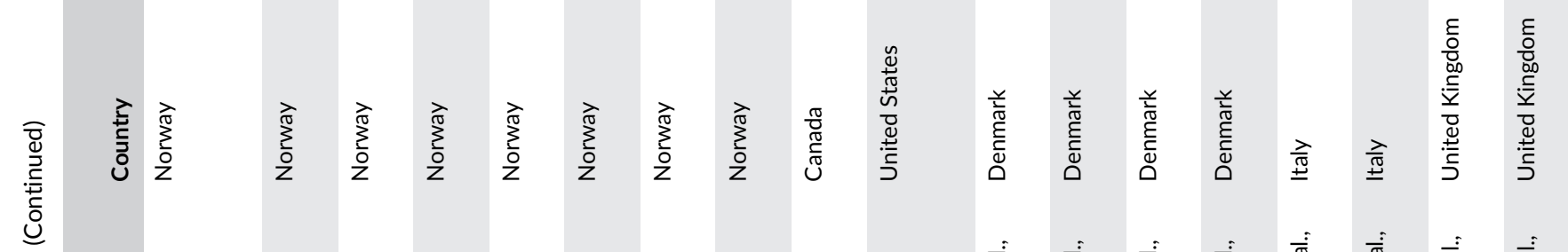

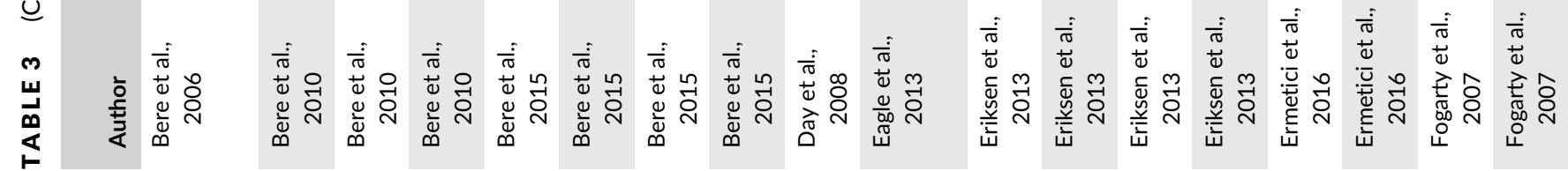




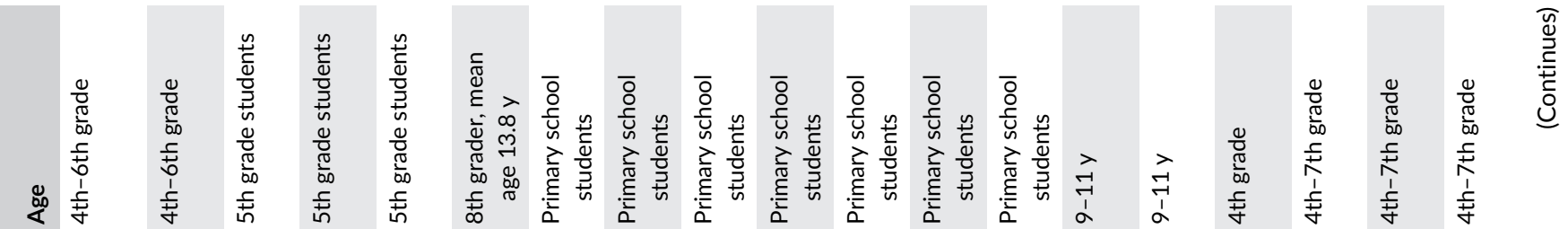

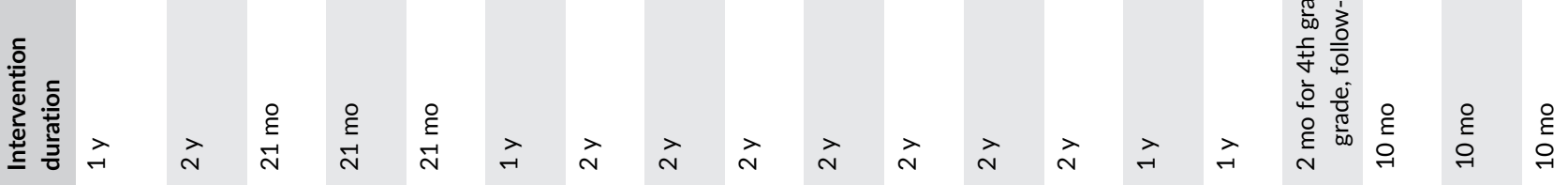

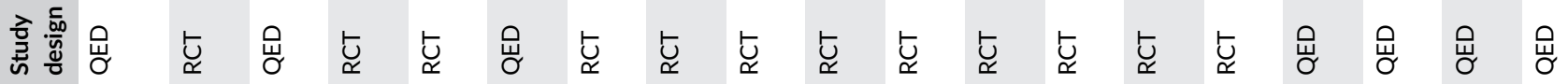

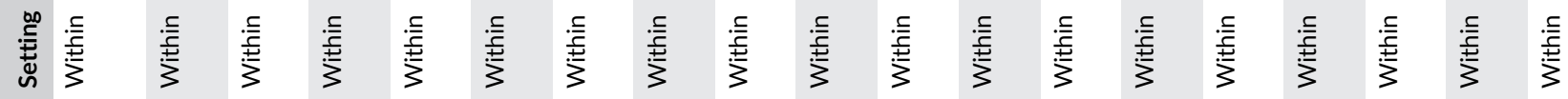

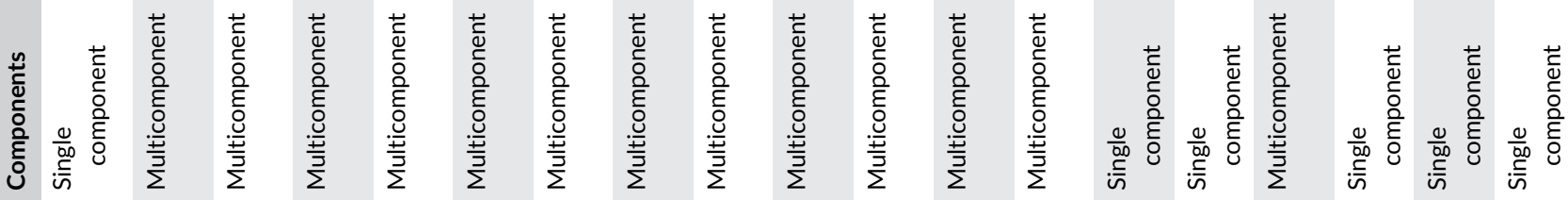

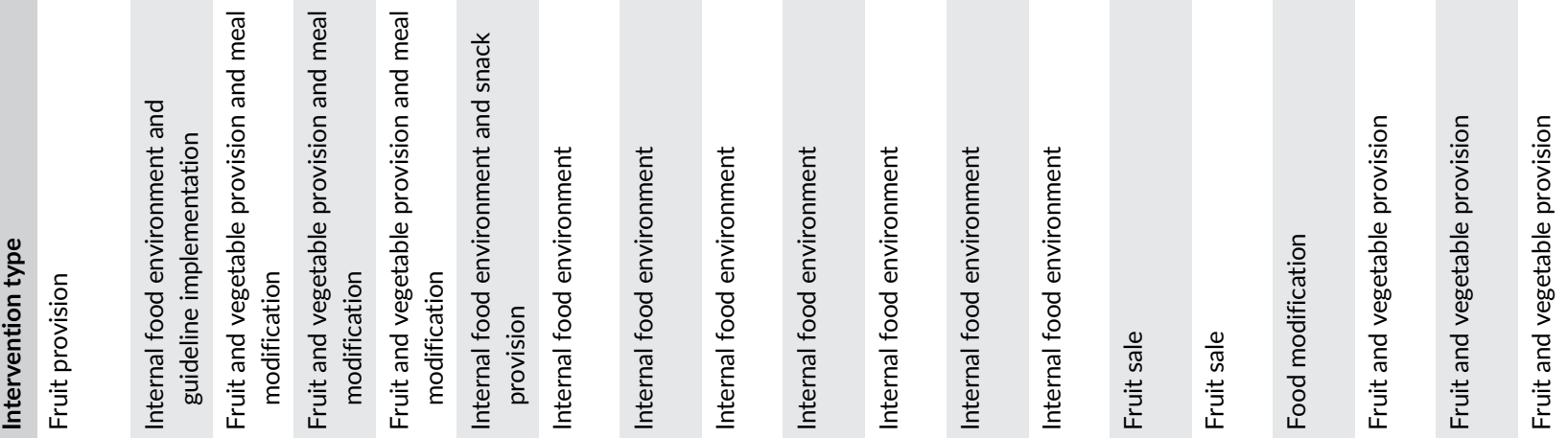

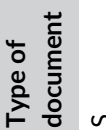

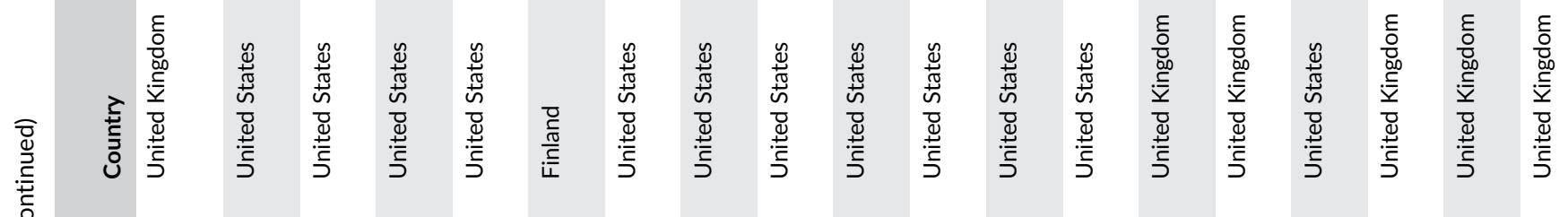

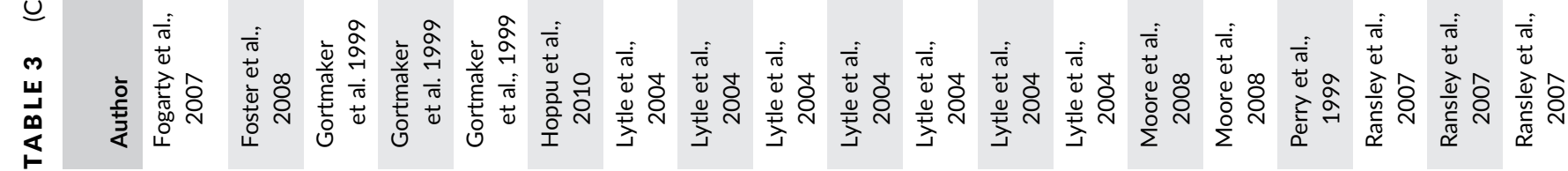




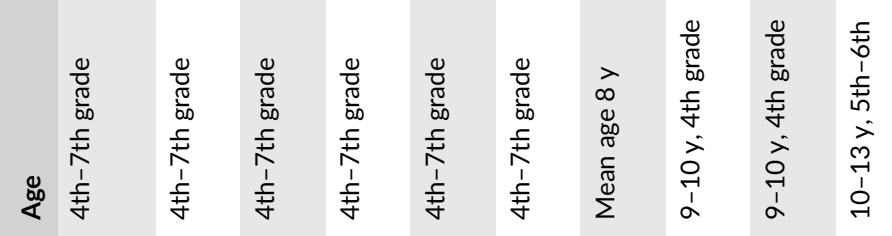

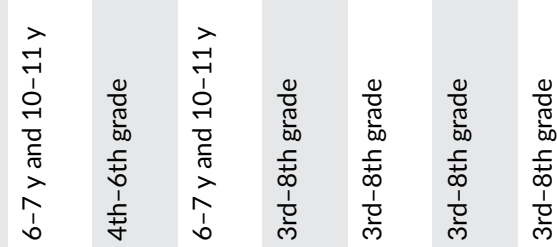

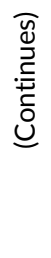

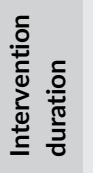

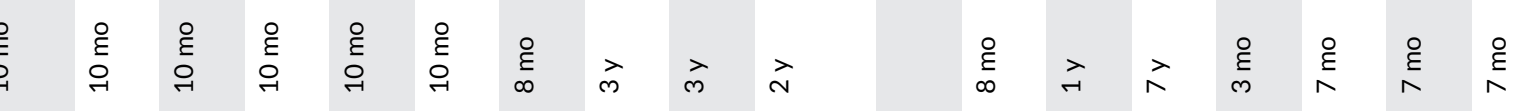

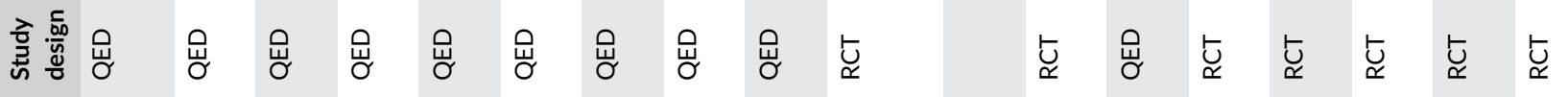

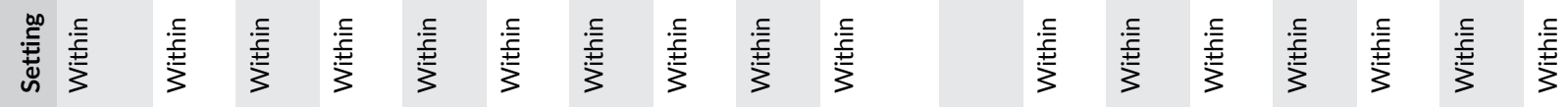

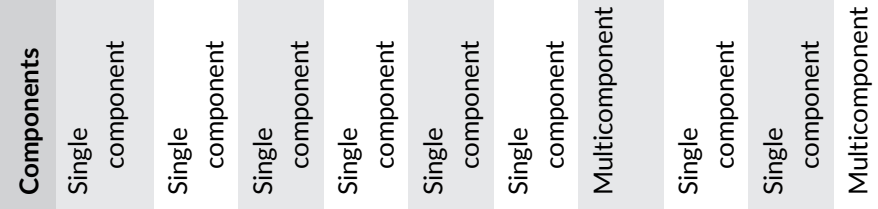
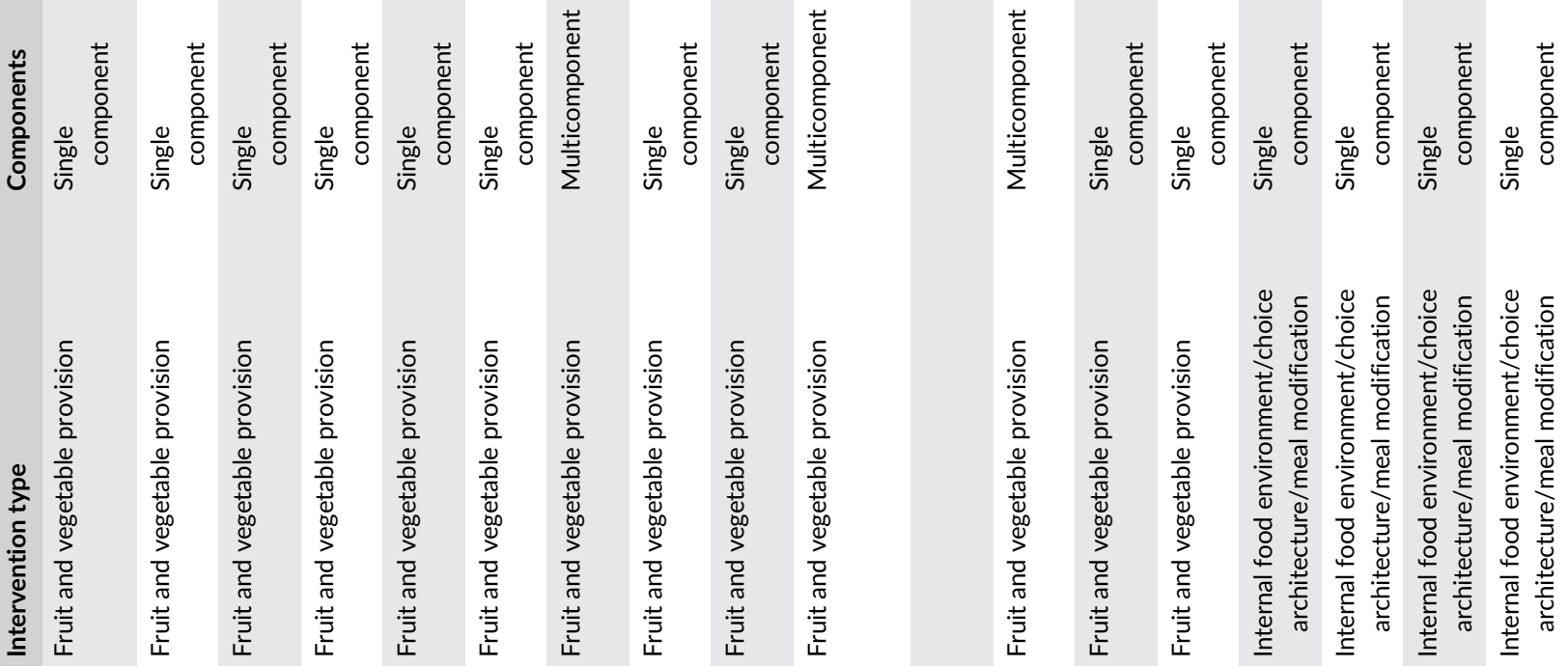

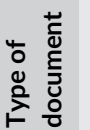

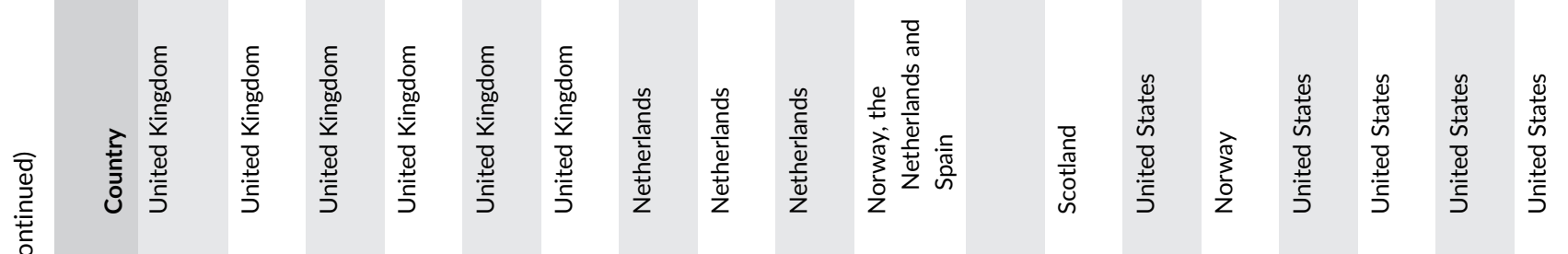

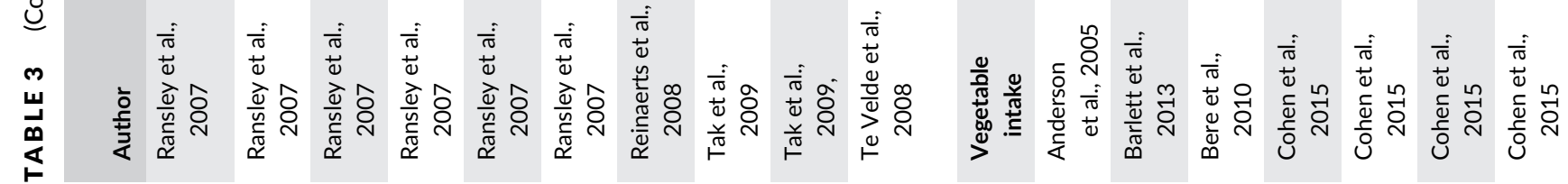




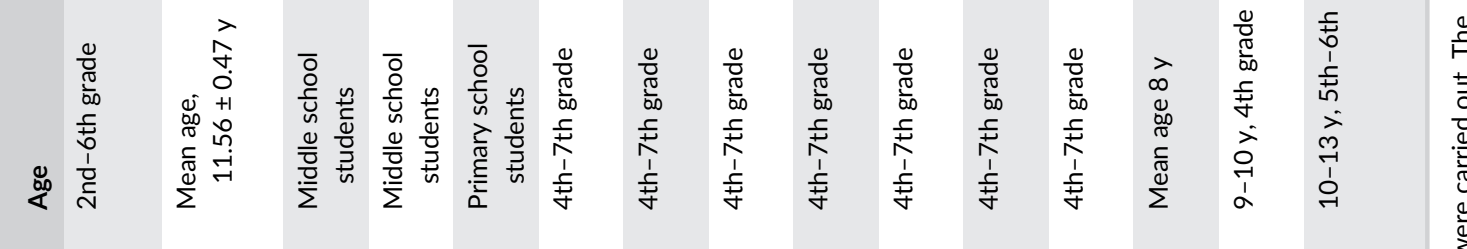

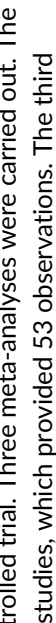

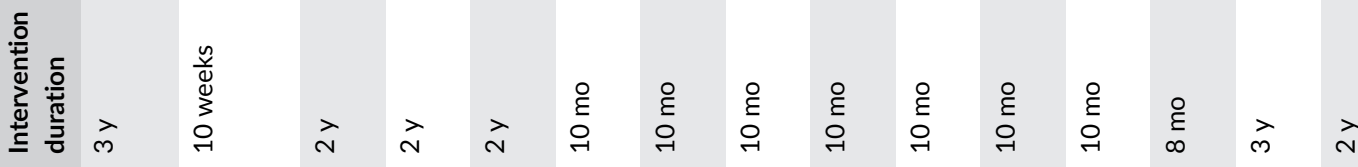

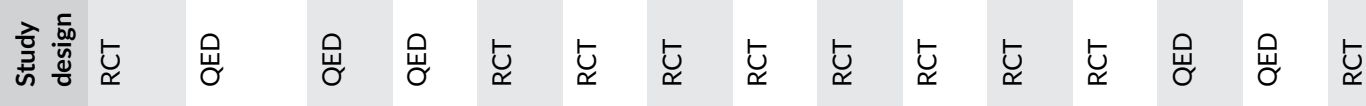

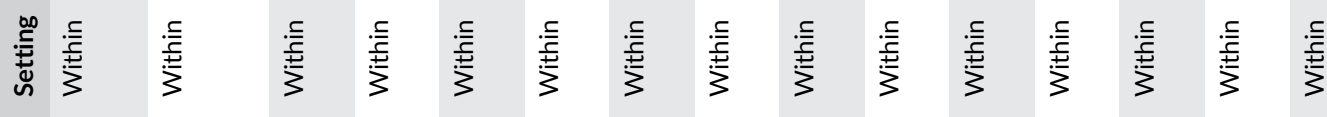

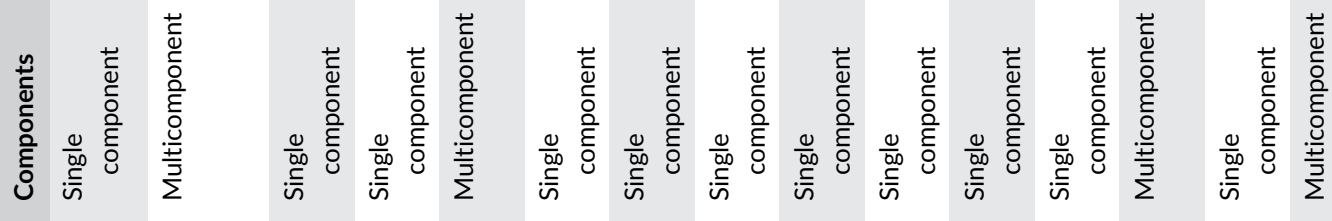

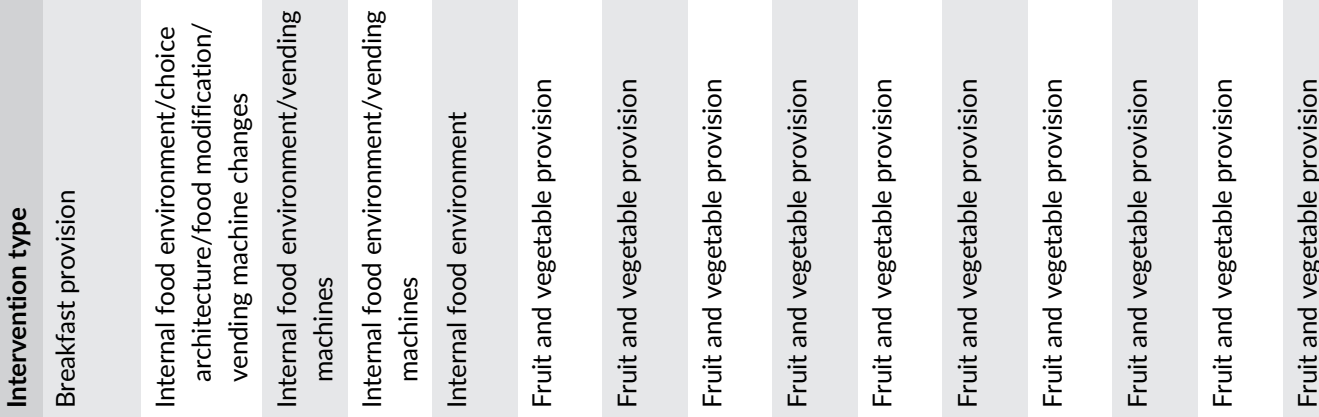

竞

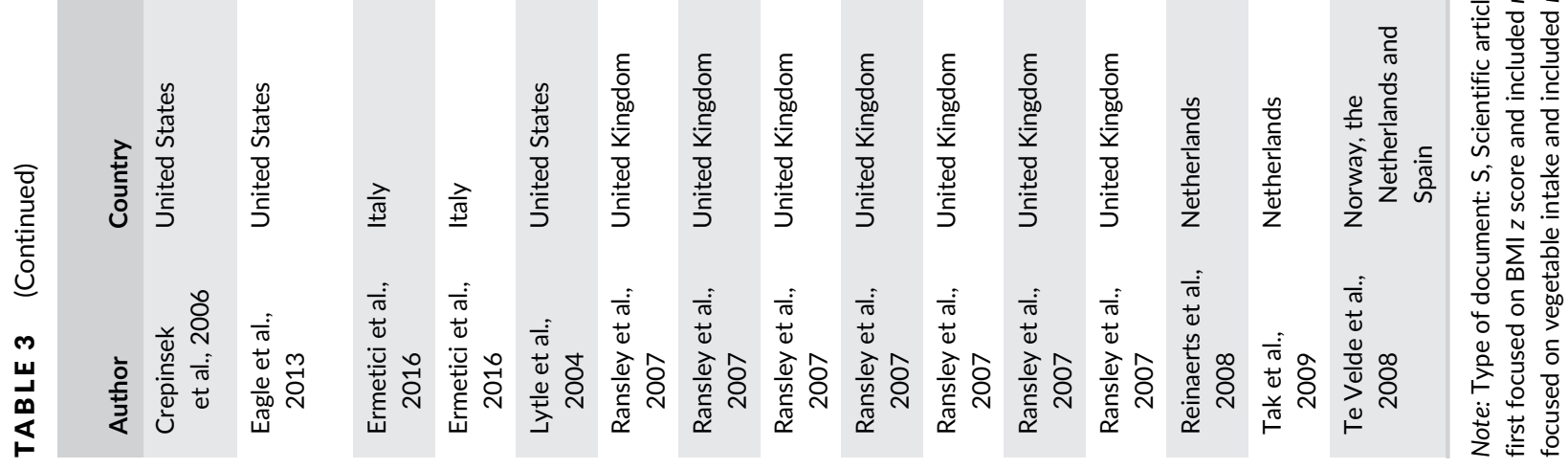




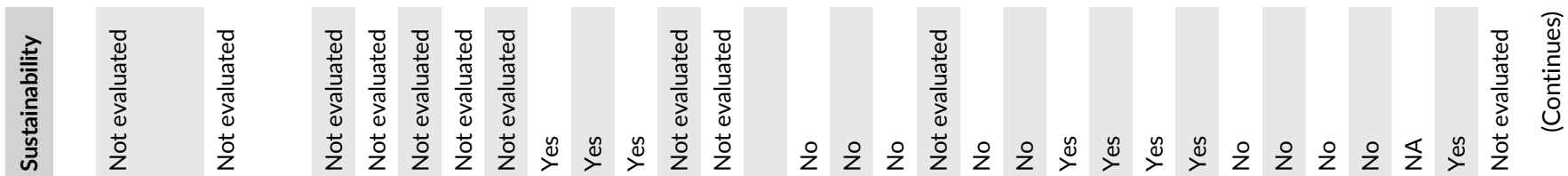

ग

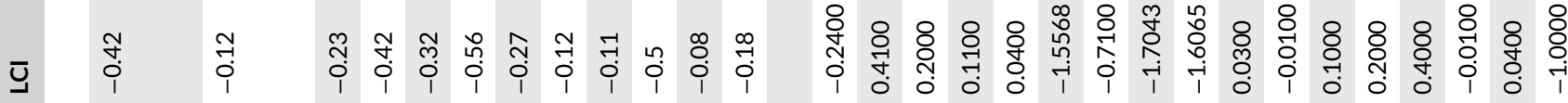

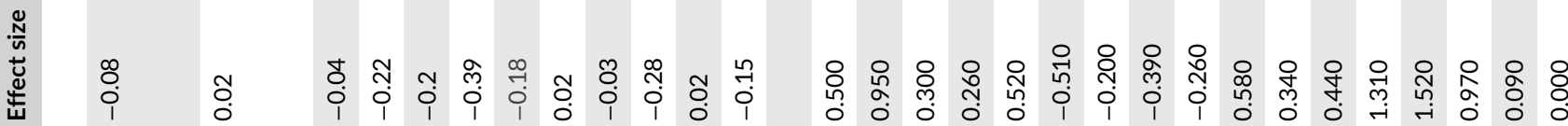

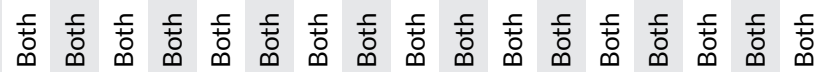

高

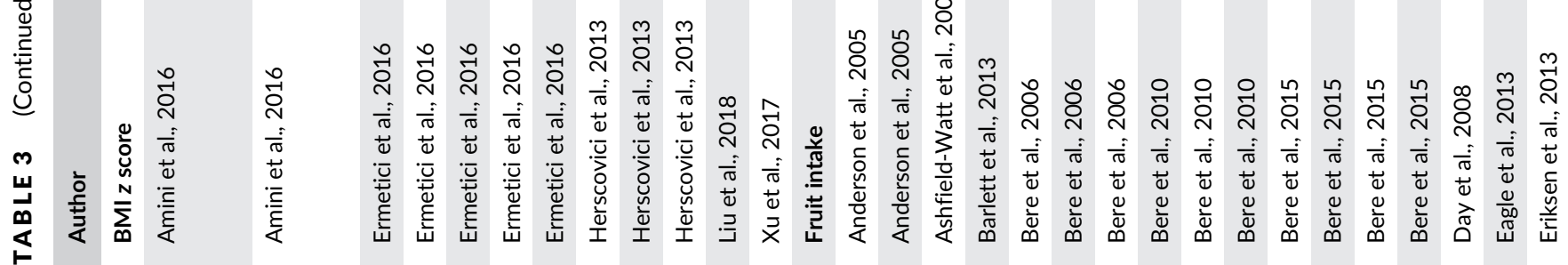

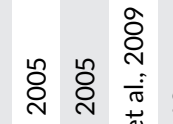




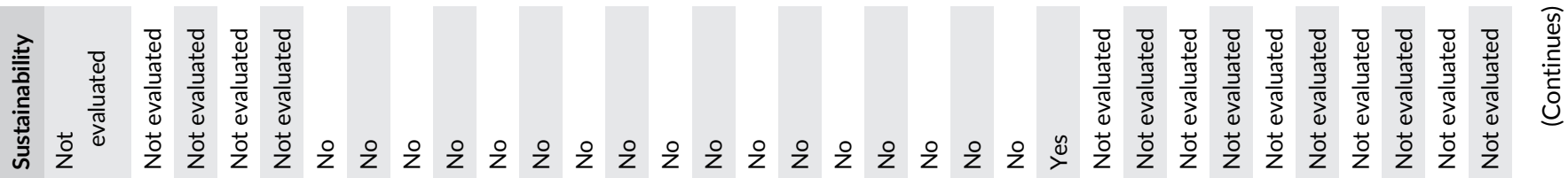

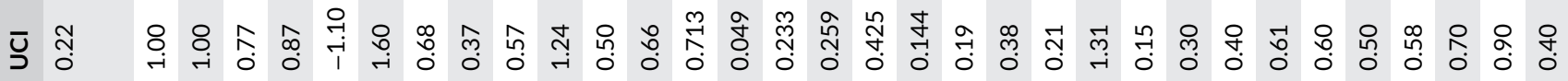

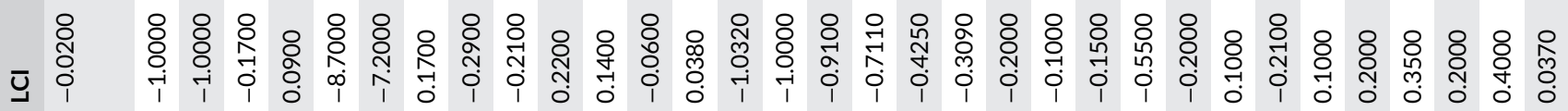

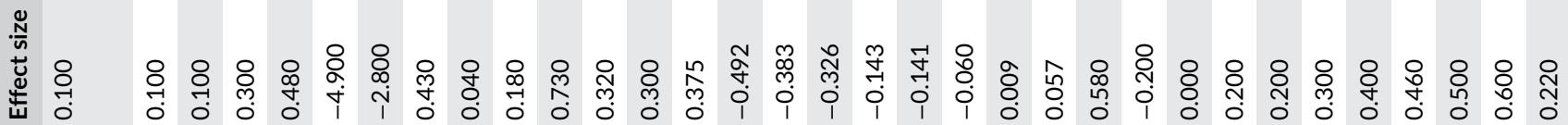

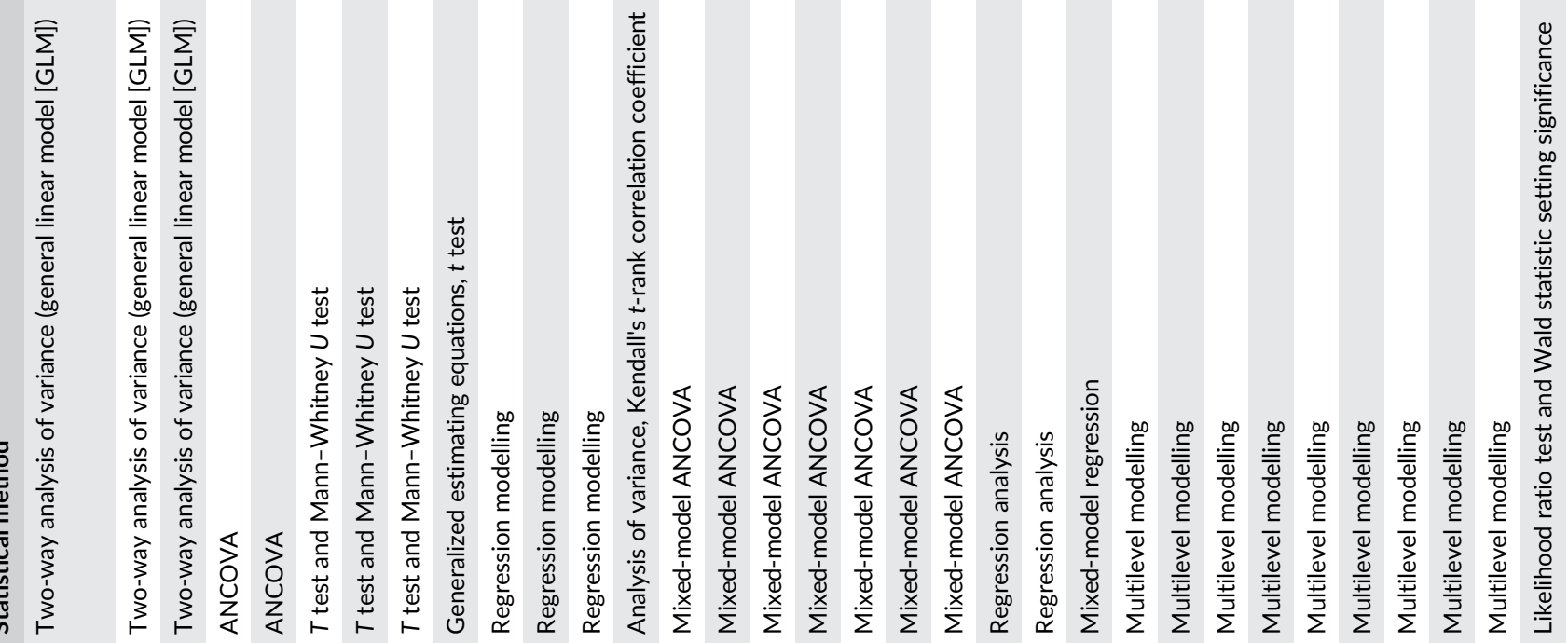

胥

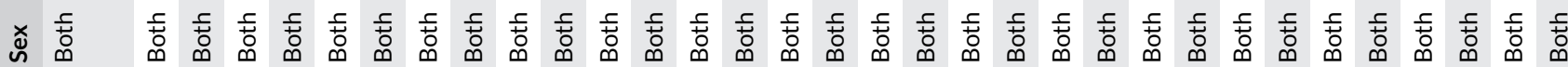

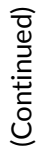

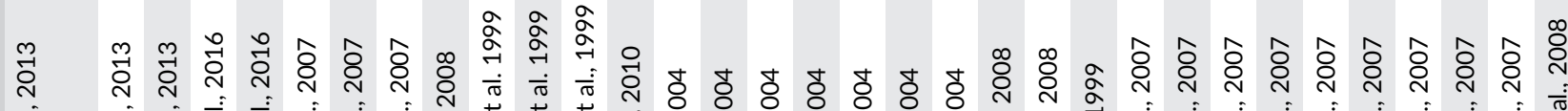

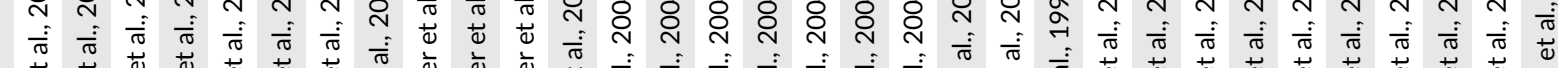

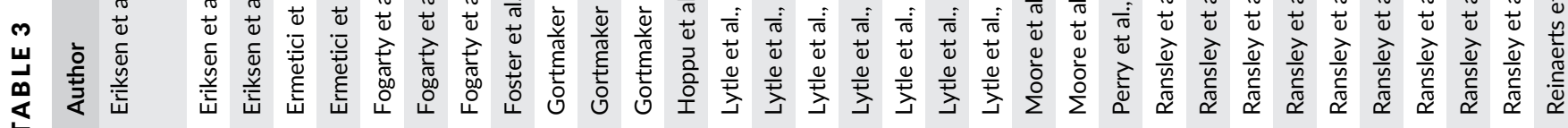




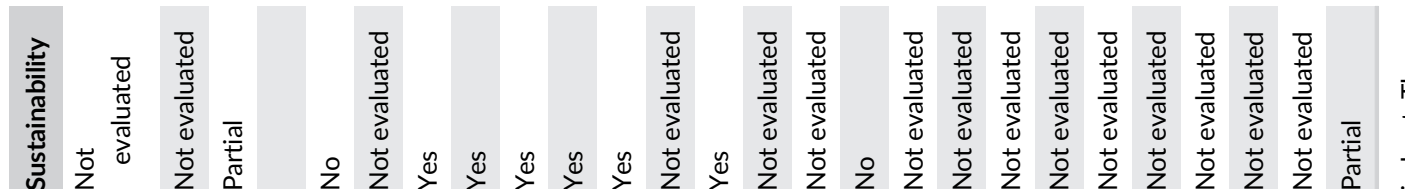

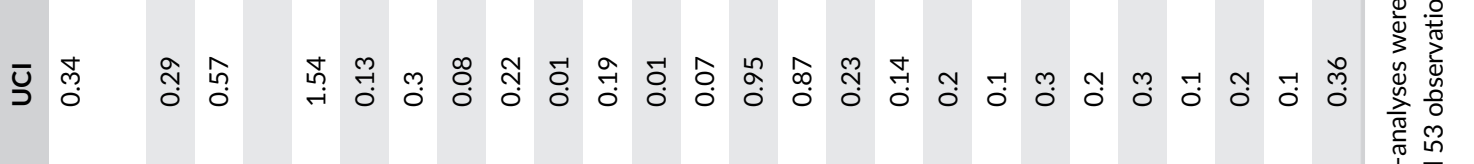

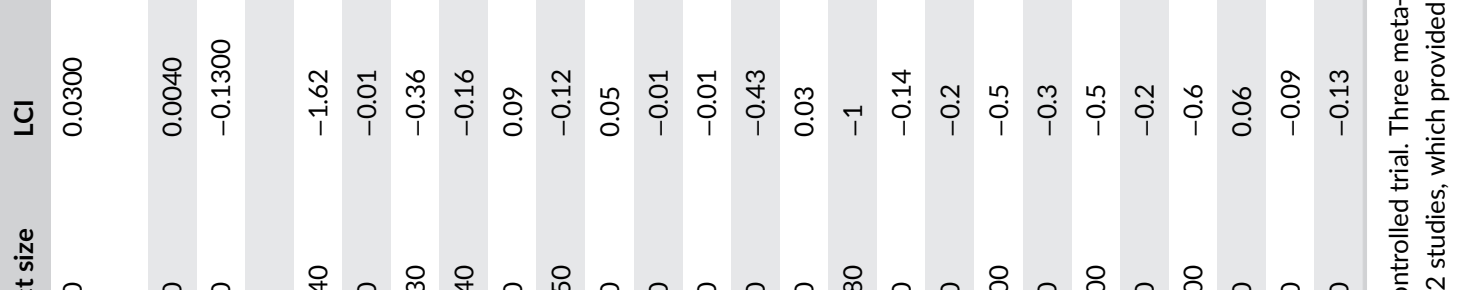
应

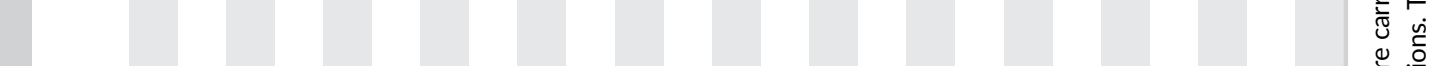

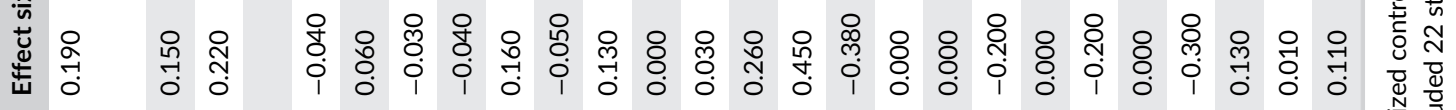
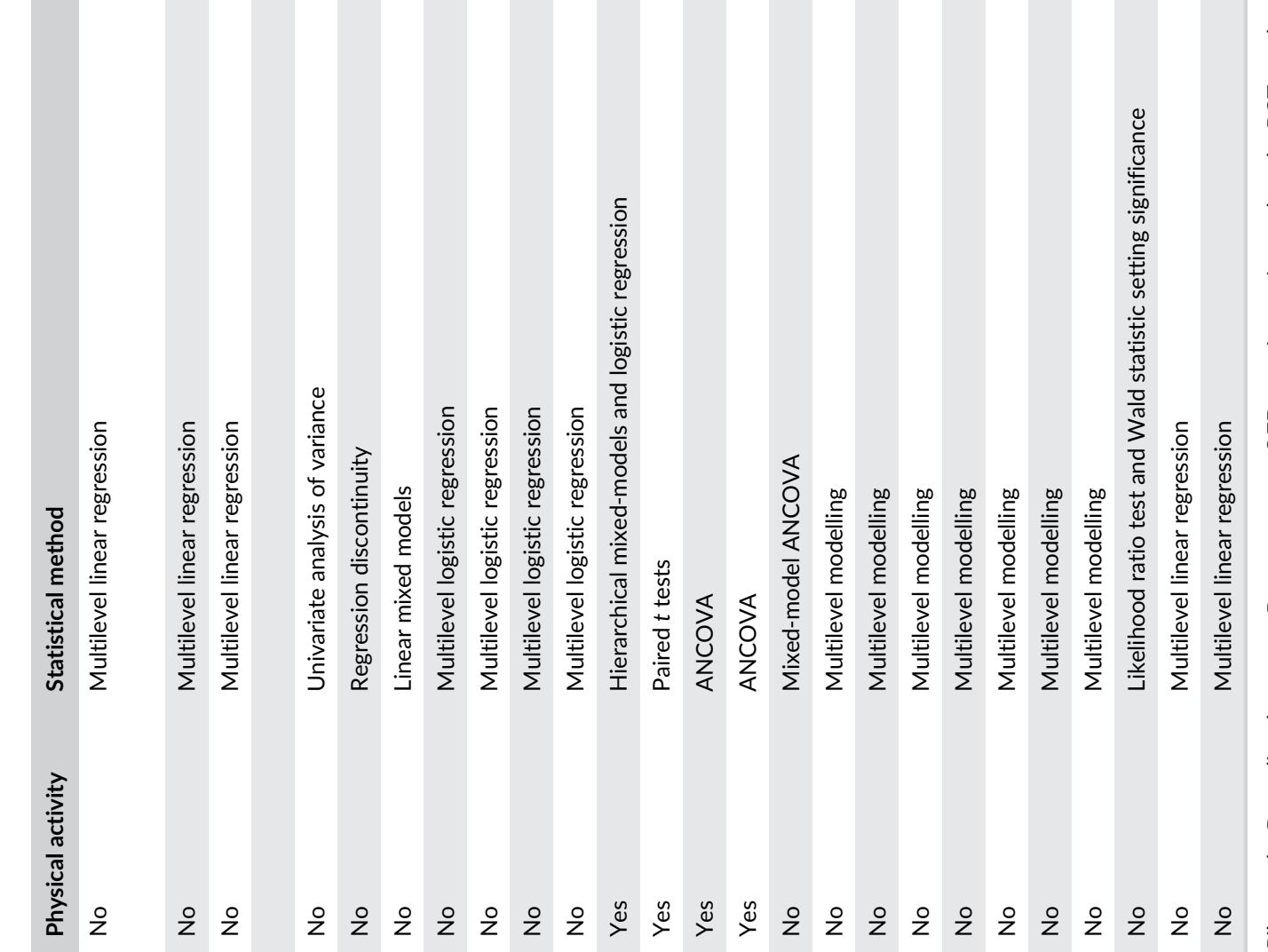

总咅 
heterogeneity. RCTs of school food environment interventions that assessed changes in BMI $z$ score showed a BMI $z$ score reduction of -0.10 standard deviations from the reference population mean $(95 \%$ $\mathrm{Cl}$ : 0.13, 0.07). QED studies showed a BMI $z$ score reduction of -0.20 (standard MD: $-0.20,95 \% \mathrm{Cl}: 0.26,0.14$ ). The overall effect of the pooled study results shows a statistically significant association between the implementation of the school food environment interventions and a reduction in $\mathrm{BMI} z$ score (standard MD: $-0.12,95 \% \mathrm{Cl}$ : $0.15,0.10$ ) (Figure 2). No significant findings were identified on changes in vegetable intake (Figure 3); however, the meta-analysis showed a small increase in fruit consumption in school children in RCT studies (standard MD: +0.20, 95\% Cl: 0.14, 0.26), QED studies (standard MD: $+0.19,95 \% \mathrm{Cl}: 0.15,0.22$ ), and overall (standard MD: $+0.19,95 \% \mathrm{Cl}: 0.16,0.22$ ) (Figure 4). The results represent the standard MD between intervention and control groups at baseline and after the implementation of the intervention.

\section{2 | Meta-regression analyses}

The characteristics of the studies included in meta-regression analyses are shown in Table 3, which presents author, country, type of document, intervention type, components, setting, study design, intervention duration, age, sex, physical activity inclusion, effect size, lower $\mathrm{Cl}$ ( $\mathrm{LCl}$ ), upper $\mathrm{Cl}(\mathrm{UCl})$, and sustainability of the intervention. Results are stratified by outcome (BMI z score, fruit intake, and vegetable intake). Meta-regression analyses showed that there were no statistically significant differences in the intervention effect size according to study design (-0.09, 95\% Cl: $-0.19,0.004, p=0.061)$. Monitored program type interventions relying on specific dietary guidelines, such as type of food items that are permitted or banned in the school canteen and regulation on portion sizes, were more likely to be effective in reducing BMI or increasing fruit or vegetable intake than interventions not based on a sustainable program $(\beta=0.33,95 \% \mathrm{Cl}$ : $0.05,0.60$, $p=0.021$ ). Pilot studies also showed larger effect sizes. We found no statistically significant differences in meta-regressions between single-component and multicomponent interventions ( $\beta=-0.02,95 \%$ $\mathrm{Cl}$ : $-0.12,0.09, p=0.741$ ). However, interventions that included a physical activity component were more likely to be effective. In terms of types of interventions, fruit and vegetable provision, as well as the provision of fruit only, were statistically significantly associated with higher fruit and vegetable intake. Girls were more likely to increase their fruit and vegetable intake or to reduce their BMI following interventions (Table 4).

\section{3 | Risk of bias assessment}

Risk of bias assessment was undertaken for $96 \%$ of the intervention studies, and not enough data were available to undertake a risk of bias assessment for $4 \%$ of the studies. From the RCT interventions, $n=38(43 \%)$ presented a high risk of bias and $n=5(12 \%)$ presented a low risk of bias. For the QED studies (55\%), $n=4$ (7\%) showed the highest score of " $4, " n=7$ (13\%) presented a score of " 3, , $n=16$ (29\%) presented a score " $2, " n=16(29 \%)$ a score of " 1 ," and $n=12$ (22\%) a score of "0." The highest risk of bias was found on attrition bias and low protection of potential contamination. There was little evidence of publication bias as evidenced by visual inspection of the plots: estimates from the included studies are distributed equally around the overall estimate for each index used, and studies with both significant and non-significant estimates were included (Tables S2 and S3).

\section{4 | DISCUSSION}

Our systematic literature review and meta-analysis focused on 100 school food environment interventions, of which $63 \%$ involved a single component and $37 \%$ encompassed multiple components. Common intervention approaches included the direct provision of food, changes in dietary guidelines for schools, and modifications of the food environment within schools, such as increasing the visibility of healthy food options, the addition of salad bars or healthy food displays in vending machines and in the canteen or kiosks, and healthy food promotion within the school and bulletin boards. Our systematic review showed that effective strategies to improve dietary intake and reduce $\mathrm{BMI}$ in children include the use of clear and precise dietary guidelines and school meal standards in terms of the type, amount, and presentation of foods. An example is requiring a specific number of fruits/vegetables-that at least half of all grains sold/served are whole grains, reductions in products that contain transfats, and/or restrictions on milk to $1 \%$ or skim milk. In the United States, childhood obesity prevalence was found to be lower in states with precise school meal standards that were specific in the requirements of healthy food items and the replacement of unhealthy food options for healthier versions. ${ }^{108}$ It was also observed that students in states with schools with nutrition standards versus no nutrition standards consumed fewer calories and less fat and sugar at school and did not gain as much weight compared with students in states with lack or reduced nutrition standards that were not specific in the requirement of fruits and vegetables and the provision of low-fat dairy products and whole grains. ${ }^{121-123}$ In addition, low-income children living in states with precise nutrition standards in schools tended to have less risk of obesity than children in states with no school meal regulations. ${ }^{108}$ Precise nutrition standards that increase the quality and nutrition of school meals are a good starting point to tackle childhood obesity.

The pooled effect size resulting from our meta-analysis, for studies using BMI $z$ score as their outcome measure, was -0.12 , reflecting a relatively important effect on the prevalence of obesity in school children, the exact magnitude of which depends on the BMI distribution to which the effect is applied. If applied to the BMI distribution of year 6 children in England, and assuming a uniform shift to the left of the distribution itself, the above effect size would correspond to a reduction of over 2 percentage points of obesity prevalence. In fact, there is at least some evidence in the papers we have reviewed that effects may be larger in children who initially had a 
TABLE 4 Meta-regression analyses

\begin{tabular}{|c|c|c|}
\hline Variable & $\beta(95 \% \mathrm{Cl})$ & $p$ value \\
\hline \multicolumn{3}{|l|}{ Study design } \\
\hline $\mathrm{RCT}$ & Ref & \\
\hline \multicolumn{3}{|l|}{ Type of study } \\
\hline Scientific study & Ref & \\
\hline Program & $0.33(0.05,0.60)$ & 0.021 \\
\hline \multicolumn{3}{|l|}{ School setting } \\
\hline Within schools & Ref & \\
\hline Within and around schools & $-0.17(-0.41,0.06)$ & 0.150 \\
\hline Latin America & $-0.14(-0.38,0.11)$ & 0.280 \\
\hline Europe & $0.02(-0.10,0.15)$ & 0.716 \\
\hline Middle East & $0.14(-0.14,0.42)$ & 0.324 \\
\hline United Kingdom & $0.08(-0.06,0.22)$ & 0.245 \\
\hline Other & $0.33(-0.04,0.70)$ & 0.085 \\
\hline \multicolumn{3}{|l|}{ Components } \\
\hline Multicomponent & Ref & \\
\hline Single component & $-0.02(-0.12,0.09)$ & 0.741 \\
\hline Food modification & $0.20(-0.001,-041)$ & 0.052 \\
\hline Fruit provision & $0.34(0.15,0.54)$ & $<0.001$ \\
\hline Guidelines & $0.10(-0.37,0.58)$ & 0.673 \\
\hline \multicolumn{3}{|l|}{ Duration (years) } \\
\hline & $0.008(-0.02,0.04)$ & 0.628 \\
\hline \multicolumn{3}{|l|}{ Sex } \\
\hline Boys \& girls & Ref & \\
\hline Boys & $-0.73(-0.28,0.13)$ & 0.487 \\
\hline Girls & $0.065(0.02,1.28)$ & 0.044 \\
\hline \multicolumn{3}{|l|}{ SEP } \\
\hline Considered & Ref & \\
\hline Not considered & $0.009(-0.099,0.12)$ & 0.863 \\
\hline \multicolumn{3}{|l|}{ Physical activity } \\
\hline Considered & Ref & \\
\hline Not considered & $-0.12(-0.22,-0.12)$ & 0.029 \\
\hline
\end{tabular}

Note: Meta-regression results are indicated as $\beta$ coefficients and $95 \%$ confidence intervals $(\mathrm{Cl}), \mathrm{N}=95$. Bold values indicate statitsically significant $(p<0.05)$ values.

Abbreviations: QED, quasi-experimental design; RCT, randomized controlled trial; SEP, socioeconomic position. 
higher BMI, ${ }^{124}$ which would suggest an even larger reduction in obesity prevalence. The pooled effect size for studies that measured fruit intake showed a standard MD of 0.19 portions per day $(95 \% \mathrm{Cl}: 0.16$, 0.22 ), which would be equivalent to $15 \mathrm{~g}$ of fruit per day, assuming that a portion of fruit is equivalent to $80 \mathrm{~g} .{ }^{125}$

Sustainability and monitoring of guideline implementation and food provision was also observed to be linked to more effective interventions. Recommendations based on scientific evidence and interventions that facilitate access to healthy and appetizing meals and snacks in schools were associated to better health outcomes. ${ }^{108,126}$ Replacement of ultra-processed and unhealthy alternatives with healthy and palatable options (e.g., vending machines), ${ }^{48,124}$ free and sustainable fruit and vegetable provision, ${ }^{33,35}$ and interventions that involve parents and staff and address physical activity and social inequalities ${ }^{100}$ may also contribute to healthier weight-related outcomes among school children.

Unsuccessful interventions were observed to provide foods that were not based on scientific evidence and that may contain elevated amounts of sugar such as fruit juice or cereal. These types of foods may provide some nutrients but tend to be ultra-processed and highly caloric. ${ }^{34,127,128}$ Standards for healthier school meals should be designed to increase fruit and vegetable contents and whole grains and pulses for refined carbohydrates. ${ }^{129,130}$ Interventions focused on increasing vegetable intake were found to be less effective and sustainable. ${ }^{32,60,109}$ Fruit intake may be easier to increase than vegetable intake due to its sweet taste and easier form of consumption and transportation compared with vegetables. ${ }^{95}$ Fruit and vegetable intake were directly associated with the provision of fruits and vegetables and the length of time in which fruits and vegetables were provided as part of the intervention. Therefore, when the fruit or vegetable provision intervention ceased, intake was observed to go down as well. ${ }^{29,131}$

A frequent limitation in unsuccessful interventions was not addressing social inequalities. ${ }^{21,132}$ Children with a lower SEP are more likely to have a higher risk of obesity than children with a higher SEP. ${ }^{133}$ This could be due to a higher exposure and accessibility to unhealthy food options and a reduced access to affordable and healthy foods typical in schools that are located in lower income and minority neighborhoods leading to disproportionately high rates of obesity and preventable, diet-related diseases. ${ }^{134,135}$ Sociocultural, political, and historical factors could influence food store preferences and food choices, particularly in ethnic minority populations. Therefore, systemic drivers of social and ethnic inequalities could play a key role in shaping food environments and in access to healthy food and mediate the association with obesity. ${ }^{136}$

According to the meta-regression analyses, monitored program type interventions relying on specific dietary guidelines, such as type of food items that are permitted or banned in the school canteen and regulation on portion sizes, were more likely to be effective in reducing $\mathrm{BMI}$ or increasing fruit or vegetable intake than interventions not based on a sustainable program $(\beta=0.33,95 \% \mathrm{Cl}$ : $0.05,0.60$, $p=0.021$ ). Although pilot studies also showed larger effect sizes than intervention and policy studies, this could be due to underpowered studies designed to detect changes (Table 4).

Although previous studies have suggested that multicomponent interventions (e.g., environment, education, and services) could be more effective in tackling obesity, our meta-regression results show no statistically significant differences between single-component and multicomponent approaches. This could be due to a low power to detect differences between studies. However, statistically significant differences were found when considering a physical activity component in the intervention. As an example of a multicomponent approach, the EatSmart program implemented in primary schools in Hong Kong ${ }^{137}$ included administrative measures, coupled with the provision and availability of healthy meals and snacks, complementary nutritional education, and advertisement all advocating a healthy eating environment in the school sector by the improvement of the food environment (healthy availability and accessibility of food). The success of this program was associated with school encouragement to initiate and take ownership of policies, structures, and practices to aid students in the development of healthy eating habits, have access to healthier foods during lunch and snack time, restricting the sale of unhealthy food items, engagement in education and promotion on healthy eating, and complying fully with nutritional guidelines established by the accreditation system. ${ }^{137}$ Similarly, a Cochrane review of RCT studies identified that there was some evidence that diet and physical activity interventions combined could reduce measures of adiposity in children aged 0 to 5 years, indicating that a combination of diet and physical activity interventions might reduce adiposity rather than single-component interventions. ${ }^{138}$

Furthermore, according to the meta-regression analyses, girls were more likely to increase their fruit and vegetable intake or to reduce their BMI following interventions compared with boys. This could be due to a higher interest in health and diet and willingness to participate in this type of interventions. Previous studies have found that women may be more susceptible of health information in general and more responsive to nutrition education in particular. ${ }^{15}$ In contrast, it is possible that men are more responsive to sports or physical activity interventions. This pleads for future carefully designed studies that offer the child more individually targeted forms of intervention. ${ }^{15,124,132,139}$

In terms of types of interventions, fruit and vegetable provision, as well as the provision of fruit only, were statistically significantly associated with higher fruit and vegetable intake. However, the metaanalysis showed no statistically significant difference in vegetable intake alone. A low intake of vegetables among children could be linked to a low taste acceptability due to lack of exposure at an early age. ${ }^{140}$ Increased meal palatability through the involvement of chefs who developed tasty, attractive, and healthy foods could increase the likelihood of healthy food acceptance by children, which could lead to an increase in fruit and vegetable intake and a decrease in $\mathrm{BMI}^{48}$ However, healthy meal alternatives within schools and their effect on weight and health may not be sustainable if there is an unhealthy food environment around schools competing with the healthy strategies. $^{29,112,141}$ 
Unhealthy school food options available on school grounds (e.g., kiosks and vending machines) and obesogenic food environment around schools are key barriers for successful school food environment interventions and the prevention of childhood obesity. ${ }^{111,126,142-144}$ Policy actions could play an essential role to improve surrounding school food environments to sustain healthy dietary intake.

Food and beverage regulations on childhood overweight and obesity showed a significant association between lower BMI z scores, lower odds of overweight or obesity, and better dietary outcomes in geographic areas with a strong food or policy compared with areas with no regulatory policies. ${ }^{92,145}$

A negative aspect of school food policies was lack of precision in dietary and school environment guidelines in terms of the provision of fruits and vegetables and quality and presentation of available meals and therefore the lack of effective implementation in schools. Another limitation that these policies confront is the political pressures from the food industry, which demand inclusion of food items that can increase the caloric intake of children in schools. ${ }^{146}$ Canteen staff and managers in schools require technical and financial assistance to effectively implement evidence-based practices. ${ }^{146}$ Among the most common nutrition guideline components that were addressed in policies were the regulation of vending machines, ${ }^{59,111,124,144,147,148}$ school kiosks, ${ }^{149}$ and a la carte food options. ${ }^{47,71,85,112,116,117,150}$

Removal of vending machines or replacements of unhealthy food items with appetizing healthy food options can represent a first step to change the food environment within schools. Continuous monitoring of sales for nutritional quality is important. ${ }^{151}$ The regulation of vending machines was also associated with a decrease of sugarsweetened beverage (SSB) consumption in children. ${ }^{152}$ However, when SSBs remain available within or around schools, partial SSB restrictions do not appear to be effective in reducing intake. ${ }^{153}$

Even though there was a positive correlation between the modification of the availability of food within schools and the prevention of obesity, studies like the Healthy Experience ${ }^{154}$ did not differentiate between the intervention and control group and therefore could not be considered for this review.

Overall, an increase in the availability of healthy and low-calorie foods, eliminating the offer of SSBs, coupled with effective labeling and reduced prices, could potentially facilitate healthier food choices, which could contribute to lower BMIs in school children. ${ }^{155}$

\subsection{Comparison with other reviews}

Prior reviews of a more varied range of school interventions identified effects of similar magnitude for total fruit and vegetable consumption. ${ }^{156,157}$ However, previous reviews ${ }^{156,158,159}$ did not specifically evaluate potential effects of food choice architecture, within and around school food environment interventions on dietary intake and obesity, and have grouped together highly varied programs potentially leading to biased inferences. Our findings extend these results by specifically evaluating school food environment policies and quantifying their effects on dietary intakes, as well as separately evaluating direct provision and environmental interventions.

\section{2 | Strengths and limitations}

Our systematic literature review and meta-analysis addresses interventions related to the built environment, food choice architecture, and direct food provision within and around schools, which makes it a unique study. The review accounts for school food environment interventions in 27 countries, involving middle-income countries that present some of the highest rates of obesity. However, there are various methodological limitations that need to be considered when interpreting the results of this meta-analysis and meta-regression analyses.

First, despite defining strictly our outcome of interest, there was heterogeneity across studies in terms of study design, gender and ethnicity of population, type of intervention, and measure of the health outcome. The robustness of pooled analyses was greatly limited by the heterogeneity of food environment exposures and diet-related health outcomes measured across the studies. Although the majority of studies measured BMI, it was variably reported using the original units $\left(\mathrm{kg} / \mathrm{m}^{2}\right)$ or normalized as a $z$ score (with an inconsistent use of World Health Organization [WHO] Growth Standards), and some studies reported end-line averages, whereas others compared groups with respect to interval changes. In relation to fruit and vegetable intake measures, the revised studies used a wide range of data collection methods, from a single-question food frequency estimate, to multiple-item food frequency questionnaires, 24-h recalls, several days of intake, and food diaries. Given this heterogeneity, study findings are not perfectly comparable, and this must be taken into consideration in interpreting the results of any meta-analysis.

Food environment interventions around schools are complicated and require policy support, which is why it was accounted by few studies (4\%). ${ }^{104,143,149,160}$ The food environment around schools could influence children's food choice and affect the effectiveness and sustainability of interventions within schools. Similarly, physical activity was only accounted for in $37 \%$ of studies and socioeconomic gradient was not accounted in the models or the population for $50 \%$ of studies, which could also affect the effectiveness and bias the potential effect of the interventions on health outcomes. Additionally, food provision and educational systems and schools vary within and across nations, which could contribute to unmeasured heterogeneity. Intensity or success of intervention implementation could modify results, but these are difficult to quantify due to varying systems of food provision services (e.g., differences in how schools prepare, offer, sell, serve, or purchase food) and policy nutritional guidelines. Costs and cost-effectiveness of interventions were generally not reported. Study and method designs were judged to have a high risk of bias for $n=43(81 \%)$ of non-randomized controlled studies and $n=41$ (95\%) of RCTs presented a high risk of contamination, which could affect recommendations of effective interventions.

None of the studies disaggregated outcome data based on the discrete dietary and/or environmental components, providing a 
limited ability to analyze and understand the food environmentspecific effect on health outcomes in school-aged children. Effect of the intervention, particularly on food provision, was highly dependent on the duration of the intervention. Behavior change and effects on $\mathrm{BMI}$ and diet-related health outcomes may be dependent on economic viability and sustainability of the effective school food environment interventions (e.g., fruit and vegetable provision).

Furthermore, few studies disaggregated outcome data by age group and gender, which is relevant due to the unique transition from childhood to adolescence, marked by specific physiological changes and increased behavioral autonomy and food choice. ${ }^{161}$

Lastly, future interventions should focus on effective components of the school food environment that may be amenable to modification, tested in the context of RCTs that are powered to examine effects on health outcomes of public health relevance such as dietary intake, obesity, and the prevention of non-communicable diseases.

\section{5 | CONCLUSIONS}

Schools offer many opportunities for developing obesity prevention strategies. Environmental changes that increase the availability of vegetables for children from an early age, the provision of healthy meals with high palatability and attractive presentation, the regulation or banning of vending machines and SSBs, and monitored program type of interventions that include the collaboration, training, education, and integration of key stake holders such as chefs, the school staff, parents, and students to increase acceptability, adaptability, and sustainability according to the local needs could contribute to the improvement of dietary intake, which could influence the reduction of childhood obesity. Limited evidence shows that schools can provide more healthful food options without economical loss by limiting nonhealthy foods and improving the salience, taste, attractiveness, and availability of healthy foods. ${ }^{162}$

Achieving a healthier school environment is a long-term project involving multiple strategies of education and incentives, as well as regulation. Long-lasting reforms require involvement from government through enforcement and continuous supervision of the implementation of regulations. Obesogenic food environments around schools remain a key barrier for successful school food environment interventions and the prevention of childhood obesity. The evidence reviewed supports the conclusion that changes in the school food environment can improve children's dietary behavior and $\mathrm{BMI}$, but policy actions are needed to improve surrounding school food environments to sustain healthy dietary intake. Once the food environment is improved, it is easier to modify individual dietary behavior, a crucial step for the prevention of childhood obesity.

\section{ACKNOWLEDGMENTS}

This review was funded by the European Commission (H2020 SC2) through the Science \& Technology in childhood Obesity Policy (STOP) project. The funder had no role in the design, analysis, or interpretation of the present study, or in the drafting of this manuscript or the decision to publish.

\section{AUTHOR CONTRIBUTIONS}

Dr Elisa Pineda conceived and designed the work that led to the submission, acquired data, and played an important role in interpreting the results. She also drafted the manuscript and had full access to the data in the study and final responsibility of the decision to submit for publication.

Josefina Bascunan-Arellano was the second reviewer and contributed to the data extraction of the literature review.

Professor Franco Sassi revised the manuscript, approved the final version, and agreed to be accountable for all aspects of the work in ensuring that questions related to the accuracy or integrity of any part of the work are appropriately investigated and resolved.

\section{CONFLICT OF INTERESTS}

The authors have no conflict of interests to report.

\section{ORCID}

Elisa Pineda (D) https://orcid.org/0000-0002-5210-1538

Josefina Bascunan (D) https://orcid.org/0000-0003-0833-3523

Franco Sassi (D) https://orcid.org/0000-0001-9773-2117

\section{REFERENCES}

1. Osei-Assibey G. The influence of the food environment on overweight and obesity in young children: a systematic review. https:// doi.org/10.1136/bmjopen-2012-001538

2. Penney TL, Almiron-Roig E, Shearer C, Mclsaac J, Kirk SFL. Modifying the food environment for childhood obesity prevention: challenges and opportunities

3. Raychaudhuri M, Sanyal D. Childhood obesity: determinants, evaluation, and prevention. Indian J Endocrinol Metab. 2012;16(Suppl 2): S192-S194. https://doi.org/10.4103/2230-8210.104037

4. Nestle M. School meals: a starting point for countering childhood obesity. JAMA Pediatr. June 2013;167(6):584-585. https://doi.org/ 10.1001/jamapediatrics.2013.404

5. Gubbels JS. Environmental influences on dietary intake of children and adolescents. Nutrients. 2020;12(4):922. https://doi.org/10. 3390/nu12040922

6. Brug J, Kremers SP, Lenthe F, Ball K, Crawford D. Environmental determinants of healthy eating: in need of theory and evidence. Proc Nutr Soc. Aug 2008;67(3):307-316. https://doi.org/10.1017/ s0029665108008616

7. Glanz K, Sallis JF, Saelens BE, Frank LD. Healthy nutrition environments: concepts and measures. Am J Health Promot. 2005/05/01. 2005;19(5):330-333. https://doi.org/10.4278/0890-1171-19.5.330

8. Welker E, Lott M, Story M. The school food environment and obesity prevention: progress over the last decade. Curr Obes Rep. 2016/06/01. 2016;5(2):145-155. https://doi.org/10.1007/s13679016-0204-0

9. Williams J, Scarborough P, Matthews A, et al. A systematic review of the influence of the retail food environment around schools on obesity-related outcomes

10. Patterson R, Risby A, Chan M-Y. Consumption of takeaway and fast food in a deprived inner London Borough: are they associated with childhood obesity? BMJ Open. 2012;2(3):e000402. https://doi.org/ 10.1136/bmjopen-2011-000402 
11. Park S, Sappenfield WM, Huang Y, Sherry B, Bensyl DM. The impact of the availability of school vending machines on eating behavior during lunch: the Youth Physical Activity and Nutrition Survey. J am Diet Assoc. Oct 2010;110(10):1532-1536. https://doi.org/10.1016/ j.jada.2010.07.003

12. Micha R, Bakogianni I, Karageorgou D, et al. Effectiveness of school procurement policies for improving dietary behaviors: a systematic review and meta-analysis. Circulation. 2016;133(SUPPL. 1):AMP89.

13. Micha R, Karageorgou D, Bakogianni I, et al. Effectiveness of school food environment policies on children's dietary behaviors: a systematic review and meta-analysis. PLoS ONE [Electronic Resource]. 2018; 13(3):e0194555. https://doi.org/10.1371/journal.pone.0194555

14. Nathan N, Janssen L, Sutherland R, et al. The effectiveness of lunchbox interventions on improving the foods and beverages packed and consumed by children at centre-based care or school: a systematic review and meta-analysis. Int J Behav Nutr Phys Act. 2019/04/29. 2019;16(1):38. https://doi.org/10.1186/s12966-0190798-1

15. Bourdeaudhuij Id, Cauwenberghe Ev, Spittaels H, et al. School-based interventions promoting both physical activity and healthy eating in Europe: a systematic review within the HOPE project

16. Micha R, Karageorgou D, Bakogianni I, et al. Effectiveness of school food environment policies on children's dietary behaviors: a systematic review and meta-analysis. PloS One. 2018;13(3):e0194555. https://doi.org/10.1371/journal.pone.0194555

17. Ensaff H, Homer M, Sahota P, Braybrook D, Coan S, McLeod H. Food choice architecture: an intervention in a secondary school and its impact on students' plant-based food choices. Nutrients. 06/01. 2015;7:4426-4437. https://doi.org/10.3390/nu7064426

18. WHO. Definition of key terms. Age groups and populations website. https://www.who.int/hiv/pub/guidelines/arv2013/intro/keyterms/ en/. Published 2013. Accessed July, 2020.

19. Romieu I, Dossus L, Barquera S, et al. Energy balance and obesity: what are the main drivers? Cancer Causes Control. 2017;28(3): 247-258. https://doi.org/10.1007/s10552-017-0869-z

20. Borenstein M, Hedges LV, Higgins JPT, Rothstein HR. Introduction to Meta-Analysis. Chichester, UK: Wiley; 2009.

21. Affenito SG, Thompson D, Dorazio A, Albertson AM, Loew A, Holschuh NM. Ready-to-eat cereal consumption and the school breakfast program: relationship to nutrient intake and weight. J Sch Health. January 2013;83(1):28-35. http://ovidsp.ovid.com/ovidweb.

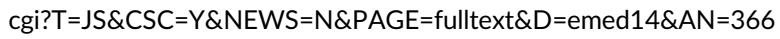
286431 http://imp-primo.hosted.exlibrisgroup.com/openurl/44IMP $/ I C L \_V U 1$ ?sid=OVID\&isbn=\&issn $=0022-4391 \&$ volume $=83$ \&issue $=1$ \&date $=2013 \&$ title $=$ Journal + of + School + Health\&atitle $=$ Ready-to-Eat + Cereal+Consumption+and+the + School+Breakfast+Program\%3A+R elationship+to+Nutrient+Intake+and+Weight\&aulast=Affenito+S.G. \&spage $=28$

22. Amini $M$, Dadkhah-Piraghaj $M$, Abtahi $M$, Abdollahi $M$, Houshiarrad A, Kimiagar M. Nutritional assessment for primary school children in Tehran: an evaluation of dietary pattern with emphasis on snacks and meals consumption. Int J Prev Med. May 2014;5(5):611-616. http://ovidsp.ovid.com/ovidweb.cgi?T=JS\& $C S C=Y \& N E W S=N \& P A G E=$ fulltext $\& D=$ emed $15 \& A N=373211018 \mathrm{ht}$ tp://imp-primo.hosted.exlibrisgroup.com/openurl/44IMP/ICL_VU1? sid $=$ OVID\&isbn $=\& i s s n=2008-7802 \&$ volume $=5$ \&issue $=5 \&$ date $=201$ $4 \&$ title=International+Journal+of+Preventive+Medicine\&atitle $=$ Nutr itional+assessment+for+primary+school+children+in+Tehran\%3A+A n+evaluation+of+dietary+pattern+with+emphasis+on+snacks+and+ meals+consumption\&aulast $=$ Amini $+M$.\&spage $=611$

23. Anderson AS, Porteous LE, Foster E, et al. The impact of a schoolbased nutrition education intervention on dietary intake and cognitive and attitudinal variables relating to fruits and vegetables. Public Health Nutr. Sep 2005;8(6):650-656. https://doi.org/10.1079/ phn2004721
24. Anderson AS. Obesity prevention and management-evidence and policy. J Hum Nutr Diet. February 2005;18(1):1-2. http://ovidsp.ovid. com/ovidweb.cgi?T=JS\&CSC=Y\&NEWS=N\&PAGE=fulltext\&D=eme d9\&AN=40220497 http://imp-primo.hosted.exlibrisgroup.com/ope nurl/44IMP/ICL_VU1?sid=OVID\&isbn=\&issn=0952-3871\&volume= 18\&issue $=1 \&$ date $=2005 \&$ title $=$ Journal + of + Human + Nutrition + and + Dietetics\&atitle=Obesity+prevention+and+management+-+Evidenc e+and+policy\&aulast=Anderson+A.S.\&spage $=1$

25. Arija V, Lopez-Toledo S, Ballonga C, Canals J. Breakfast food consumption in peruvian schoolchildren: a comparison between rural and urban areas. Ann Nutr Metab. 2017;71:245-246. http://ovidsp. ovid.com/ovidweb.cgi?T $=J S \& C S C=Y \& N E W S=N \& P A G E=$ fulltext\&D $=$ emed18\&AN=619277837 http://imp-primo.hosted.exlibrisgroup. com/openurl/44IMP/ICL_VU1?sid=OVID\&isbn=\&issn=1421-9697\& volume $=71$ \&issue $=$ Supplement $+2 \&$ date $=2017 \&$ title $=$ Annals + of $+\mathrm{Nu}$ trition+and+Metabolism\&atitle $=$ Breakfast + food + consumption $+i n+p$ eruvian+schoolchildren\%3A+A+comparison+between+rural+and+ur ban+areas\&aulast $=$ Arija $+\mathrm{V} . \&$ spage $=245$

26. Arsenault JE, Mora-Plazas M, Forero Y, et al. Provision of a school snack improves vitamin B12 and iron status of school children in Bogota, Colombia. FASEB J Conf: Exp Biol. 2009;2009:23. http:// ovidsp.ovid.com/ovidweb.cgi?T=JS\&CSC=Y\&NEWS=N\&PAGE=fullt ext\&D=emed11\&AN=70054441 http://imp-primo.hosted.exlibrisgr oup.com/openurl/44IMP/ICL_VU1?sid=OVID\&isbn=\&issn=0892-66 $38 \&$ volume $=23 \&$ issue $=S 1 \&$ date $=2009 \&$ title $=$ The $+F A S E B+$ Journal $\&$ atitle=Provision+of+a+school+snack+improves+vitamin $+B 12+a n d+i$ ron+status+of+school+children+in+Bogota $\% 2 C+$ Colombia\&aulast= Arsenault+J.E.\&spage=

27. Asada Y, Chriqui J, Chavez N, Odoms-Young A, Handler A. USDA snack policy implementation: best practices from the front lines, United States, 2013-2014. Prev Chronic Dis. 16 Jun 2016;13:E79. http://ovidsp.ovid.com/ovidweb.cgi?T=JS\&CSC=Y\&NEWS=N\&PAG $\mathrm{E}=$ fulltext\&D=emed17\&AN=618621427 http://imp-primo.hosted.e xlibrisgroup.com/openurl/44IMP/ICL_VU1?sid=OVID\&isbn=\&issn= $1545-1151 \&$ volume $=13 \&$ issue $=\&$ date $=2016 \&$ title $=$ Preventing + chro nic+disease\&atitle=USDA+Snack+Policy+Implementation\%3A+Best + Practices+From+the+Front+Lines\%2C+United+States\%2C+20132014\&aulast $=$ Asada + Y.\&spage $=E 79$

28. Asada Y, Ziemann M, Zatz L, Chriqui J. Successes and challenges in school meal reform: qualitative insights from food service directors. J Sch Health. 01 Aug 2017;87(8):608-615. http://ovidsp.ovid.com/

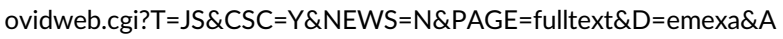
$\mathrm{N}=621698115 \mathrm{http}: / /$ imp-primo.hosted.exlibrisgroup.com/openurl/ 44IMP/ICL_VU1?sid=OVID\&isbn=\&issn=1746-1561\&volume=87\&i ssue $=8 \&$ date $=2017 \&$ title $=$ The + Journal + of + school + health\&atitle $=S u$ ccesses+and+Challenges+in+School+Meal+Reform\%3A+Qualitative + Insights + From+Food+Service+Directors\&aulast $=$ Asada $+Y$.\&spag $\mathrm{e}=608$

29. Ashfield-Watt PA, Stewart EA, Scheffer JA. A pilot study of the effect of providing daily free fruit to primary-school children in Auckland, New Zealand. Public Health Nutr. May 2009;12(5):693701. https://doi.org/10.1017/s1368980008002954

30. Ask AS, Hernes S, Aarek I, Vik F, Brodahl C, Haugen M. Serving of free school lunch to secondary-school pupils-a pilot study with health implications. Public Health Nutr. Feb 2010;13(2):238-244. http://ovidsp.ovid.com/ovidweb.cgi?T=JS\&CSC $=Y \& N E W S=N \& P A G$

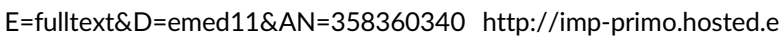
xlibrisgroup.com/openurl/44IMP/ICL_VU1?sid=OVID\&isbn=\&issn= 1475-2727\&volume=13\&issue $=2 \&$ date $=2010 \&$ title $=$ Public + health + nutrition\&atitle=Serving+of+free+school+lunch+to+secondary-scho ol+pupils+-+a+pilot+study+with+health+implications\&aulast=Ask+A .S.\&spage $=238$

31. Bartlett SOL, Klerman JLPK, Blocklin M, Connor P, et al. Evaluation of the Fresh Fruit and Vegetable Program (FFVP): Final Evaluation Report. Alexandria, VA: USDA Food and Nutrition Service; 2013. 
32. Bere E, Veierød MB, Bjelland M, Klepp Kl. Outcome and process evaluation of a Norwegian school-randomized fruit and vegetable intervention: Fruits and Vegetables Make the Marks (FVMM). Health Educ Res. Apr 2006;21(2):258-267. https://doi.org/10.1093/her/ cyh062

33. Bere $E$, Veierød MB, Bjelland M, Klepp KI. Free school fruitsustained effect 1 year later. Health Educ Res. Apr 2006;21(2): 268-275. https://doi.org/10.1093/her/cyh063

34. Bere E, Hilsen M, Klepp K-I. Effect of the nationwide free school fruit scheme in Norway. Br J Nutr. 2010;104:589-594. https://doi. org/10.1017/S0007114510000814

35. Bere E, te Velde SJ, Småstuen MC, Twisk J, Klepp K-I. One year of free school fruit in Norway-7 years of follow-up. Int J Behav Nutr Phys Act. 2015;12(1):139. https://doi.org/10.1186/s12966-0150301-6

36. Bhave S, Pandit A, Yeravdekar R, et al. Effectiveness of a 5-year school-based intervention programme to reduce adiposity and improve fitness and lifestyle in Indian children; the SYM-KEM study. Arch Dis Child. January 2016;101(1):33-41. http://ovidsp.ovid.com/ ovidweb.cgi?T=JS\&CSC=Y\&NEWS=N\&PAGE=fulltext\&D=emed17\& $\mathrm{AN}=607441678 \mathrm{http}: / / \mathrm{imp}$-primo.hosted.exlibrisgroup.com/open url/44IMP/ICL_VU1?sid=OVID\&isbn=\&issn=0003-9888\&volume=1 $01 \&$ issue $=1 \&$ date $=2016 \&$ title $=$ Archives + of + Disease + in + Childhood \&atitle=Effectiveness+of+a+5-year+school-based+intervention+pro gramme+to+reduce+adiposity+and+improve+fitness+and+lifestyle+i $\mathrm{n}+$ Indian+children\%3B+the+SYM-KEM+study\&aulast=Bhave+S.\&sp age $=33$

37. Brauchla M, McCabe GP, Miller KB, Kranz S. The effect of high fiber snacks on digestive function and diet quality in a sample of schoolage children. Nutr J. 2013;12(1). https://doi.org/10.1186/14752891-12-153

38. Brunello G, Labartino G. Regional differences in overweight rates: the case of Italian regions. Econ Hum Biol. 2014;12:20-29. http://ovidsp. ovid.com/ovidweb.cgi?T=JS\&CSC=Y\&NEWS=N\&PAGE=fulltext\&D= med10\&AN=23168254 http://imp-primo.hosted.exlibrisgroup.com/ openurl/44IMP/ICL VU1?sid=OVID\&isbn=\&issn=1570-677X\& volume $=12 \&$ issue $=\&$ date $=2014 \&$ title $=$ Economics $+\% 26+$ Human +Biology\&atitle=Regional+differences+in+overweight+rates\%3A+the + case+of+Italian+regions.\&aulast $=$ Brunello+G\&spage $=20$

39. Cadzow RB, Chambers MK, Sandell AM. School-based obesity intervention associated with three year decrease in student weight status in a low-income school district. J Community Health. 01 Aug 2015; 40(4):709-713. http://ovidsp.ovid.com/ovidweb.cgi? T=JS\&CSC $=Y \&$ NEWS $=N \& P A G E=$ fulltext\&D $=$ emed16\&AN $=613041366$ http:// imp-primo.hosted.exlibrisgroup.com/openurl/44IMP/ICL_VU1?sid= OVID\&isbn $=$ \&issn $=1573-3610 \&$ volume $=40$ \&issue $=4 \&$ date $=2015 \&$ title=Journal+of+community+health\&atitle=School-Based+Obesity +Intervention+Associated+with+Three+Year+Decrease+in+Student + Weight+Status+in+a+Low-Income+School+District\&aulast= Cadzow+R.B.\&spage $=709$

40. Malcata M, Santo E, Pinto A, Nunes M. An intervention on eating habits of children of a group of schools in Portalegre. Aten Primaria. 2014;48:896-901. http://ovidsp.ovid.com/ovidweb.cgi?T=JS\&CSC= $Y \& N E W S=N \& P A G E=$ fulltext $\& D=$ emexa\&AN $=621220595 \mathrm{http}: / /$ imp-primo.hosted.exlibrisgroup.com/openurl/44IMP/ICL_VU1?sid= OVID\&isbn=\&issn=1578-1275\&volume $=48 \&$ issue $=$ Supplement $+C \&$ date $=2016 \&$ title $=$ Atencion+Primaria\&atitle $=A n+$ intervention+on +eating+habits+of+children+of+a+group+of+schools+in + portalegre\&aulast $=$ Malcata + M.\&spage $=68$

41. Canterberry M, Francois S, van Hattum T, Rudov L, Carton TW. School lunch consumption among 3 food service providers in New Orleans. J Sch Health. 2018;88(2):93-100. http://ovidsp.ovid.com/ ovidweb.cgi?T=JS\&CSC=Y\&NEWS=N\&PAGE=fulltext\&D=prem2\& $\mathrm{AN}=29333644 \mathrm{http} / / /$ imp-primo.hosted.exlibrisgroup.com/openurl/ $44 I \mathrm{MP} / \mathrm{ICL}$ VUU1?sid=OVID\&isbn=\&issn=0022-4391\&volume=88\& issue $=2 \&$ date $=2018 \&$ title $=$ Journal + of + School + Health\&atitle $=$ School+Lunch+Consumption+Among $+3+$ Food+Service+Providers + in + New + Orleans. \&aulast $=$ Canterberry $+M \&$ spage $=93$

42. Cao Z-J, Wang S-M, Chen Y. A randomized trial of multiple interventions for childhood obesity in China. Am J Prev Med. 2015;48(5): 552-560. http://doi.org/10.1016/j.amepre.2014.12.014

43. Capogrossi K, You W. The influence of school nutrition programs on the weight of low-income children: a treatment effect analysis. Health Econ. Aug 2017;26(8):980-1000. https://doi.org/10.1002/ hec.3378

44. Carlin E, Savonitto C, Pilotto L, Savoia A, Vidal E, Tenore A. The "contract for a healthy snack": a winning strategy for nutritional education in an Italian primary school district. Ital J Pediatr. August 2006;32(4):221-228. http://ovidsp.ovid.com/ovidweb.cgi?T=JS\& $C S C=Y \& N E W S=N \& P A G E=$ fulltext $\& D=$ emed $9 A N=46155838$ http://imp-primo.hosted.exlibrisgroup.com/openurl/44IMP/ICL VU1? sid $=$ OVID\&isbn $=$ \&issn $=1720-8424 \&$ volume $=32$ \&issue $=4 \&$ date $=2006 \&$ title $=$ Italian+Journal+of + Pediatrics\&atitle $=$ The $+\%$ 22 contract+for+a+healthy+snack\%22\%3A+A+winning+strategy+for +nutritional+education+in+an+Italian+primary+school+district\& aulast $=$ Carlin + E.\&spage $=221$

45. Chellappah J, Tonkin A, Gregg MED, Reid C. A pilot study of effects of fruit intake on cardiovascular risk factors in children

46. Clark MA, Fox MK. Nutritional quality of the diets of us public school children and the role of the school meal programs. (Special Issue: The school food environment, children's diets, and obesity findings from the third School Nutrition Dietary Assessment Study (Robert Wood Johnson Foundation).).

47. Cluss P, Fee L, Culyba R, Bhat K, Owen K. Effect of food service nutrition improvements on elementary school cafeteria lunch purchase patterns. J Sch Health. 2014;84:355-362. https://doi.org/10. 1111/josh.12157

48. Cohen JFW, Richardson SA, Cluggish SA, Parker E, Catalano PJ, Rimm EB. Effects of choice architecture and chef-enhanced meals on the selection and consumption of healthier school foods: a randomized clinical trial. JAMA Pediatr. 2015;169(5):431-437. https:// doi.org/10.1001/jamapediatrics.2014.3805

49. Coleman KJ, Shordon M, Caparosa SL, Pomichowski ME, Dzewaltowski DA. The healthy options for nutrition environments in schools (Healthy ONES) group randomized trial: using implementation models to change nutrition policy and environments in low income schools. Int J Behav Nutr Phys Act. 2012;9:80. http://ovidsp. ovid.com/ovidweb.cgi?T=JS\&CSC $=Y \& N E W S=N \& P A G E=$ fulltext $\&$ $\mathrm{D}=$ med8\&AN=22734945 http://imp-primo.hosted.exlibrisgroup. com/openurl/44IMP/ICL_VU1?sid=OVID\&isbn=\&issn=1479-5868\& volume $=9$ \&issue $=\&$ date $=2012 \&$ title $=$ International + Journal + of +Behavioral+Nutrition+\%26+Physical+Activity\&atitle=The+healthy +options+for+nutrition+environments+in+schools+\%28Healthy +ONES\%29+group+randomized+trial\%3A+using+implementation +models+to+change+nutrition+policy+and+environments+in+low + income + schools. \&aulast $=$ Coleman $+K J$ \&spage $=80$

50. Coyle K, Potter S, Schneider D, et al. Distributing free fresh fruit and vegetables at school: results of a pilot outcome evaluation. Public Health Rep (Washington, DC: 1974). 2009;124:660-669. https://doi. org/10.1177/003335490912400508

51. Crepinsek MK, Gordon AR, McKinney PM, Condon EM, Wilson A. Meals offered and served in US public schools: do they meet nutrient standards? (Special Issue: The school food environment, children's diets, and obesity - findings from the third School Nutrition Dietary Assessment Study (Robert Wood Johnson Foundation).).

52. Cullen KW, Hartstein J, Reynolds KD, et al. Improving the school food environment: results from a pilot study in middle schools

53. Cunningham-Sabo L, Snyder MP, Anliker J, et al. Prev med. December 2003;37(SUPPL. 1):S46-S54. http://ovidsp.ovid.com/ovidweb. cgi? $T=J S \& C S C=Y \& N E W S=N \& P A G E=$ fulltext $\& D=$ emed $8 \& A N=$ 
$37433901 \mathrm{http} / /$ imp-primo.hosted.exlibrisgroup.com/openurl/44 $\mathrm{MP} / I C L \_V U 1$ ?sid $=$ OVID\&isbn=\&issn=0091-7435\&volume $=37$ \&issu e=SUPPL.+1\&date=2003\&title=Preventive+Medicine\&atitle=Impact +of+the+pathways+food+service+intervention+on+breakfast+serve $\mathrm{d}+$ +in+American-Indian+schools\&aulast=Cunningham-Sabo+L.\&spag $\mathrm{e}=\mathrm{S} 46$

54. Damsgaard CT, Dalskov SM, Petersen RA, et al. Design of the OPUS School Meal Study: a randomised controlled trial assessing the impact of serving school meals based on the new Nordic diet. Scand J Public Health. Dec 2012;40(8):693-703. http://ovidsp.ovid.com/ ovidweb.cgi?T $=J S \& C S C=Y \& N E W S=N \& P A G E=$ fulltext\&D=emed13\& $\mathrm{AN}=366380657 \mathrm{http}: / / \mathrm{imp}$-primo.hosted.exlibrisgroup.com/openur /44IMP/ICL_VU1?sid=OVID\&isbn=\&issn=1651-1905\&volume $=40 \&$ issue $=8 \&$ date $=2012 \&$ title $=$ Scandinavian + journal + of + public + health $\&$ atitle=Design+of+the+OPUS+School+Meal+Study\%3A+a+randomis ed+controlled+trial+assessing+the+impact+of+serving+school+meal s+based+on+the+New+Nordic+Diet\&aulast=Damsgaard+C.T.\&spag $\mathrm{e}=693$

55. Datar A, Nicosia N. The effect of state competitive food and beverage regulations on childhood overweight and obesity. J Adolesc Health. 2017;60(5):520-527. http://ovidsp.ovid.com/ovidweb.cgi? $\mathrm{T}=\mathrm{JS} \& C S C=\mathrm{Y} \& N E W S=\mathrm{N} \& P A G E=$ fulltext $\& D=$ med $13 \& A N=2783$ 6530

56. Day ME, Strange KS, McKay HA, Naylor P-J. Action schools! BChealthy eating: effects of a whole-school model to modifying eating behaviours of elementary school children. Can J Public Health. 2008; 99(4):328-331. www.jstor.org/stable/41995114. Accessed 2020/ 08/12/

57. Baxter SD, Hardin JW, Guinn $\mathrm{CH}$, Royer JA, Mackelprang AJ, Devlin CM. Children's body mass index, participation in school meals, and observed energy intake at school meals. Int J Behav Nutr Phys Act. 2010;7(24). http://ovidsp.ovid.com/ovidweb.cgi?T=JS\& $C S C=Y \& N E W S=N \& P A G E=$ fulltext $\& D=$ prem $1 \& A N=20334667 \mathrm{http}:$ //imp-primo.hosted.exlibrisgroup.com/openurl/44IMP/ICL_VU1?sid $=$ OVID\&isbn $=$ \&issn $=1479-5868 \&$ volume $=7 \&$ issue $=\&$ date $=2010 \&$ tit le $=$ International+Journal+of+Behavioral+Nutrition+\%26+Physical+A ctivity\&atitle $=$ Children $\% 27 \mathrm{~s}+$ body + mass + index $\% 2 \mathrm{C}+$ participation $+\mathrm{i}$ $\mathrm{n}+$ school+meals\%2C+and+observed+energy+intake+at+school+mea Is. \&aulast $=$ Baxter + SD\&spage $=24$

58. Baxter SD, Paxton-Aiken AE, Tebbs JM, Royer JA, Guinn $\mathrm{CH}$, Finney CJ. Secondary analyses of data from 4 studies with fourthgrade children show that sex, race, amounts eaten of standardized portions, and energy content given in trades explain the positive relationship between body mass index and energy intake at schoolprovided meals. Nutr Res. 2012;32(9):659-668. http://ovidsp.ovid. com/ovidweb.cgi?T=JS\&CSC=Y\&NEWS=N\&PAGE=fulltext \&D=med 8\&AN=23084638 http://imp-primo.hosted.exlibrisgroup.com/open url/44IMP/ICL_VU1?sid=OVID\&isbn=\&issn=0271-5317\&volume=3 2\&issue $=9$ \&date $=2012 \&$ title $=$ Nutrition + Research\&atitle $=$ Secondary +analyses+of+data+from+4+studies+with+fourth-grade+children+s how+that+sex\%2C+race\%2C+amounts+eaten+of+standardized+por tions\%2C+and+energy+content+given+in+trades+explain+the+posit ive+relationship+between+body+mass+index+and+energy+intake+a $t+$ school-provided+meals.\&aulast $=$ Baxter $+S D \&$ spage $=659$

59. Eagle TF, Gurm R, Smith CA, et al. A middle school intervention to improve health behaviors and reduce cardiac risk factors. Am J med. Oct 2013;126(10):903-908. https://doi.org/10.1016/j.amjmed. 2013.04.019

60. Eriksen K, Haraldsdóttir J, Pederson R, Flyger HV. Effect of a fruit and vegetable subscription in Danish schools. Public Health Nutr. Feb 2003;6(1):57-63. https://doi.org/10.1079/phn2002356

61. Ermetici F, Zelaschi RF, Briganti S, et al. Association between a school-based intervention and adiposity outcomes in adolescents: the Italian "eAT" project. Obesity. 01 Mar 2016;24(3):687-695. http://ovidsp.ovid.com/ovidweb.cgi?T=JS\&CSC $=$ Y\&NEWS=N\&PAG
$\mathrm{E}=$ fulltext $\& D=$ emed17\&AN=608751121 http://imp-primo.hosted. exlibrisgroup.com/openurl/44IMP/ICL_VU1?sid=OVID\&isbn=\&issn $=1930-7381 \&$ volume $=24 \&$ issue $=3 \&$ date $=2016 \&$ title=Obesity \&atitl e=Association+between+a+school-based+intervention+and+adiposi ty+outcomes+in+adolescents\%3A+The+Italian+\%22eAT\%22+projec t\&aulast $=$ Ermetici+F.\&spage $=687$

62. Fitzpatrick C, Datta GD, Henderson M, Gray-Donald K, Kestens $\mathrm{Y}$, Barnett TA. School food environments associated with adiposity in Canadian children. Int J Obes (Lond). 01 Jul 2017;41(7):1005-1010. http://ovidsp.ovid.com/ovidweb.cgi?T=JS\&CSC=Y\&NEWS=N\&PAG $E=$ fulltext\&D=emexa\&AN=614799546 http://imp-primo.hosted.exli brisgroup.com/openurl/44IMP/ICL_VU1?sid=OVID\&isbn=\&issn=03 07-0565\&volume $=41 \&$ issue $=7 \&$ date $=2017 \&$ title $=$ International $+\mathrm{Jou}$ rnal+of+Obesity\&atitle $=$ School+food+environments+associated+wit $\mathrm{h}+$ adiposity+in+Canadian+children\&aulast=Fitzpatrick+C.\&spage= 1005

63. Fogarty A, Antoniak M, Venn A, et al. Does participation in a population-based dietary intervention scheme have a lasting impact on fruit intake in young children? Int J Epidemiol. 2007;36(5):10801085. https://doi.org/10.1093/ije/dym133

64. Foster GD, Sherman S, Borradaile KE, et al. A policy-based school intervention to prevent overweight and obesity. Pediatrics. April 2008;121(4):e794-e802. http://ovidsp.ovid.com/ovidweb.cgi?T=JS $\& C S C=Y \& N E W S=N \& P A G E=$ fulltext\&D=emed10\&AN $=354416786$ http://imp-primo.hosted.exlibrisgroup.com/openurl/44IMP/ICL_VU 1 ?sid=OVID\&isbn=\&issn=0031-4005\&volume $=121$ \&issue $=4 \&$ date $=$ 2008\&title=Pediatrics\&atitle=A+policy-based+school+intervention+ to+prevent+overweight+and+obesity\&aulast=Foster+G.D.\&spage= e794

65. Fu YCA, To KC, Tao WY, et al. School accreditation scheme reduces childhood obesity in Hong Kong. Glob Health Promot. 2018;26(4): 70-78. http://ovidsp.ovid.com/ovidweb.cgi?T=JS\&CSC=Y\&NEWS= N\&PAGE=fulltext\&D=medp\&AN=29809101 http://imp-primo.host ed.exlibrisgroup.com/openurl/44IMP/ICL_VU1?sid=OVID\&isbn=\&is sn $=1757-9759 \&$ volume $=$ \&issue $=\&$ date $=2018 \&$ title $=$ Global + Health + Promotion\&atitle $=$ School + accreditation + scheme+reduces + childhoo $d+$ obesity+in+Hong+Kong.\&aulast $=F u+Y C A \&$ spage $=17579759187$ 64318

66. Fung C, Mclsaac JL, Kuhle S, Kirk SF, Veugelers PJ. The impact of a population-level school food and nutrition policy on dietary intake and body weights of Canadian children. Prev med. Dec 2013;57(6): 934-940. https://doi.org/10.1016/j.ypmed.2013.07.016

67. Gabriel CG, Vasconcelos Fde A, Andrade DF, Schmitz Bde A. First law regulating school canteens in Brazil: evaluation after seven years of implementation. Arch Latinoam Nutr. 2009;59(2):128-138. http:// ovidsp.ovid.com/ovidweb.cgi?T=JS\&CSC=Y\&NEWS=N\&PAGE=fullt ext\&D=med6\&AN=19719008 http://imp-primo.hosted.exlibrisgrou p.com/openurl/44IMP/ICL_VU1?sid=OVID\&isbn=\&issn=0004-062 $2 \&$ volume $=59 \&$ issue $=2 \&$ date $=2009 \&$ title $=$ Archivos + Latinoamerican os+de+Nutricion\&atitle $=$ First+law+regulating+school+canteens + in + Brazil\%3A+evaluation+after+seven+years+of+implementation.\&aula st $=$ Gabriel+CG\&spage $=128$

68. Goldberg JP, Collins JJ, Folta SC, et al. Retooling food service for early elementary school students in Somerville, Massachusetts: the Shape Up Somerville experience. Prev Chronic Dis. Jul 2009;6(3): A103. http://ovidsp.ovid.com/ovidweb.cgi?T=JS\&CSC $=Y \& N E W S=$ N\&PAGE=fulltext\&D=emed11\&AN=355241130 http://imp-primo. hosted.exlibrisgroup.com/openurl/44IMP/ICL_VU1?sid=OVID\&isbn $=$ \&issn $=1545-1151 \&$ volume $=6 \&$ issue $=3 \&$ date $=2009 \&$ title $=$ Preventi ng+chronic+disease \&atitle=Retooling+food+service+for+early+elem entary+school+students+in+Somerville\%2C+Massachusetts\%3A+th $\mathrm{e}+$ Shape+Up+Somerville+experience\&aulast $=$ Goldberg+J.P.\&spage $=$ A103

69. Gortmaker SL, Peterson K, Wiecha J, et al. Reducing obesity via a school-based interdisciplinary intervention among youth: Planet 
Health. Arch Pediatr Adolesc med. Apr 1999;153(4):409-418. https:// doi.org/10.1001/archpedi.153.4.409

70. Gortmaker SL, Cheung LW, Peterson KE, et al. Impact of a schoolbased interdisciplinary intervention on diet and physical activity among urban primary school children: eat well and keep moving. Arch Pediatr Adolesc med. Sep 1999;153(9):975-983. https://doi. org/10.1001/archpedi.153.9.975

71. Greece JA, Kratze A, DeJong W, Cozier YC, Quatromoni PA. Body mass index and sociodemographic predictors of school lunch purchase behavior during a year-long environmental intervention in middle school. Behav Sci. 2015;5(2):324-340. http://ovidsp.ovid. com/ovidweb.cgi? $T=J S \& C S C=Y \& N E W S=N \& P A G E=$ fulltext $\& D=$ prem1\&AN=26067683 http://imp-primo.hosted.exlibrisgroup.com/ openurl/44IMP/ICL_VU1?sid=OVID\&isbn=\&issn=2076-328X\& volume $=5 \&$ issue $=2 \&$ date $=2015 \&$ title $=$ Behavioral + sciences\&atitle $=$ Body+Mass+Index+and+Sociodemographic+Predictors+of+School +Lunch+Purchase+Behavior+during+a+Year-Long+Environmental +Intervention+in+Middle+School.\&aulast $=$ Greece+JA\&spage $=324$

72. Guinn $\mathrm{CH}$, Baxter SD, Royer JA, Hitchcock DB. Explaining the positive relationship between fourth-grade children's body mass index and energy intake at school-provided meals (breakfast and lunch). J Sch Health. May 2013;83(5):328-334. http://ovidsp.ovid.com/

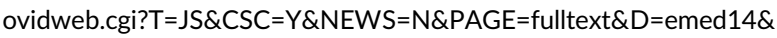
$\mathrm{AN}=368613871 \quad$ http://imp-primo.hosted.exlibrisgroup.com/ openurl/44IMP/ICL_VU1?sid=OVID\&isbn=\&issn=0022-4391\& volume $=83$ \&issue $=5$ \&date $=2013 \&$ title $=$ Journal + of + School + Health $\&$ atitle=Explaining+the+Positive+Relationship+Between+FourthGrade+Children\%27s+Body+Mass+Index+and+Energy+Intake+at +School-Provided+Meals+\%28Breakfast+and+Lunch\%29\&aulast= Guinn+C.H.\&spage $=328$

73. Hanks AS, Just DR, Smith LE, Wansink B. Healthy convenience: nudging students toward healthier choices in the lunchroom. J Pub Health (United Kingdom). August 2012;34(3):370-376. http://ovidsp. ovid.com/ovidweb.cgi?T=JS\&CSC=Y\&NEWS=N\&PAGE=fulltext\& $\mathrm{D}=$ emed13\&AN=365539501 http://imp-primo.hosted.exlibrisgroup. com/openurl/44IMP/ICL_VU1?sid=OVID\&isbn=\&issn=1741-3842\& volume $=34 \&$ issue $=3 \&$ date $=2012 \&$ title $=$ Journal + of + Public + Health + $\% 28$ United+Kingdom\%29\&atitle=Healthy+convenience\%3A +Nudging+students+toward+healthier+choices+in+the+lunchroom\& aulast $=$ Hanks+A.S.\&spage $=370$

74. Hawkins KR, Burton JH, Apolzan JW, Thomson JL, Williamson DA, Martin CK. Efficacy of a school-based obesity prevention intervention at reducing added sugar and sodium in children's school lunches: the LA Health randomized controlled trial. Int J Obes (Lond). 2018;42(11):1845-1852. http://ovidsp.ovid.com/ovidweb.cgi?T= $J S \& C S C=Y \& N E W S=N \& P A G E=$ fulltext $\& D=$ prem $2 \& A N=30254362$ https://www.nature.com/articles/s41366-018-0214-y.pdf

75. Heelan KA, Bartee RT, Nihiser A, Sherry B. Healthier school environment leads to decreases in childhood obesity: the Kearney Nebraska story. Child Obes (Print). 01 Oct 2015;11(5):600-607. http://ovidsp. ovid.com/ovidweb.cgi?T=JS\&CSC=Y\&NEWS=N\&PAGE=fulltext\& $\mathrm{D}=$ emed16\&AN=615851779 http://imp-primo.hosted.exlibrisgroup. com/openurl/44IMP/ICL_VU1?sid=OVID\&isbn=\&issn=2153-2176\& volume $=11 \&$ issue $=5 \&$ date $=2015 \&$ title $=$ Childhood + obesity $+\%$ 28Print\%29\&atitle=Healthier+School+Environment+Leads+to +Decreases+in+Childhood+Obesity\%3A+The+Kearney+Nebraska + Story\&aulast $=$ Heelan+K.A.\&spage $=600$

76. Hennessy E, Oh A, Agurs-Collins T, et al. State-level school competitive food and beverage laws are associated with children's weight status. J Sch Health. 01 Sep 2014;84(9):609-616. http://ovidsp.ovid. com/ovidweb.cgi? $T=J S \& C S C=Y \& N E W S=N \& P A G E=$ fulltext $\& D=$ emed15\&AN=613623590 http://imp-primo.hosted.exlibrisgroup. com/openurl/44IMP/ICL_VU1?sid=OVID\&isbn=\&issn=1746-1561\& volume $=84 \&$ issue $=9 \&$ date $=2014 \&$ title $=$ The + Journal + of + school +health\&atitle=State-level+school+competitive+food+and +beverage+laws+are+associated+with+children\%27s+weight + status\&aulast $=$ Hennessy+E.\&spage $=609$

77. Herscovici CR, Kovalskys I, De Gregorio MJ. Gender differences and a school-based obesity prevention program in Argentina: a randomized trial. Rev Panam Salud Publica. August 2013;34(2):75-82. http:// ovidsp.ovid.com/ovidweb.cgi?T=JS\&CSC=Y\&NEWS=N\&PAGE= fulltext\&D=emed14\&AN=1369975936 http://imp-primo.hosted exlibrisgroup.com/openurl/44IMP/ICL_VU1?sid=OVID\&isbn=\& issn $=1020-4989 \&$ volume $=34 \&$ issue $=2 \&$ date $=2013 \&$ title $=$ Revista +Panamericana+de+Salud+Publica\%2FPan+American+Journal+of + Public + Health\&atitle $=$ Gender + differences + and $+a+$ school-based +obesity+prevention+program+in+Argentina\%3A+A+randomized +trial\&aulast=Herscovici+C.R.\&spage $=75$

78. Himes JH, Ring K, Gittelsohn J, et al. Impact of the Pathways intervention on dietary intakes of American Indian schoolchildren. Prev med. 2003;37(6 Pt 2):S55-S61. http://ovidsp.ovid.com/ovidweb.cgi? $T=J S \& C S C=Y \& N E W S=N \& P A G E=$ fulltext $\& D=$ med $4 \& A N=14636809$ http://imp-primo.hosted.exlibrisgroup.com/openurl/44IMP/ICL VU1? sid $=$ OVID\&isbn $=$ \&issn $=0091-7435 \&$ volume $=37$ \&issue $=6 \&$ date $=2003 \&$ title $=$ Preventive + Medicine $\&$ atitle $=$ Impact + of + the +Pathways+intervention+on+dietary+intakes+of+American+Indian + schoolchildren.\&aulast=Himes+JH\&spage $=$ S55

79. Hollar D, Messiah SE, Lopez-Mitnik G, Hollar TL, Almon M, Agatston AS. Healthier options for public school children program improves weight and blood pressure in 6- to 13-year-olds. J am Diet Assoc. February 2010;110(2):261-267. http://ovidsp.ovid.com/ ovidweb.cgi?T=JS\&CSC=Y\&NEWS=N\&PAGE=fulltext\&D=emed11\& $\mathrm{AN}=358143858 \quad \mathrm{http}: / / \mathrm{imp}$-primo.hosted.exlibrisgroup.com/ openurl/44IMP/ICL_VU1?sid=OVID\&isbn=\&issn=0002-8223\& volume $=110 \&$ issue $=2 \&$ date $=2010 \&$ title $=$ Journal + of + the + American + Dietetic+Association\&atitle=Healthier+Options+for+Public + Schoolchildren+Program+Improves+Weight+and+Blood+Pressure + in $+6-+$ to $+13-$ Year-Olds\&aulast $=$ Hollar+D.\&spage $=261$

80. Hollar D, Zhou W, Riggle Z. Afterschool soccer fitness and nutrition program improves BMI percentile, waist circumference, and fitness levels in participants compared to nonparticipants. Circulation. 2015; 131(SUPPL. 1):A12. http://ovidsp.ovid.com/ovidweb.cgi?T=JS\& $C S C=Y \& N E W S=N \& P A G E=$ fulltext $\& D=$ emed $16 \& A N=71819397$ http://imp-primo.hosted.exlibrisgroup.com/openurl/44IMP/ICL_ VU1?sid=OVID\&isbn $=\& i s s n=0009-7322 \&$ volume $=131 \&$ issue $=$ SUPPL.+1\&date $=2015 \&$ title $=$ Circulation\&atitle $=$ Afterschool + soccer +fitness+and+nutrition+program+improves+BMl+percentile\% $2 \mathrm{C}$ +waist+circumference $\% 2 \mathrm{C}+$ and+fitness+levels+in+participants +compared+to+nonparticipants\&aulast=Hollar+D.\&spage=

81. Holmes E, Palmer K. A partnership approach to tackling inequalities through a summer holiday enrichment programme. Rev Espanol Nutri Hum Dietet. 2016;20(Supplement 1):555. http://ovidsp.ovid.com/ ovidweb.cgi?T=JS\&CSC $=Y \& N E W S=N \& P A G E=$ fulltext\&D=emed17\& $\mathrm{AN}=619527212 \quad \mathrm{http}: / / \mathrm{imp}$-primo.hosted.exlibrisgroup.com/ openurl/44IMP/ICL_VU1?sid=OVID\&isbn=\&issn=2173-1292\& volume $=20 \&$ issue $=$ Supplement $+1 \&$ date $=2016 \&$ title $=$ Revista + Espanola+de+Nutricion+Humana $+y+$ Dietetica\&atitle $=A$ +partnership+approach+to+tackling+inequalities+through+a +summer+holiday+enrichment+programme\&aulast=Holmes+E. \&spage $=555$

82. Hoppu U, Lehtisalo J, Kujala J, et al. The diet of adolescents can be improved by school intervention. Public Health Nutr. Jun 2010;13 (6a):973-979. https://doi.org/10.1017/s1368980010001163

83. Johnson CC, Spruance LA, O'Malley K, Begalieva M, Myers L. Using a problem-solving/decision-making model to evaluate school lunch salad bars. J Child Nutr Mgmt. 2017;41(n1).

84. Kain J, Uauy R, Vio F, Cerda R, Leyton B. School-based obesity prevention in Chilean primary school children: methodology and evaluation of a controlled study. Int J Obes (Lond). April 2004;28(4):483493. https://doi.org/10.1038/sj.ijo.0802611 
85. Kalarchian MA, Levine MD, Marcus MD. Structured dietary interventions in the treatment of severe pediatric obesity: a pilot study. Bariatr Surg Pract Patient Care. 01 Jun 2013;8(2):58-60. http:// ovidsp.ovid.com/ovidweb.cgi? $\mathrm{T}=J \mathrm{JS} \& C S C=Y \& N E W S=N \& P A G E=$ fulltext\&D=emed14\&AN=369174954 http://imp-primo.hosted. exlibrisgroup.com/openurl/44IMP/ICL_VU1?sid=OVID\&isbn=\& issn $=2168-023 X \&$ volume $=8 \&$ issue $=2 \&$ date $=2013 \&$ title $=$ Bariatric + Surgical+Patient+Care\&atitle $=$ Structured+dietary+interventions+in +the+treatment+of+severe+pediatric+obesity\%3A+A+pilot+study\& aulast $=$ Kalarchian+M.A.\&spage $=58$

86. Kimbro RT, Rigby E. Federal food policy and childhood obesity: a solution or part of the problem? Health Aff. March 2010;29(3):411418. http://ovidsp.ovid.com/ovidweb.cgi?T=JS\&CSC=Y\&NEWS= $N \& P A G E=$ fulltext\&D=emed11\&AN=359688513 http://imp-primo. hosted.exlibrisgroup.com/openurl/44IMP/ICL_VU1?sid=OVID\& isbn $=\&$ issn $=0278-2715 \&$ volume $=29 \&$ issue $=3 \&$ date $=2010 \&$ title $=$ Health+Affairs\&atitle=Federal+food+policy+and+childhood+obesity $\% 3 \mathrm{~A}+\mathrm{A}+$ solution+or+part+of+the+problem\%3F\&aulast=Kimbro+R. T.\&spage $=411$

87. Liu Z, Li Q, Maddison R, et al. A school-based comprehensive intervention for childhood obesity in China: a cluster randomized controlled trial. Child Obes. 2019;15(2):105-115. https://doi.org/10. 1089/chi.2018.0251

88. Lytle LA. Considering the potential effect of federal policy on childhood obesity. JAMA Pediatr. 01 Jan 2015;169(1):15-16. http:// ovidsp.ovid.com/ovidweb.cgi?T=JS\&CSC=Y\&NEWS=N\&PAGE= fulltext\&D=emed16\&AN=604793894 http://imp-primo.hosted. exlibrisgroup.com/openurl/44IMP/ICL_VU1?sid=OVID\&isbn=\& issn $=2168-6203 \&$ volume $=169 \&$ issue $=1 \&$ date $=2015 \&$ title $=$ JAMA + Pediatrics\&atitle $=$ Considering+the+potential+effect+of+federal +policy+on+childhood+obesity\&aulast=Lytle+L.A.\&spage $=15$

89. Ni Mhurchu C, Turley M, Gorton D, et al. Effects of a free school breakfast programme on school attendance, achievement, psychosocial function, and nutrition: a stepped wedge cluster randomised trial. BMC Public Health. 2010;10:738. http://ovidsp.ovid.com/ ovidweb.cgi? $T=J S \& C S C=Y \& N E W S=N \& P A G E=$ fulltext $\& D=$ emed $11 \&$ $\mathrm{AN}=360278255 \quad \mathrm{http}$ //imp-primo.hosted.exlibrisgroup.com/ openurl/44IMP/ICL_VU1?sid=OVID\&isbn=\&issn=1471-2458\& volume $=10 \&$ issue $=\&$ date $=2010 \&$ title $=B M C+$ public + health $\&$ atitle $=$ Effects+of+a+free+school+breakfast+programme+on+school +attendance $\% 2 \mathrm{C}+$ achievement $\% 2 \mathrm{C}+$ psychosocial+function $\% 2 \mathrm{C}$ +and+nutrition\%3A+a+stepped+wedge+cluster+randomised+trial\& aulast $=\mathrm{Ni}+$ Mhurchu+C.\&spage $=738$

90. Mobley CC, Stadler DD, Staten MA, et al. Effect of nutrition changes on foods selected by students in a middle school-based diabetes prevention intervention program: the HEALTHY experience. J Sch Health. February 2012;82(2):82-90. http://ovidsp.ovid.com/ ovidweb.cgi?T=JS\&CSC $=Y \& N E W S=N \& P A G E=$ fulltext $\& D=$ emed $13 \&$ $\mathrm{AN}=364094138 \quad$ http://imp-primo.hosted.exlibrisgroup.com/ openurl/44IMP/ICL_VU1?sid=OVID\&isbn=\&issn=0022-4391\& volume $=82 \&$ issue $=2 \&$ date $=2012 \&$ title $=$ Journal + of + School + Health $\&$ atitle $=$ Effect+of + nutrition+changes+on+foods+selected+by +students+in+a+middle+school-based+diabetes+prevention +intervention+program\%3A+The+HEALTHY+experience\&aulast= Mobley+C.C.\&spage $=82$

91. Moore L, Tapper K. The impact of school fruit tuck shops and school food policies on children's fruit consumption: a cluster randomised trial of schools in deprived areas. J Epidemiol Community Health. Oct 2008;62(10):926-931. https://doi.org/10.1136/jech.2007.070953

92. Nanney MS, MacLehose RF, Kubik MY, et al. School obesity prevention policies and practices in Minnesota and student outcomes: a longitudinal cohort study. Am J Prev med. Nov 2016;51(5):656-663. https://doi.org/10.1016/j.amepre.2016.05.008

93. Nanney MS, MacLehose RF, Kubik MY, et al. School obesity prevention policies and practices in Minnesota and student outcomes: a longitudinal cohort study. Am J Prev med. 01 Nov 2016;51(5):656663. http://ovidsp.ovid.com/ovidweb.cgi? $T=J S \& C S C=Y \& N E W S=$ N\&PAGE=fulltext\&D=emexa\&AN=613092291 http://imp-primo. hosted.exlibrisgroup.com/openurl/44IMP/ICL_VU1?sid=OVID\& isbn $=$ \&issn $=0749-3797 \&$ volume $=51$ \&issue $=5+$ Supplement $3 \&$ date $=$ 2016\&title=American+Journal+of+Preventive+Medicine\&atitle= School+Obesity+Prevention+Policies+and+Practices+in+Minnesota tand+Student+Outcomes\%3A+A+Longitudinal+Cohort+Study\& aulast $=$ Nanney + M.S.\&spage $=656$

94. Nanney MS, Shanafelt A, Wang Q, et al. Project BreakFAST: rationale, design, and recruitment and enrollment methods of a randomized controlled trial to evaluate an intervention to improve school breakfast program participation in rural high schools. Contemp Clin Trials Comm. 2016;3:12-22. http://ovidsp.ovid.com/ovidweb.cgi?T= $J S \& C S C=Y \& N E W S=N \& P A G E=$ fulltext\&D=emed17\&AN $=$ 610877448 http://imp-primo.hosted.exlibrisgroup.com/openurl/ 44IMP/ICL_VU1?sid=OVID\&isbn=\&issn=2451-8654\&volume $=3 \&$ issue $=\&$ date $=2016 \&$ title $=$ Contemporary + Clinical + Trials + Communications\&atitle=Project+BreakFAST\%3A+Rationale\%2C +design\%2C+and+recruitment+and+enrollment+methods+of+a +randomized+controlled+trial+to+evaluate+an+intervention+to +improve+school+breakfast+program+participation+in+rural+high +schools\&aulast=Nanney+M.S.\&spage=12 https://www.ncbi.nlm. nih.gov/pmc/articles/PMC4850496/pdf/main.pdf

95. Perry CL, Bishop DB, Taylor G, et al. Changing fruit and vegetable consumption among children: the 5-a-Day Power Plus program in St. Paul, Minnesota. Am J Public Health. Apr 1998;88(4):603-609. https://doi.org/10.2105/ajph.88.4.603

96. Powell C, Grantham-McGregor S, Elston M. An evaluation of giving the Jamaican government school meal to a class of children. Human Nutrition. Sep 1983;Clinical nutrition;37(5):381-388. http://ovidsp. ovid.com/ovidweb.cgi?T $=J S \& C S C=Y \& N E W S=N \& P A G E=$ fulltext\& $\mathrm{D}=$ =med3\&AN=14686489 http://imp-primo.hosted.exlibrisgroup. com/openurl/44IMP/ICL_VU1?sid=OVID\&isbn=\&issn=0263-8290\& volume $=37 \&$ issue $=5 \&$ date $=1983 \&$ title $=$ Human + nutrition.+ Clinical +nutrition\&atitle $=A n+$ evaluation+of+giving+the+Jamaican +government+school+meal+to+a+class+of +children\&aulast=Powell $+C$. \&spage $=381$

97. Ramírez-López E, Grijalva-Haro MI, Valencia ME, Antonio Ponce J, Artalejo E. Effect of a school breakfast program on the prevalence of obesity and cardiovascular risk factors in children. Salud Publica Mex. Mar-Apr 2005;47(2):126-133. https://doi.org/10.1590/s003636342005000200006

98. Ransley JK, Greenwood DC, Cade JE, et al. Does the school fruit and vegetable scheme improve children's diet? A non-randomised controlled trial. J Epidemiol Community Health. Aug 2007;61(8): 699-703. https://doi.org/10.1136/jech.2006.052696

99. Reilly KL, Reeves P, Deeming S, et al. Economic analysis of three interventions of different intensity in improving school implementation of a government healthy canteen policy in Australia: costs, incremental and relative cost effectiveness. BMC Public Health. 20 Mar 2018;18(1):378. https://doi.org/10.1186/s12889-018-5315-y

100. Reinaerts E, Crutzen R, Candel M, De Vries NK, De Nooijer J. Increasing fruit and vegetable intake among children: comparing long-term effects of a free distribution and a multicomponent program. Health Educ Res. 2008;23(6):987-996. https://doi.org/10. 1093/her/cyn027

101. Ritchie LD, Wakimoto P, Woodward-Lopez G, et al. The healthy communities study nutrition assessments: child diet and the school nutrition environment. Am J Prev med. 01 Oct 2015;49(4):647-652. http://ovidsp.ovid.com/ovidweb.cgi?T=JS\&CSC $=Y \& N E W S=N \&$ PAGE=fulltext\&D=emed16\&AN=606062054 http://imp-primo. hosted.exlibrisgroup.com/openurl/44IMP/ICL_VU1?sid=OVID\& isbn $=$ \&issn $=0749-3797 \&$ volume $=49$ \&issue $=4 \&$ date $=2015$ \&title $=$ American+Journal+of+Preventive+Medicine\&atitle=The+healthy 
+communities+study+nutrition+assessments\%3A+Child+diet+and +the+school+nutrition+environment\&aulast=Ritchie+L.D. \&spage $=647$

102. Schwartz MB, O'Connell M, Henderson KE, Middleton AE, Scarmo S. Testing variations on family-style feeding to increase whole fruit and vegetable consumption among preschoolers in child care. Child Obes (Print). 01 Oct 2015;11(5):499-505. http://ovidsp.ovid.com/ovidweb.cgi? $T=J S \& C S C=Y \& N E W S=N \& P A G E=$ fulltext $\& D=$ emed $16 \& A N=611701881$ http://imp-primo.hosted.exlibrisgroup.com/openurl/44IMP/ICL_VU1? sid $=$ OVID\&isbn $=\& i s s n=2153-2176 \&$ volume $=11$ \&issue $=5 \&$ date $=2015 \&$ title=Childhood + obesity $+\% 28$ Print\%29\&atitle=Testing+Variations+on +Family-Style+Feeding+To+Increase+Whole+Fruit+and+Vegetable +Consumption+among+Preschoolers+in+Child+Care\&aulast=Schwartz + M.B.\&spage $=499$

103. Sharma AK, Singh S, Meena S, Kannan AT. Impact of NGO run mid day meal program on nutrition status and growth of primary school children. Indian J Pediatr. July 2010;77(7):763-769. http://ovidsp. ovid.com/ovidweb.cgi?T=JS\&CSC=Y\&NEWS=N\&PAGE=fulltext\& $\mathrm{D}=$ emed11\&AN=50974549 http://imp-primo.hosted.exlibrisgroup. com/openurl/44IMP/ICL_VU1?sid=OVID\&isbn=\&issn=0019-

$5456 \&$ volume $=77$ \&issue $=7 \&$ date $=2010 \&$ title $=$ Indian + Journal + of + Pediatrics\&atitle=Impact+of+NGO+run+mid+day+meal+program +on+nutrition+status+and+growth+of+primary+school+children\& aulast $=$ Sharma + A.K.\&spage $=763$

104. Sharma SV, Markham C, Chow J, Ranjit N, Pomeroy M, Raber M. Evaluating a school-based fruit and vegetable co-op in low-income children: a quasi-experimental study. Prev med. 01 Oct 2016;91: 8-17. http://ovidsp.ovid.com/ovidweb.cgi?T=JS\&CSC=Y\&NEWS= $N \& P A G E=$ fulltext\&D=emed17\&AN=611415844 http://imp-primo. hosted.exlibrisgroup.com/openurl/44IMP/ICL_VU1?sid=OVID\& isbn $=$ \&issn $=0091-7435 \&$ volume $=91$ \&issue $=\&$ date $=2016 \&$ title $=$ Preventive+Medicine\&atitle=Evaluating + a + school-based + fruit + and +vegetable+co-op+in+low-income+children\%3A+A+quasiexperimental + study\&aulast $=$ Sharma $+S . V . \&$ spage $=8$

105. Spence S, Delve J, Stamp E, Matthews JNS, White M, Adamson AJ. The impact of food and nutrient-based standards on primary school children's lunch and total dietary intake: a natural experimental evaluation of government policy in England. PLoS ONE. 2013;8:e78298. http://ovidsp.ovid.com/ovidweb.cgi?T=JS\&CSC $=Y \& N E W S=N \&$ PAGE=fulltext\&D=emed14\&AN=604820787 http://imp-primo. hosted.exlibrisgroup.com/openurl/44IMP/ICL_VU1?sid=OVID\& isbn $=$ \&issn $=1932-6203 \&$ volume $=8$ \&issue $=10 \&$ date $=2013 \&$ title $=$ PLoS+ONE\&atitle $=$ The+impact+of + food + and + nutrient-based +standards+on+primary+school+children $\% 27 \mathrm{~s}+$ lunch+and+total +dietary+intake\%3A+A+natural+experimental+evaluation+of +government+policy+in+England\&aulast $=$ Spence + S.\&spage $=$ e78298

106. Story M, Snyder MP, Anliker J, et al. Changes in the nutrient content of school lunches: results from the Pathways study. Prev med. December 2003;37(SUPPL. 1):S35-S45. http://ovidsp.ovid. com/ovidweb.cgi? $T=J S \& C S C=Y \& N E W S=N \& P A G E=$ fulltext $\& D=$ emed8\&AN=37433900 http://imp-primo.hosted.exlibrisgroup.com/ openurl/44IMP/ICL_VU1?sid=OVID\&isbn=\&issn=0091-7435\& volume $=37$ \&issue $=$ SUPPL. $+1 \&$ date $=2003 \&$ title $=$ Preventive + Medicine\&atitle $=$ Changes + in + the + nutrient+content+of + school +lunches\%3A+Results+from+the+Pathways+study\&aulast=Story + M. \&spage $=$ S35

107. Sudharsanan N, Romano S, Cunningham SA. School breakfast receipt and obesity among American fifth- and eighth-graders. J Acad Nutr Diet. 01 Apr 2016;116(4):599-607. http://ovidsp.ovid.

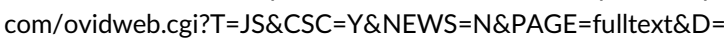
emed17\&AN=615198294 http://imp-primo.hosted.exlibrisgroup. com/openurl/44IMP/ICL_VU1?sid=OVID\&isbn=\&issn=2212$2672 \&$ volume $=116 \&$ issue $=4 \&$ date $=2016 \&$ title $=$ Journal + of + the +Academy+of+Nutrition+and+Dietetics\&atitle=School+Breakfast
+Receipt+and+Obesity+among+American+Fifth-+and+EighthGraders\&aulast $=$ Sudharsanan + N.\&spage $=599$

108. Taber DR, Chriqui JF, Powell L, Chaloupka FJ. Association between state laws governing school meal nutrition content and student weight status: implications for new USDA school meal standards. JAMA Pediatr. June 2013;167(6):513-519. https://doi.org/10.1001/ jamapediatrics.2013.399

109. Tak NI, Te Velde SJ, Brug J. Long-term effects of the Dutch Schoolgruiten project--promoting fruit and vegetable consumption among primary-school children. Public Health Nutr. Aug 2009;12(8): 1213-1223. https://doi.org/10.1017/s1368980008003777

110. Te Velde SJ, Brug J, Wind M, et al. Effects of a comprehensive fruitand vegetable-promoting school-based intervention in three European countries: the Pro Children Study. Br J Nutr. Apr 2008;99 (4):893-903. https://doi.org/10.1017/s000711450782513x

111. The HEALTHY Study Group. A school-based intervention for diabetes risk reduction. N Engl J Med. 2010;363(5):443-453. https://doi. org/10.1056/NEJMoa1001933

112. Thomas LN, Hill TF, Gaines A, Dollahite JS. Implementing Smarter Lunchrooms Makeovers in New York state middle schools: an initial process evaluation. Arch Public Health. 2016;74:41. http://ovidsp. ovid.com/ovidweb.cgi?T=JS\&CSC=Y\&NEWS=N\&PAGE=fulltext\& $\mathrm{D}=$ prem1\&AN=27708776 http://imp-primo.hosted.exlibrisgroup. com/openurl/44IMP/ICL_VU1?sid=OVID\&isbn=\&issn=0778$7367 \&$ volume $=74$ \&issue $=1 \&$ date $=2016 \&$ title $=$ Archives + of + Public + Health\&atitle=Implementing+Smarter+Lunchrooms+Makeovers+in + New+York+state+middle+schools\%3A+an+initial+process +evaluation.\&aulast=Thomas+LN\&spage $=41 \mathrm{https} / / / \mathrm{www} . \mathrm{ncbi} . \mathrm{nlm}$. nih.gov/pmc/articles/PMC5043616/pdf/13690_2016_Article_ 153.pdf

113. Vinit F, Tremolieres J. Enquiry into the provision of extra milk in orphanages. [French]. Bull I'Institut National d'hygiene. 1950;5(2): 257-269. http://ovidsp.ovid.com/ovidweb.cgi?T=JS\&CSC $=Y \&$ NEWS=N\&PAGE $=$ fulltext\&D $=$ emcl1\&AN=280699007 http://impprimo.hosted.exlibrisgroup.com/openurl/44IMP/ICL_VU1?sid= OVID\&isbn $=\&$ issn $=0366-0443 \&$ volume $=5 \&$ issue $=2 \&$ date $=1950 \&$ title=Bulletin $+d e+\mid \% 27$ Institut + national $+d \% 27$ hygiene\&atitle $=$ Enquetes+sur+la+distribution+de+supplements+lactes+dans+les +orphelinats\&aulast $=$ Vinit $+F$.\&spage $=257$

114. Warren E, Parry O, Lynch R, Murphy S. 'If I don't like it then I can choose what I want': Welsh school children's accounts of preference for and control over food choice. Health Promot Int. 23(2):144151. http://ovidsp.ovid.com/ovidweb.cgi? T=JS\&CSC $=$ Y\&NEWS $=$ N\&PAGE $=$ fulltext\&D=hmic\&AN=DH328465 http://imp-primo. hosted.exlibrisgroup.com/openurl/44IMP/ICL_VU1?sid=OVID\& isbn $=$ \&issn $=0957-4824 \&$ volume $=23 \&$ issue $=2 \&$ date $=2008 \&$ title $=$ Health+Promotion+International\&atitle $=\% 27 \mathrm{lf}+\mid+$ don $\% 27 \mathrm{t}+$ like + it +then+I+can+choose+what+I+want $\% 27 \% 3 \mathrm{~A}+$ Welsh+school +children\%27s+accounts+of+preference+for+and+control+over + food+choice\&aulast=Warren\%2C+Emily.\&spage $=$ http://impprimo.hosted.exlibrisgroup.com/openurl/44IMP/44IMP_services_ page?sid=OVID\&isbn=\&issn $=0957-4824 \&$ volume $=23 \&$ issue $=2 \&$ date $=2008 \&$ title $=$ Health + Promotion+International $\&$ atitle $=\% 27|\mathrm{f}+|$ + don\% $27 \mathrm{t}+$ like+it+then+1+can+choose+what+l+want\%27\%3A +Welsh+school+children\%27s+accounts+of+preference+for+and +control+over+food+choice\&aulast $=$ Warren\%2C+Emily.\&spage $=$

115. Williams CL, Squillace MM, Bollella MC, et al. Healthy start: a comprehensive health education program for preschool children. Prev med. March 1998;27(2):216-223. http://ovidsp.ovid.com/ovidweb. cgi?T=JS\&CSC $=Y \& N E W S=N \& P A G E=$ fulltext $\& D=$ emed $6 \& A N=$ 28360846 http://imp-primo.hosted.exlibrisgroup.com/openurl/ 44IMP/ICL_VU1?sid=OVID\&isbn=\&issn=0091-7435\&volume $=27$ \& issue $=2 \&$ date $=1998 \&$ title $=$ Preventive + Medicine $\&$ atitle $=$ Healthy +start\%3A+A+comprehensive+health+education+program+for + preschool+children\&aulast $=$ Williams + C.L.\&spage $=216$ 
116. Williams CL, Bollella MC, Strobino BA, et al. "Healthy-Start": outcome of an intervention to promote a heart healthy diet in preschool children. J am Coll Nutr. 2002;21(1):62-71. http://ovidsp. ovid.com/ovidweb.cgi? $\mathrm{T}=\mathrm{JS} \& C S C=Y \& N E W S=N \& P A G E=$ fulltext $\&$ $\mathrm{D}=$ =med7\&AN=34123711 http://imp-primo.hosted. exlibrisgroup. com/openurl/44IMP/ICL_VU1?sid=OVID\&isbn=\&issn=07315724 \& volume $=21 \&$ issue $=1 \&$ date $=2002 \&$ title $=$ Journal + of + the + American+College+of+Nutrition\&atitle $=\% 22$ Healthy-Start $\% 22 \%$ $3 \mathrm{~A}+$ Outcome+of+an+intervention+to+promote+a+heart+healthy +diet+in+preschool+children\&aulast=Williams+C.L.\&spage $=62$

117. Xu H, Li Y, Zhang Q, et al. Comprehensive school-based intervention to control overweight and obesity in China: a cluster randomized controlled trial. Asia Pac J Clin Nutr. 2017;26(6):1139-1151. https:// doi.org/10.6133/apjcn.112016.05

118. Vilsack TJ. The healthy, hunger-free kids act-building healthier schools. Child Obes. February 2012;8(1):4. http://ovidsp.ovid.com/ ovidweb.cgi?T=JS\&CSC $=Y \& N E W S=N \& P A G E=$ fulltext\&D=emed13\& $\mathrm{AN}=364175368 \quad \mathrm{http}: / / \mathrm{imp}$-primo.hosted.exlibrisgroup.com/ openurl/44IMP/ICL_VU1?sid=OVID\&isbn=\&issn=2153-2168\& volume $=8 \&$ issue $=1 \&$ date $=2012 \&$ title $=$ Childhood + Obesity \&atitle $=$ The+healthy\%2C+hunger-free+kids+act+-+Building+healthier + schools\&aulast $=$ Vilsack + T.J.\&spage $=4$

119. Pike J, Colquhoun D. The relationship between policy and place: the role of school meals in addressing health inequalities. (Special Issue: Social determinants of child health and wellbeing.).

120. Young KD, Snelling A, Maroto M, Young KA. Consumption of fruits and vegetables in middle school students following the implementation of a school district wellness policy. J Child Nutr Manag. 2013;37 (2):1-6. https://schoolnutrition.org/5-News-and-Publications/4The-Journal-of-Child-Nutrition-and-Management/Fall-2013/ Volume-37,-Issue-2,-Fall-2013-Young,-Snelling,-Maroto,-Young/

121. Taber DR, Chriqui JF, Powell L, Chaloupka FJ. Association between state laws governing school meal nutrition content and student weight status: implications for new USDA school meal standards. JAMA Pediatr. Jun 2013;167(6):513-519. https://doi.org/10.1001/ jamapediatrics.2013.399

122. Taber DR, Chriqui JF, Chaloupka FJ. Differences in nutrient intake associated with state laws regarding fat, sugar, and caloric content of competitive foods nutrient intake, state laws for competitive foods. JAMA Pediatr. 2012;166(5):452-458. https://doi.org/10. 1001/archpediatrics.2011.1839

123. Taber DR, Chriqui JF, Perna FM, Powell LM, Chaloupka FJ. Weight status among adolescents in states that govern competitive food nutrition content. Pediatrics. Sep 2012;130(3):437-444. https://doi. org/10.1542/peds.2011-3353

124. Ermetici F, Zelaschi RF, Briganti S, et al. Association between a school-based intervention and adiposity outcomes in adolescents: the Italian "EAT" project. Obesity. 2016;24(3):687-695. https://doi. org/10.1002/oby. 21365

125. British Nutrition Foundation. Fruits and vegetables. website. https://www.nutrition.org.uk/healthyliving/healthydiet/fruit-andvegetables.html. Published 2018. Accessed October, 2020.

126. Amini M, Djazayery A, Majdzadeh R, et al. A school-based intervention to reduce excess weight in overweight and obese primary school students. Biol Res Nurs. 2016;18(5):531-540. https://doi.org/ 10.1177/1099800416654261

127. Ferreira CS, Silva DA, Gontijo CA, Rinaldi AEM. Consumption of minimally processed and ultra-processed foods among students from public and private schools. Rev Paul Pediatr. Apr-Jun 2019;37 (2):173-180. https://doi.org/10.1590/1984-0462/;2019;37;2; 00010

128. Poti JM, Braga B, Qin B. Ultra-processed food intake and obesity: what really matters for health-processing or nutrient content? Curr Obes Rep. 2017;6(4):420-431. https://doi.org/10.1007/s13679017-0285-4
129. Shiu LK, Loke WM, Vijaya K, Sandhu NK. Nurturing healthy dietary habits among children and youth in Singapore. Asia Pac J Clin Nutr. 2012;21(1):144-150.

130. Weker $\mathrm{H}$. Simple obesity in children. A study on the role of nutritional factors. Med Wieku Rozwoj. Jan-Mar 2006;10(1):3-191.

131. Ransley JK, Greenwood DC, Cade JE, et al. Does the school fruit and vegetable scheme improve children's diet? A non-randomised controlled trial. J Epidemiol Community Health. 2007;61(8):699-703. https://doi.org/10.1136/jech.2006.052696

132. Herscovici CR, Kovalskys I, De Gregorio MJ. Gender differences and a school-based obesity prevention program in Argentina: a randomized trial. Rev Panam Salud Publica. August 2013;34(2):75-82. https://pubmed.ncbi.nlm.nih.gov/24096971/

133. Wu S, Ding Y, Wu F, et al. Socio-economic position as an intervention against overweight and obesity in children: a systematic review and meta-analysis. Sci Rep. 2015;5(1):11354-11354. https://doi.org/ 10.1038/srep11354

134. Parker L, Burns AC, Sanchez E. Local Government Actions to Prevent Childhood Obesity. Washington (DC): National Academies Press (US); 2009 https://www.ncbi.nlm.nih.gov/books/NBK219682/

135. Strugnell C, Mathrani S, Sollars L, Swinburn B, Copley V. Variation in the socioeconomic gradient of obesity by ethnicity-England's National Child Measurement Programme. Obesity. 2020;28(10): 1951-1963. https://doi.org/10.1002/oby.22970

136. Kumanyika SK. Unraveling common threads in obesity risk among racial/ethnic minority and migrant populations. Public Health. 2019; 172:125-134. https://doi.org/10.1016/j.puhe.2019.04.010

137. Fu YCA, Tol KC, Tao WY, et al. School accreditation scheme reduces childhood obesity in Hong Kong. Glob Health Promot. 2018;26: 70-78. https://doi.org/10.1177/1757975918764318

138. Brown T, Moore THM, Hooper L, et al. Interventions for preventing obesity in children. Cochrane Database Syst Rev. 2019;7. https://doi. org/10.1002/14651858.CD001871.pub4

139. Vandelanotte C, De Bourdeaudhuij I, Brug J. Acceptability and feasibility of an interactive computer-tailored fat intake intervention in Belgium. Health Promot Int. 2004;19(4):463-470. https://doi.org/10. 1093/heapro/dah408

140. Cotwright CJ, Alvis C, de Jesus JF, et al. Improving willingness to try fruits and vegetables among low-income children through use of characters. Health Equity. 2020;4(1):84-90. https://doi.org/10. 1089/heq.2019.0113

141. Avery A, Bostock L, McCullough F. A systematic review investigating interventions that can help reduce consumption of sugarsweetened beverages in children leading to changes in body fatness. J Hum Nutr Diet. 2015;28(s1):52-64. https://doi.org/10.1111/jhn. 12267

142. Kain J, Uauy R, Vio F, Cerda R, Leyton B. School-based obesity prevention in Chilean primary school children: methodology and evaluation of a controlled study. Int J Obes (Lond). 2004;28(4):483-493. https://doi.org/10.1038/sj.ijo.0802611

143. Bhave S, Pandit A, Yeravdekar R, et al. Effectiveness of a 5-year school-based intervention programme to reduce adiposity and improve fitness and lifestyle in Indian children; the SYM-KEM study. Arch Dis Child. 2016;101(1):33-41. https://doi.org/10.1136/ archdischild-2015-308673

144. Nanney MS, MacLehose RF, Kubik MY, et al. School obesity prevention policies and practices in Minnesota and student outcomes: a longitudinal cohort study. Am J Prev med. 2016;51(5 Supplement3): 656-663. https://doi.org/10.1016/j.amepre.2016.05.008

145. Datar A, Nicosia N. The effect of state competitive food and beverage regulations on childhood overweight and obesity. J Adolesc Health. May 2017;60(5):520-527. https://doi.org/10.1016/j. jadohealth.2016.09.003

146. Belansky ES, Cutforth N, Delong E, et al. Early impact of the federally mandated local wellness policy on physical activity in rural, low- 
income elementary schools in Colorado. J Public Health Policy. 2009; 30(Suppl 1):S141-S160. https://doi.org/10.1057/jphp.2008.50

147. Foster GD, Sherman S, Borradaile KE, et al. A policy-based school intervention to prevent overweight and obesity. Pediatrics. April 2008;121(4):e794-e802. https://doi.org/10.1542/peds.2007-1365

148. Cullen KW, Hartstein J, Reynolds KD, et al. Improving the school food environment: results from a pilot study in middle schools. $\mathrm{J} \mathrm{am}$ Diet Assoc. March 2007;107(3):484-489. https://doi.org/10.1016/j. jada.2006.12.004

149. Kain J, Concha F, Moreno L, Leyton B. School-based obesity prevention intervention in Chilean children: effective in controlling, but not reducing obesity. J Obesity. 2014;2014(1):618293. http://ovidsp.ovid.com/ ovidweb.cgi?T=JS\&CSC=Y\&NEWS=N\&PAGE=fulltext\&D=emed15\& $\mathrm{AN}=373140518$, http://imp-primo.hosted.exlibrisgroup.com/openurl/ 44IMP/ICL_VU1?sid=OVID\&isbn=\&issn=2090-0708\&volume=2014\& issue $=\&$ date $=2014 \&$ title $=$ Journal + of + Obesity \&atitle $=$ School-based +obesity+prevention+intervention+in+chilean+children\%3A+Effective +in+controlling\%2C+but+not+reducing+obesity\&aulast=Kain+J. \&spage $=618293$

150. Reilly KL, Nathan N, Wiggers J, Yoong SL, Wolfenden L. Scale up of a multi-strategic intervention to increase implementation of a school healthy canteen policy: findings of an intervention trial. BMC Public Health. Jul 11 2018;18(1):860. https://doi.org/10.1186/s12889018-5786-x

151. Davee AM, Blum JE, Devore RL, et al. The vending and a la carte policy intervention in Maine public high schools. Prev Chronic Dis. Nov 2005. 2 Spec no: A14. https://pubmed.ncbi.nlm.nih.gov/ $16263047 /$

152. Ermetici F, Zelaschi RF, Briganti S, et al. Association between a school-based intervention and adiposity outcomes in adolescents: the Italian "EAT" project. Obesity (Silver Spring, MD). 2016;24(3): 687-695. https://doi.org/10.1002/oby.21365

153. Jensen CD, Sato AF, McMurtry CM, Hart CN, Jelalian E. School nutrition policy: an evaluation of the Rhode Island healthier beverages policy in schools. ICAN: Infant Child Adolesc Nutr. 2012;4(5): 276-282. https://doi.org/10.1177/1941406412458314

154. Mobley CC, Stadler DD, Staten MA, et al. Effect of nutrition changes on foods selected by students in a middle school-based diabetes prevention intervention program: the HEALTHY experience. J Sch Health. Feb 2012;82(2):82-90. https://doi.org/10.1111/j.17461561.2011.00670.x

155. Fletcher A, Frisvold D, Tefft N. Taxing soft drinks and restricting access to vending machines to curb child obesity. Health Aff. 2010; 29(5):1059-1066. https://doi.org/10.1377/hlthaff.2009.0725

156. Micha R, Karageorgou D, Bakogianni I, et al. Effectiveness of school food environment policies on children's dietary behaviors: a systematic review and meta-analysis. PLoS ONE. 2018;13(3): e0194555. https://doi.org/10.1371/journal.pone.0194555

157. Evans CE, Christian MS, Cleghorn CL, Greenwood DC, Cade JE. Systematic review and meta-analysis of school-based interventions to improve daily fruit and vegetable intake in children aged 5 to $12 \mathrm{y}$. Am J Clin Nutr. 2012;96(4):889-901. https://doi.org/10.3945/ajcn. 111.030270

158. Vargas-Garcia EJ, Evans CEL, Prestwich A, Sykes-Muskett BJ, Hooson J, Cade JE. Interventions to reduce consumption of sugarsweetened beverages or increase water intake: evidence from a systematic review and meta-analysis. Obes Rev. Nov 2017;18(11): 1350-1363. https://doi.org/10.1111/obr.12580

159. Katz DL, O'Connell M, Njike VY, Yeh MC, Nawaz H. Strategies for the prevention and control of obesity in the school setting: systematic review and meta-analysis. Int J Obes (2005). 2008;32(12): 1780-1789. https://doi.org/10.1038/ijo.2008.158

160. Brunello G, De Paola M, Labartino G. More apples fewer chips? The effect of school fruit schemes on the consumption of junk food. Health Policy. 2014;118(1):114-126. http://ovidsp.ovid.com/ ovidweb.cgi?T=JS\&CSC $=Y \& N E W S=N \& P A G E=$ fulltext $\& D=$ emed15\& $\mathrm{AN}=53108054 \mathrm{http}: / / \mathrm{imp}$-primo.hosted.exlibrisgroup.com/openurl/ 44IMP/ICL_VU1?sid=OVID\&isbn=\&issn=0168-8510\&volume= 118\&issue $=1 \&$ date $=2014 \&$ title $=$ Health + Policy\&atitle=More + apples +fewer+chips\%3F+The+effect+of+school+fruit+schemes+on+the +consumption+of+junk+food\&aulast=Brunello+G.\&spage $=114$

161. Patton GC, Sawyer SM, Santelli JS, et al. Our future: a Lancet commission on adolescent health and wellbeing. Lancet (London, England). 2016;387(10036):2423-2478. https://doi.org/10.1016/ S0140-6736(16)00579-1

162. Story M, Kaphingst KM, French S. The role of schools in obesity prevention. Future Child. Spring 2006;16(1):109-142.

\section{SUPPORTING INFORMATION}

Additional supporting information may be found online in the Supporting Information section at the end of this article.

How to cite this article: Pineda E, Bascunan J, Sassi F. Improving the school food environment for the prevention of childhood obesity: What works and what doesn't. Obesity Reviews. 2021;22:e13176. https://doi.org/10.1111/obr.13176 